


\section{Urban food security in Ghana: a policy review}

Vincent Linderhof, Ricardo Vlijm, Vasco Pinto, Ireen Raaijmakers, Marijke Dijkshoorn-Dekker

This study was carried out by Wageningen Economic Research and was commissioned and financed by the Dutch Ministry of Agriculture, Nature and Food Quality within the context of the 'Metropolitan Solutions' research theme of the Knowledge Base (project number KB-25)

Wageningen Economic Research

Wageningen, June 2019

REPORT

2019-057b

ISBN 978-94-6343-968-8 
Vincent Linderhof, Ricardo Vlijm, Vasco Pinto, Ireen Raaijmakers, Marijke Dijkshoorn-Dekker, 2019. Urban food security in Ghana: a policy review. Wageningen, Wageningen Economic Research, Report 2019-057b. 72 pp.; 9 fig.; 13 tab.; 125 ref.

This policy review aimed (i) to investigate how urgencies such as urbanisation and climate change are recognised in the current policies of a low-income country, and (ii) to investigate how food security, and urban food security in particular, interacts with these policies. Ghana is used as an example. The policy review revealed that the agricultural, nutrition and health, spatial development and climate policies dealt with one or more aspects of food security within the food system framework. The overall conclusion is that the aspects of food security are still covered by the traditional policies: agriculture mainly deals with production, distribution and exchange of food. Nutritional value and food safety, for instance, are main concerns of the health and nutrition policy. However, Ghana is developing the Long-Term National Development Plan (LTNDP) which combines several policies. Food safety is also increasingly considered for the exchange of food from an export perspective: export requires particular food quality standards. The results of our policy review confirm that the integration of food security elements is still in an early process of development. In addition, the urban aspect of food security was hardly considered in the policies relating to food security in Ghana. This review was explored for (urban) food security in Ghana. It is likely that results for other African countries or other low-income countries in other continents would have yielded similar results.

Key words: Food security, Ghana, policy, urban, food system, food safety

This report can be downloaded for free at https://doi.org/10.18174/476849 or at www.wur.eu/economic-research (under Wageningen Economic Research publications).

(C) 2019 Wageningen Economic Research

P.O. Box 29703, 2502 LS The Hague, The Netherlands, T +31 (0)70 3358330 ,

E communications.ssg@wur.nl, http://www.wur.eu/economic-research. Wageningen Economic Research is part of Wageningen University \& Research.

\section{(cc) BY-NC}

This work is licensed under a Creative Commons Attribution-Non Commercial 4.0 International License.

(c) Wageningen Economic Research, part of Stichting Wageningen Research, 2019

The user may reproduce, distribute and share this work and make derivative works from it. Material by third parties which is used in the work and which are subject to intellectual property rights may not be used without prior permission from the relevant third party. The user must attribute the work by stating the name indicated by the author or licensor but may not do this in such a way as to create the impression that the author/licensor endorses the use of the work or the work of the user. The user may not use the work for commercial purposes.

Wageningen Economic Research accepts no liability for any damage resulting from the use of the results of this study or the application of the advice contained in it.

Wageningen Economic Research is ISO 9001:2008 certified.

Wageningen Economic Research Report 2019-057b | Project code 2282700373

Cover photo: Nataly Reinch/Shutterstock.com 


\section{Contents}

$\begin{array}{ll}\text { Summary } & 5\end{array}$

$\begin{array}{ll}\text { Acronyms } & 8\end{array}$

1

$\begin{array}{ll}\text { Introduction } & 9\end{array}$

1.1 Background 9

1.2 Research question $\quad 12$

1.3 Methodology 12

$\begin{array}{lll}1.4 & \text { Structure of the report } & 15\end{array}$

$2 \quad$ Policies overview for UFS Ghana $r$

2.1 Approach 16

2.2 Context of policy on UFS in Ghana $\quad 19$

2.2.1 International collaboration 19

2.2.2 Export and the food system $\quad 21$

2.2.3 Long-term development policy $\quad 22$

$\begin{array}{lll}2.3 & \text { Agricultural policies } & 23\end{array}$

2.3.1 FASDEP II $\quad 24$

2.3.2 METASIP II 24

2.3.3 The Plan for Food and Jobs (PFJ) initiative $\quad 25$

$\begin{array}{lll}2.4 & \text { Nutrition policy } & 26\end{array}$

$\begin{array}{lll}2.5 & \text { Spatial development policy } & 27\end{array}$

2.6 Climate change policy 29

$3 \quad$ Availability $\quad 32$

3.1 Link to the food system $\quad 32$

3.2 Review of the policies $\quad 33$

3.2.1 Agricultural policy $\quad 34$

$\begin{array}{ll}3.2 .2 \text { Nutrition policy } & 36\end{array}$

3.2.3 Spatial development policy 36

3.2.4 Climate change policy $\quad 36$

$\begin{array}{lll}3.3 & \text { Synthesis } & 37\end{array}$

4 Access to food $\quad 40$

4.1 Links to the food system $\quad 40$

$\begin{array}{lll}4.2 & \text { Review of the policies } & 41\end{array}$

4.2.1 Agricultural policy $\quad 42$

$\begin{array}{ll}4.2 .2 \text { Nutrition policy } & 43\end{array}$

$\begin{array}{ll}4.2 .3 \text { Spatial development policy } & 44\end{array}$

4.2.4 Climate change policy $\quad 44$

$\begin{array}{lll}4.3 & \text { Synthesis } & 44\end{array}$

$\begin{array}{llr}5 & \text { Utilisation } & 48\end{array}$

5.1 Link to the food system $\quad 48$

$\begin{array}{lll}5.2 & \text { Review of the policies } & 49\end{array}$

5.2.1 Agricultural policy $\quad 50$

5.2.2 Nutrition policy $\quad 52$

5.2.3 Spatial development policy $\quad 52$

5.2.4 Climate change policy $\quad 53$

$\begin{array}{lll}5.3 & \text { Synthesis } & 53\end{array}$ 
References and websites

61

Appendix 1

68

Appendix 2 


\section{Summary}

\section{Urgencies in urban food security}

Climate change and urbanisation are both expected to have a significant impact on future food security in low-income countries and in sub-Saharan African countries in particular. On the one hand, climate change will affect global food production due to more extreme weather events such as droughts and floods, which will also have impacts on crop diseases. Consequently, the supply of food in these countries becomes more uncertain. On the other hand, demand for food increases due to population growth and the urbanisation trend of population implies that more and more people will be less involved in food production. In addition, the rapid growth of large cities like Accra, Nairobi and Lagos will also lead to unemployment and more unequal wealth distribution amongst the urban population, and the gap between the rich and the poor is maintained or might even increase. These trends make the food security of the population in SSA countries even more challenging (e.g. regarding food access, food availability and affordability, and food utilisation in urban/metropolitan areas). In the last two or three decades, the majority of interventions to overcome poverty were focused on the promotion of agricultural activities, because the majority of the population was living in rural areas and involved in agriculture. The trend of less involvement in agriculture is extra challenging.

Population projections for 2050 indicate that almost two-thirds of the world's population will be living in cities. In African countries the urbanisation process is expected to go more rapidly than in the rest of the world. Fewer people will be active in agriculture. Moreover, climate change is likely to endanger the agriculture production and food availability the African countries in the future due to unfavourable climatic conditions. These developments raise concerns about the food security of rural and urban people as they are more likely to suffer from food insecurity risks.

\section{Aim of the policy review}

This policy review aims (i) to investigate how urgencies such as urbanisation and climate change are recognised in the current policies of a low-income country, and (ii) to investigate how food security, and urban food security in particular, interacts with these policies.

\section{Approach and conceptual framework}

For the review of urban food security, we used the food system-food security framework (see Figure S.1). Within this framework the food security elements of food availability, food access and food utilisation are linked to the nine activities or outputs of the food system framework as described by Ingram (2011). Availability refers to the supply of food and includes the production, distribution and exchange of food. Access to food refers to the demand for food and includes affordability, allocation and preference for food. Utilisation refers to other aspects of food such as health in terms of nutritional value and food safety, and social value. The fourth pillar, stability, was not included in this review as we took a snapshot of the current situation of forward-looking policies. 


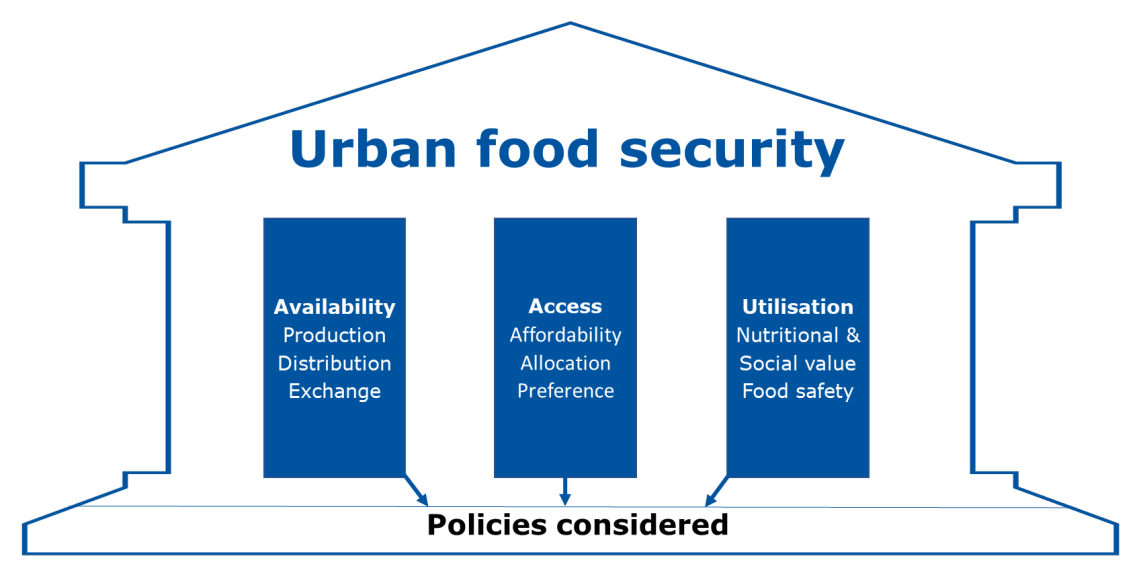

Figure S.1 The food system-food security framework, derived from Ingram (2011)

We use Ghana as an example. The policies and (associated) policy documents were selected in three steps. First, we created an initial list of potential policies and policy documents based upon a literature search. Next, the documents on the initial list were quickly scanned for the presence of terms related to the nine elements of the food system (see Figure S.1). In the final step, an additional Internet search was conducted with more specific search terms in combination with the selected policies and (associated) policy documents. This resulted in a list of 25 policy documents. These documents were categorised into three different geographical levels: global level, regional level and national level.

Next, the policies with direct links to (urban) food security were extensively reviewed when they met the following inclusion criteria:

- Policy documents were publicly available;

- Policies were forward-looking and non-reactive measures;

- Policies and plans were the domain of specific sectors or ministries, hence they were all from the national level;

- Only the most recent policies were considered although exceptions were made when policies had officially expired but not been replaced yet (e.g. METASIP II as METASIP III are not released yet);

- When available, we reviewed the implementation plans.

This selection process resulted in the extensive review of the following policy documents:

\begin{tabular}{ll} 
Policies & Specific policy documents \\
Agricultural policy & FASDEP II (agricultural policy) \\
\hline & METASIP II (agricultural policy) \\
\hline Putrition and health policy & National Nutrition Policy (NNP) \\
\hline Spatial policy & Ghana National Spatial Development Framework (GNSDF) \\
\hline Climate policy & National Climate Change Adaptation Strategy (NCCAS) \\
\hline & Ghana National Climate Change Policy (GNCCP) \\
\hline
\end{tabular}

Table S.1 presents the results with respect to the degree of incorporation of the nine food elements of the food system in the policy documents considered. In addition, potential conflicts between policies and those policies that pay specific attention to urban food security were identified. 
Table S.1 Overview of the incorporation of the food security elements in the reviewed policy documents of Ghana

\begin{tabular}{|c|c|c|c|c|c|c|c|}
\hline \multirow{3}{*}{$\begin{array}{l}\text { Food security } \\
\text { pillar }\end{array}$} & \multirow{3}{*}{ Food system elements } & \multicolumn{6}{|c|}{ Policies } \\
\hline & & \multicolumn{3}{|c|}{ Agricultural policy } & \multirow{2}{*}{$\begin{array}{l}\text { Health/ } \\
\text { nutrition }\end{array}$} & \multirow{2}{*}{$\begin{array}{l}\text { Climate } \\
\text { change }\end{array}$} & \multirow{2}{*}{$\begin{array}{c}\text { Spatial } \\
\text { develop- } \\
\text { ment }\end{array}$} \\
\hline & & Overall & METASIP & PFJ & & & \\
\hline \multirow[t]{2}{*}{ Availability } & Production & & & $* A$ & & & \\
\hline & Distribution & & & & & & $* A$ \\
\hline \multirow[t]{3}{*}{ Access } & Affordability & & & $*$ & & & \\
\hline & Allocation & & & A & & & \\
\hline & Preference & & & $A$ & & & \\
\hline Utilisation & Nutritional value & & & A & & & \\
\hline
\end{tabular}

Green $=$ the policy extensively considers the element, using the specific term and directly describing it. Orange $=$ the element is mentioned but not taken into account, or the policy considers the element without explicitly using the term. Grey = the element is not taken into account and not mentioned either. '\#' denotes possible adverse impacts of the policy on food security. '*' indicates that the policy is relevant especially for urban areas. ' $A$ ' denotes adverse impacts of the policy on food security.

For the food availability pillar, the element production of food was extensively integrated in the four policies, while the elements distribution and exchange were considered less frequently. The policy documents PFJ and the Ghana National Spatial Development Framework (GNSDF) were especially relevant for urban areas in the food security elements production.

The food accessibility pillar includes the elements affordability, allocation and preference. Both affordability and allocation were mentioned the most in all of the included policies, but not extensively. The programme Planting for Food and Jobs (PFJ) also has a focus on urban areas next to the rural areas. It promotes the growing of crops also for urban, non-farming households. The preference of food was not included in any policy documents explicitly, except in the nutrition policy of the Ministry of Health.

The elements nutritional value, social value and food safety from the utilisation pillar were included in the National Nutrition Policy (NNP) of the Ministry of Health. The other policy documents did not include these elements in their programmes.

The policy review revealed that the agricultural, nutrition and health, spatial development and climate policies dealt with one or more aspects of food security within the food system framework. The overall conclusion is that the aspects of food security are still covered by the traditional policies: agriculture is mainly dealing with production, distribution and exchange of food. Nutritional value and food safety, for instance are main concerns of the health and nutrition policy. However, Ghana is developing the Long-term National Development Plan (LTNDP) which combines several policies. Food safety is also considered more and more for the exchange of food from an export perspective: export requires particular food quality standards. The results of our review of the policies confirm that the integration of food security elements is still in an early process of development. In addition, the urban aspect of food security was hardly considered in the policies relating to food security in Ghana. This review was explored for (urban) food security in Ghana. We realise that Ghana is an example and it is likely that results for other African countries or other low-income countries in other continents would have yielded similar results. 


\section{Acronyms}

\begin{tabular}{|c|c|}
\hline Acronym & Description \\
\hline $4 \mathrm{G}$ & Ghana Goes for Green Growth \\
\hline AGC & Agricultural Growth Corridor \\
\hline AGOA & African Growth and Opportunity Act \\
\hline AIDS & Acquired Immune Deficiency Syndrome \\
\hline CAADP & Comprehensive Africa Agriculture Development Programme \\
\hline CC-DARE & Climate Change and Development - Adapting by Reducing Vulnerability \\
\hline $\operatorname{CCAFS}(\mathrm{P})$ & Climate Change Agriculture and Food Security (Platform) \\
\hline CDKN & Climate and Development Knowledge Network \\
\hline CET & Common External Tariff \\
\hline CGIAR & Consultative Group for International Agricultural Research \\
\hline CJD & Creutzfeldt-Jakob disease \\
\hline CLTS & Community-led Total Sanitation \\
\hline ECOWAS & Economic Community of West African States \\
\hline EPA & Environmental Protection Agency \\
\hline FAO & Food and Agriculture Organisation \\
\hline FASDEP & Food and Agricultural Sector Development Plan \\
\hline FSP & Food Safety Policy \\
\hline GNCCP & Ghana National Climate Change Policy \\
\hline GNUPAP & Ghana National Urban Policy and Action Plan \\
\hline GSGDA & Ghana Shared Growth and Development Agenda \\
\hline GTP & Ghana Trade Policy \\
\hline HIV & Human immunodeficiency virus \\
\hline IMF & International Monetary Fund \\
\hline LTNDP & Long-term National Development Plan \\
\hline M\&E & Monitoring and evaluation \\
\hline MDA & Ministries, departments and agencies \\
\hline MDG & Millennium Development Goals \\
\hline MESTI & Ministry of Environment, Science, Technology and Innovation \\
\hline METASIP & Medium Term Agricultural Sector Investment Plan \\
\hline MoFA & Ministry of Food and Agriculture \\
\hline $\mathrm{MoH}$ & Ministry of Health \\
\hline MTI & Ministry of Trade and Industry \\
\hline NCCAS & National Climate Change Adaptation Strategy \\
\hline NCCC & National Climate Change Committee \\
\hline NCCPF & National Climate Change Policy Framework \\
\hline NCD & Non-communicable diseases \\
\hline NEDP & National Export Development Programme \\
\hline NENRC & National Environmental and Natural Resources Council \\
\hline NES & National Export Strategy \\
\hline NFBSC & National Food Buffer Stock Companies \\
\hline NNP & National Nutrition Policy \\
\hline OECD & Organisation for Economic Cooperation and Development \\
\hline PFJ & Planting for Food and Jobs \\
\hline SDG & Sustainable Development Goals \\
\hline TSSP & Trade Sector Support Programme \\
\hline UFS & Urban food security \\
\hline UN & United Nations \\
\hline UNDP & United Nations Development Programme \\
\hline UNEP & United Nations Environmental Programme \\
\hline UNFCCC & United Nations Framework Convention on Climate Change \\
\hline WHO & World Health Organization \\
\hline WTO & World Trade Organization \\
\hline ZHSR & Zero Hunger Strategic Review \\
\hline WFP & World Food Programme \\
\hline
\end{tabular}




\section{Introduction}

\section{$1.1 \quad$ Background}

\section{Urgencies}

The population of the world is increasingly becoming urbanised due to natural increase and ruralurban migration (Codjoe et al. 2016). Data on urbanisation show that a much greater part of the world population is living in cities in 2015 compared to 1950 - a trend that will likely continue (UNDESA 2015). There is a wide variety in the current share of urban population in the regions of the world (see Table 1). In high-income regions like Europe and northern America for instance, the degree of urban population is higher than the world average. In fact, the share of urban population in these regions is more than $70 \%$ in 2015 and more than $80 \%$ in the projection for 2050 (see Table 1). In low- and middle-income regions of the world, the urban population share increased sharply from 1950 onwards.

In Africa, $40.4 \%$ of the population lived in urban areas in 2015, while in northern America the share is $81.6 \%$ (UNDESA 2015). However, the projections show a further increase in the share of urban population for all regions and it also shows there is a converging trend in the shares. The shares of urban population in Africa and Asia will increase the most, with Africa expected to be the least urbanised region as it is today, yet even it is projected to be as urbanised as the whole world is on average today (see Table 1 ).

Table 1 Share of urban population in the regions of the world, 1950, 2015 and projection for 2050

\begin{tabular}{|c|c|c|c|}
\hline Regions of the world & 1950 & 2015 & 2050 projection \\
\hline Africa & 14.0 & 40.4 & 55.9 \\
\hline Asia & 17.5 & 48.2 & 64.2 \\
\hline Europe & 51.5 & 73.6 & 82.0 \\
\hline Caribbean & 41.3 & 79.8 & 86.2 \\
\hline World & 29.6 & 54.0 & 66.4 \\
\hline
\end{tabular}

Source: (UNDESA 2015)

Looking at the population of Ghana specifically, it is shown that it grew from 5.0 million in 1950 to 26.4 million in 2014 while the urban share of the population has increased from 15\% to 54\% in 2015 (UNDESA 2015). Figure 1 shows that the projections for the future Ghana populations indicate that the share of urban population will increase to $70.4 \%$ in 2050 , which is higher than the share for Africa (55.9\%) or western Africa (63.0\%) including Ghana (UNDESA 2015). This indicates that during the second decade of this century, the Ghanaian urbanisation rate had already overtaken the world average. 


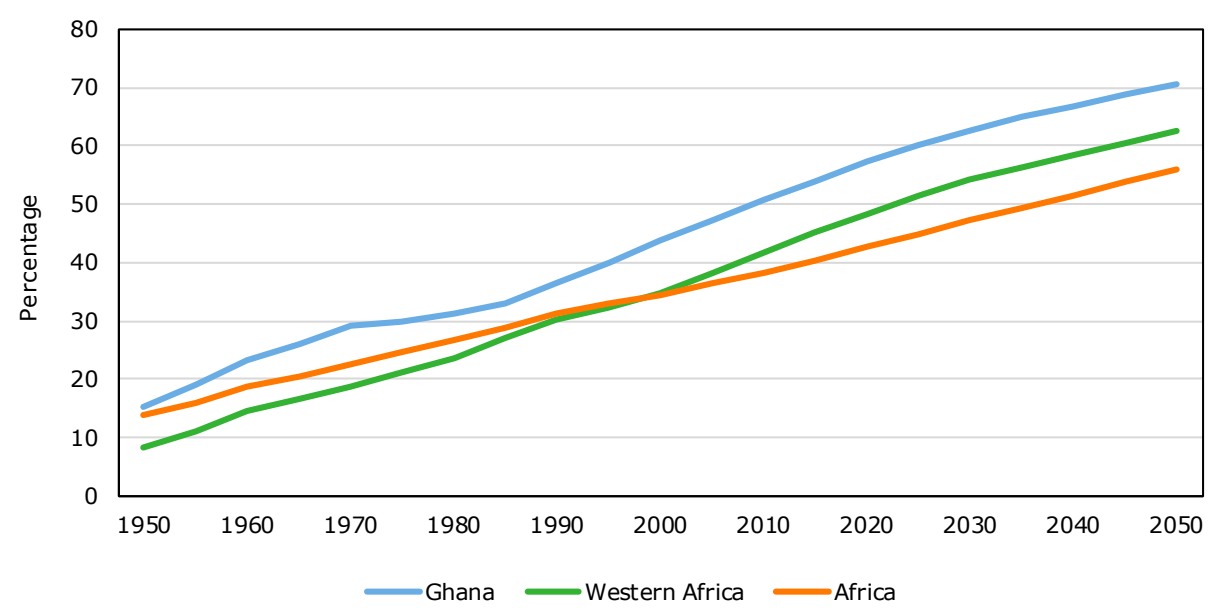

Figure 1 Share (\%) of urban population in Ghana, western Africa and Africa, 1950-2050 Source: (UNDESA 2015).

Another main urgency related to urban food security (UFS) is climate change. The world is currently, both in terms of pledges under the Paris climate treaty and actual policies, on a pathway towards more severe climate change than might be safely managed (Tollefson 2018). This makes both mitigation and adaptation increasingly important especially for developing countries (IPCC 2018).

\section{UFS and urgencies}

Food security policy should look beyond agricultural development when addressing the urbanisation and climate change challenges (Shutes et al. 2015; Kuiper et al. 2017))). First of all, those urgencies influence UFS in multiple ways, because urban diets are influenced by lifestyles, social relationships, marriage patterns, family structures, the availability of packaged and processed foods, and advertising and the media (Atkinson 1995). A recent study in Accra showed that there is high dietary diversity in the communities of Accra but a low consumption of foods rich in micronutrients from fruit and milk/dairy products (Codjoe et al. 2016). As a result, females, poor households and the non-educated have food insecurity problems.

Second, price changes result in price and income effects which need to be assessed to determine the food accessibility (Hertel 2016). Households earning an income in agriculture (farmers or labourers) will also benefit from higher agricultural prices while net food consumers living in either rural or urban areas of low-income countries will be harmed. Conversely, net food consumers will benefit from lower agricultural prices, while households earning an income in agriculture will be harmed due to the lower market prices. Although there is little empirical evidence on UFS and how people living in urban areas are coping with sustained high food prices, the poor urban households in low-income countries might even suffer harder (Birhane et al. 2014), because poor people spend a high share of their income on food. In Mozambique, for instance, urban residents spend $83 \%$ of their income on food (Garrett and Ruel 1999). In Accra (Ghana), families spend an average of $54 \%$ of their income on food (Maxwell 2000). Either way, the size of these price impacts will depend on a range of factors affecting price transmissions (Swinnen 2010). In addition, the share of urban population increases and this development alters the balance between winners and losers of price changes (Kuiper et al. 2017). This reasoning might induce a rationale to target future policies towards lowering agricultural prices, even though currently the majority of the poor benefit from higher agricultural prices (Headey and Martin 2016).

Third, urbanisation can for instance affect food security as the increasing concentration of people in a limited area brings with it challenges related to the distribution of food, land issues and the related infrastructural challenges with respect to both the transport of the food itself, and water availability for example. At the same time, changing preferences of people in cities can lead to increased demand for convenient and other processed foods (Hollinger and Staatz 2015), which is also related to an increasing share of the population having no access to land that would otherwise allow them a subsistence existence (Armar-Klemesu and Maxwell 2000; De Zeeuw et al. 2011; Dake et al. 2016; Szabo 2016; Galbete et al. 2017; Andam et al. 2017; Annan et al. 2018). 
Climate change in turn can have adverse impacts on food security through reduced micronutrient shares in major crops as $\mathrm{CO}_{2}$ levels rise, or by making rainfall patterns more erratic which could lead to yield losses of more than $10 \%$ in the latter case (Roudier et al. 2011; Zhu et al. 2018). These changes are already noticeable in Ghana, as it is also highly dependent on rain-fed agriculture (Armah et al. 2011).

\section{Literature review on urban food security}

Given how diverse the impacts of these urgencies on food security are and thus how many options exist for policy to affect this, our investigation will have to follow an approach that appreciates this complexity of the interactions of UFS with these urgencies, but also the multidimensionality of the concept itself. To our knowledge, such policy reviews on UFS in a developing country that appreciates the multidimensionality of the concept of food security (as defined by FAO, 1996), have so far been carried out in a systematic but limited manner.

For the literature review on urban food security, we started with a list of 130 documents (with some duplicated results) based on multiple Google Scholar searches with different search terms, and selected the first ten results of each search. The terms were: UFS; Urban food availability; Urban food access; Urban food utilisation; Metropolitan food security; Metropolitan food availability; Metropolitan food access; Metropolitan food utilisation; Cities food security; Cities food availability; Cities food access; Cities food utilisation; Urban food security policy review.

Of the 130 results, 67 documents were related to research on UFS or some element of it in developed countries, mostly the USA, Canada and Australia. Eleven documents were books, which were excluded for reasons of practicality. Six documents were not fully accessible; and based on the abstracts, none of these was relevant with respect to UFS in developing countries. Four documents were not related to human nutrition, instead these were descriptions of feeding practices of animals.

Of the other 42 documents, 13 (some of them again double ones) dealt with food systems and worldwide trends such as climate change (Gregory et al. 2005; Ericksen 2008), soil quality (Chen 2007) or with general concerns such as the increasing scarcity of phosphorus (Cordell et al. 2009) while others provided a general, non-place specific overview of issues such as urban agriculture (Armar-Klemesu and Maxwell 2000) or the conceptualisation of food security (Maxwell 1996). The remaining 29 documents were, after filtering the duplicate ones, further reduced to a list of 17 scientific documents that were published in scientific journals and which looked at some aspect of UFS (see Appendix 1 for this shortlist). Availability has been investigated mainly by looking at urban agriculture and the production of food in cities, which represented one of the main themes within this list (4 out of 17 results) with specific attention to Ghana, but also southern Africa and the developed world in general (Zezza and Tasciotti 2010; Crush et al. 2011; Barthel and Isendahl 2013; Eigenbrod and Gruda 2015).

However, UFS as it is holistically understood by the FAO (FAO 1996) was not systematically reviewed for any one specific country even though pillars such as access (Arene and Anyaeji 2010; Labadarios et al. 2011; Crush and Frayne 2011; Battersby 2011) and utilisation (Garrett and Ruel 1999) have been reviewed separately by carrying out quantitative analyses and by reviewing literature (Pingali 2007).

None of the articles found, however, dealt qualitatively with all the multiple dimensions of food security and the urgencies in a systematic manner. Codjoe and Owusu (2011) discussed the three pillars in relation to climate change; however, they were focused on the impacts in rural areas. Moreover, none of the studies that assessed some elements of food security explicitly reviewed policies in a systematic way taking into account both food systems and a food security approach. 


\subsection{Research question}

\section{Aim and research question}

In this study we aim to investigate how a government in a low-income country is using its policies to deal with the aforementioned urgencies of urbanisation and climate change, and their interactions with UFS. We address food security in a broad definition (FAO 1996) and from the perspective of the food system. Our central research question then is:

What are the food security prospects for the urban population or UFS in a low-income country given the high growth rates of the urban population, climate change and their recognition by the government?

Based on this central research question, we have formulated the following research questions:

1. Which policies in a low-income country relate to food security and the pressures of urbanisation and climate change?

2. How do these policies consider food security?

3. How do these policies consider urban food security (UFS) in particular?

4. How do these policies relate to each other with respect to the elements of the food system/food security perspective?

We use Ghana as an example, and as far as we know there have not been similar review studies published for other countries.

\subsection{Methodology}

\section{Food system and food security}

To answer the research questions, we used the framework of the food system. The food system includes consumers, producers and all retail and wholesale agents in the food chain. Moreover, we use the framework as presented by Ingram (2011) who has linked the food system elements to the different aspects of food security (availability, access, utilisation and stability).

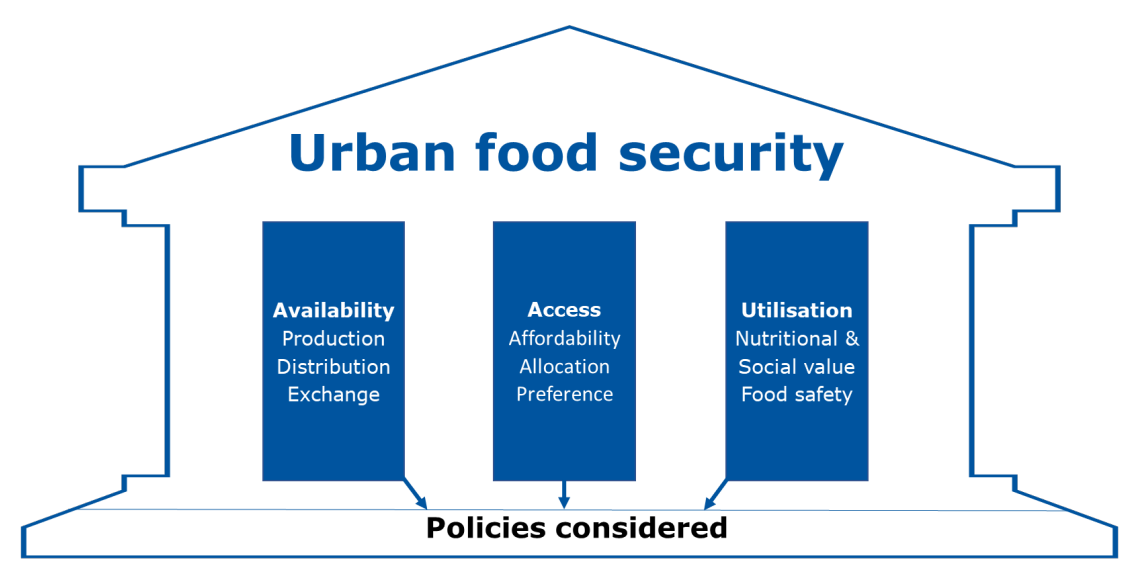

Figure 2 Food system-food security framework derived from Ingram (2011)

The food system concept originates from the social sciences in the 1990s but these approaches were not suitable for the incorporation of global environmental changes like climate change and food security issues (Ingram 2011). Therefore, an adjusted food system concept was proposed by Ericksen (2008) to adjust the food system concept to assess global environmental changes. Ingram (2011) proposed another food system concept which is suitable to assess global environmental changes and food security issues. In this report, we use this concept proposed by Ingram (2011) because we are interested in the impacts of policy in Ghana on the food system and food security. In particular, we 
are interested in the impact of policies on UFS and the interactions between the urgency of urbanisation and UFS on the one hand, and climate change and UFS on the other hand (see Figure 2).

The food system distinguishes activities and output. Food system activities include producing, processing, distributing and consuming food (see Table 2). These activities lead to food system outcomes, such as food security issues but also environmental and social issues. The activities and outcomes of the food system interact with the social, economic and environmental drivers of the system.

Table 2 Definitions of the four food system activities

\begin{tabular}{ll}
$\begin{array}{l}\text { Activities in the } \\
\text { food system }\end{array}$ & Description of the activities \\
Producing food & $\begin{array}{l}\text { Includes all activities involved in the production of the raw food materials. Key factors include } \\
\text { farmers, hunters, fishermen, the multiple suppliers of production inputs including agrichemicals, } \\
\text { agricultural labourers and land owners. }\end{array}$ \\
\hline $\begin{array}{l}\text { Processing and } \\
\text { packaging food }\end{array}$ & $\begin{array}{l}\text { Includes the various transformations that the raw food material (e.g. grain, vegetable, fruit, } \\
\text { livestock) undergoes before it is sent to the retail market for sale. Key factors include the } \\
\text { middlemen who buy from producers and sell to processors; the managers and workers in } \\
\text { processing and packaging plants; and trade organisations that set standards. } \\
\text { distributing food }\end{array} \quad \begin{array}{l}\text { Retailing and distributing includes a range of middlemen who go between the producers, } \\
\text { processors, packers and the final markets, and the many actors involved in transport, delivery and } \\
\text { warehousing operations, advertising, trading and supermarkets for example. }\end{array}$ \\
\hline Consuming food & $\begin{array}{l}\text { Includes all consumers themselves, and the varied actors that control what they consume, e.g. } \\
\text { market regulators, advertisers, consumer groups. }\end{array}$ \\
\hline
\end{tabular}

Source: Ingram (2011).

For the outputs of the food system, we focus on food security and UFS in particular. The food system outcomes are divided into three components, which are three of the four food security pillars according to the FAO definition of food security (FAO 1996): food availability, food access and food utilisation, and stability. Food availability concerns how much is available and how it is allocated. Food access deals with how readily food is accessed by consumers. Food utilisation is how consumers deal with food and its nutritional value (diets). For achieving food security according to the definition of FAO, Ingram (2011) mentions that all three components have to be satisfied and be stable over time. The different components of food security can be linked to the activities of the food system as was done by Ingram (2011) (see Table 3). In particular, it is not only the activities of the food system but also the drivers of the food system such as preferences, nutrition security (which is different from food security), social issues and health/food safety that are important.

\section{Scope}

In the framework, Ingram (2011) discussed food security in general and he did not particularly distinguish between rural and urban food security. Obviously, our focus is on urban food security UFS, which is the UFS of the urban population. The urban population is the part of the population that lives in urban centres and which is usually not involved in agricultural production. They are occupied with or searching other types of jobs in other economic sectors like manufacturing industries, service sector or the government, or are unemployed. They might thus be working in sectors that are related to food such as processing and they might have a home garden. 
Table 3 Definitions of the food system activities and drivers linked to food security

\begin{tabular}{|c|c|c|}
\hline $\begin{array}{l}\text { Food security } \\
\text { component }\end{array}$ & $\begin{array}{l}\text { Activities/drivers of } \\
\text { the food system }\end{array}$ & Description of the activities and examples \\
\hline \multirow[t]{3}{*}{ Food availability } & Production & How much and which types of food are available through local production. \\
\hline & Distribution & $\begin{array}{l}\text { How food is made available (physically moved), in what form, when and to } \\
\text { whom. }\end{array}$ \\
\hline & Exchange & $\begin{array}{l}\text { How much of the available food is obtained through exchange mechanisms } \\
\text { such as barter, trade, purchase or loans. }\end{array}$ \\
\hline \multirow[t]{3}{*}{$\begin{array}{l}\text { Food } \\
\text { accessibility }\end{array}$} & Affordability & $\begin{array}{l}\text { The purchasing power of households or communities relative to the price of } \\
\text { food. }\end{array}$ \\
\hline & Allocation & $\begin{array}{l}\text { The economic, social and political mechanisms governing when, where and } \\
\text { how food can be accessed by consumers. }\end{array}$ \\
\hline & Preference & $\begin{array}{l}\text { Social, religious or cultural norms and values that influence consumer } \\
\text { demand for certain types of food. }\end{array}$ \\
\hline \multirow[t]{3}{*}{ Food utilisation } & Nutritional value & $\begin{array}{l}\text { How much of the daily requirements of calories, vitamins, protein and } \\
\text { micronutrients are provided by the food people consume. }\end{array}$ \\
\hline & Social value & The social, religious and cultural functions and benefits food provides. \\
\hline & Food safety & $\begin{array}{l}\text { Toxic contamination introduced during producing, processing and packaging, } \\
\text { distribution or marketing food; and food-borne diseases such as salmonella } \\
\text { and CJD. }\end{array}$ \\
\hline
\end{tabular}

Source: Ingram (2011).

When reading the policy documents, we noticed that the urban dimension was sometimes mentioned. However, in many cases, the policy documents referred to urban areas from a geographical perspective but not from a demographic perspective i.e. urban population. These two perspectives do not necessarily coincide. There can be urban centres in rural areas and there can be people active in agricultural production in urban centres. From the food security perspective, urban food security relates to the demographic perspective. In this study, we will emphasise the urban population and not the urban areas per se. As we discuss food security from a broad perspective, so not only from the nutritional value for consumers or individuals, we realise that we have to focus on a broad range of policy dimensions. We therefore also focus attention on indirectly related external developments such as export policy that might affect food security in Ghana.

As mentioned above, this study is used to inform a follow-up study on the adequacy of land availability compared to land needed to satisfy food demand (Dijkshoorn-Dekker et al. 2019). In this report, we will therefore primarily consider food security in terms of malnutrition, i.e. food shortage/undernutrition. The other two elements of malnutrition (micronutrient shortage and overfeeding/overweight, obesity and diet-related NCDs) are acknowledged, but are not our main concern here.

For the activities of the food system, we limit ourselves to the producing, processing, distribution and consumption of land-based foods - thus excluding sea-based foods. While these sea-based foods can be quite important for diets in Ghana (FAO 2016), the dominant activities related to sea food in Ghana (e.g. fishing) are much different from those related to non-extractive land-based activities (so those described above, thus also excluding for example hunting). For this reason, sea food is beyond the scope of this review.

For the concept of food security, we focus attention on the first three pillars as these are directly related to economic activities in the food system and because we are only reviewing forward-looking policies (see also below for the criteria). Explicit consideration of stability is thus beyond the scope of this study. We use a systematic approach which means that all policies selected are reviewed in a similar way (see Chapter 2). 


\subsection{Structure of the report}

The structure of the report is as follows. Chapter 2 lists and describes the initial list of policies. Based on the criteria of the most relevant and recent policies, we select a number of policies which are used for review in the next chapters. In Chapters 3 to 5 we discuss the review of the policy documents with respect to the three included pillars of food security namely food availability (Chapter 3 ), food access (Chapter 4) and food utilisation (Chapter 5). Chapters 3 to 5 each include a synthesis section which will summarise the main issues, placed in perspective by scientific literature. Chapter 6 discusses the findings and Chapter 7 presents the conclusions. 


\section{Policies overview for UFS Ghana}

\section{$2.1 \quad$ Approach}

In this chapter, we provide an overview of policies in Ghana related to food security and UFS in particular. We first created an initial list of policies and policies documents, and then we used criteria (see below) to select the most relevant policies and policy documents to review. We limited the policies to documents that were publicly available through Internet. The policy fields included agriculture, trade, food security, poverty alleviation, economic development and health, spatial development and climate change, because these policy fields relate to UFS directly or indirectly.

For the initial list of policies and policy documents, we took three steps:

1. Literature search on the Internet. We looked at the websites of the government of the Republic of Ghana (website of Parliament, websites that list the ministries etc.) and we used Google Scholar with several search terms or combinations of search terms, such as Ghana, food security, nutrition, food prices, markets, linkages, policy.

2. Quick scan of documents. We quickly scanned the documents for the presence of the terms of a number of food security elements in combination with the term 'food system'. To ensure the accuracy and relevance of the policy documents found, we checked the websites of ministries other than the ones relevant for the aforementioned themes to ensure that no important policies were left out.

3. Google search. More specific search terms for the policies and policy documents were used: policy, nutrition, food, health, Ghana, urban, Accra, Accra metropolitan, Kumasi, urban policy. We used the elements of the food security-food system framework in Figure 2 in combination with the names of the policies.

This search process resulted in an initial list of 23 policies and policy documents; see Appendix 2 for a list of descriptions of the policy documents. The policies can be categorised into three different geographical levels (see Figure 3). As we are interested in the impact of policies in Ghana, we will be focusing on policies at the national level (the lowest level). Policies induced by international and regional organisations such as the World Bank, the United Nations (UN) and ECOWAS respectively, will be shortly presented as context. These agreements and regulations of international organisations, and a review previously carried out by a Ghanaian organisation and the World Food Program (WFP) were thus included to show the broader environment in which policymaking in Ghana takes place and to provide context in Section 2.2. 


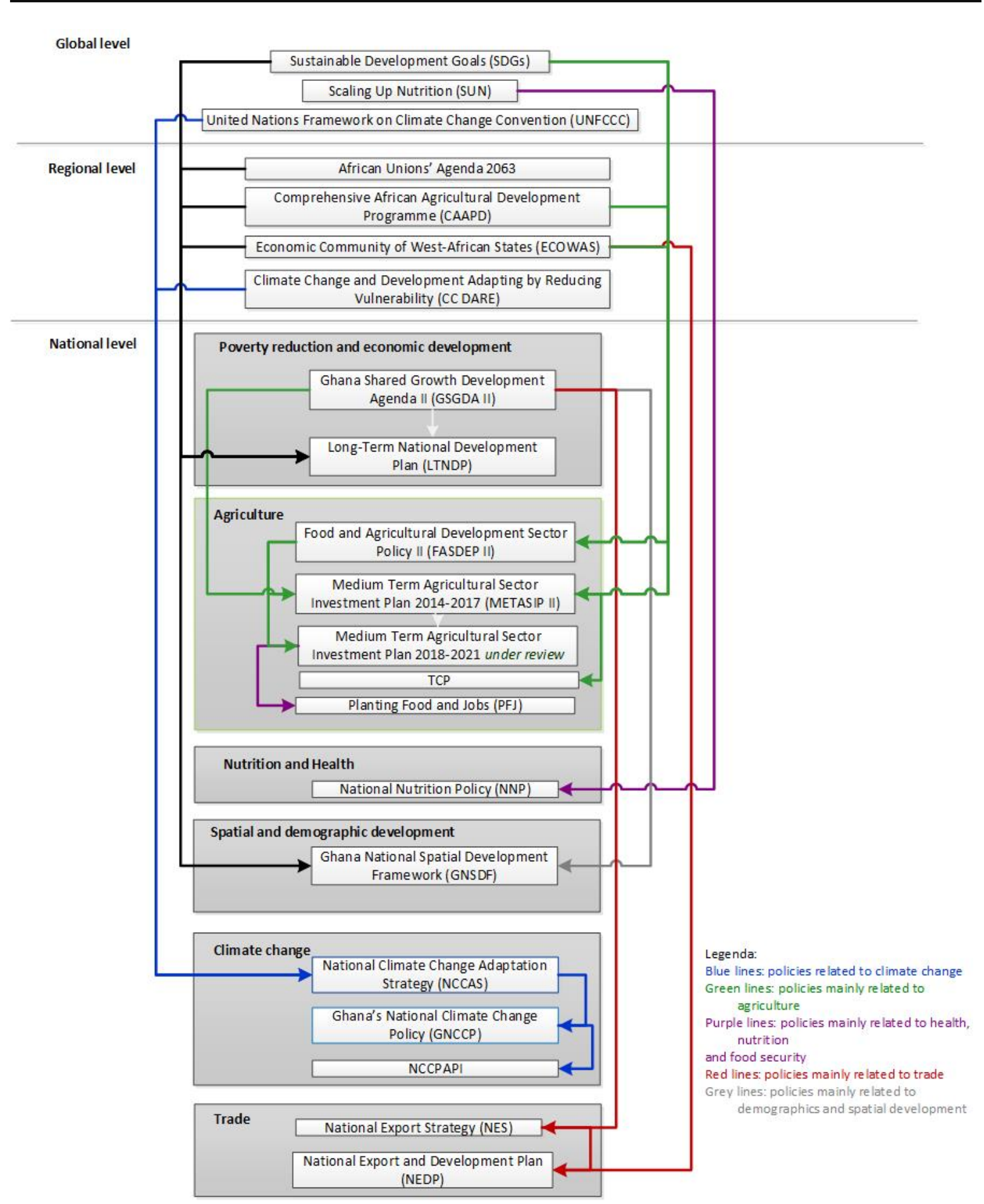

Figure 3 Scheme with policies related to UFS in Ghana 
All policies and associated policies identified in the graph in Figure 3 have a connection to (urban) food security, either directly such as the PFJ, or indirectly such as the export-related policies (e.g. the National Export Strategy (NES)) and the general social-economic development strategies. Figure 4 describes the periods of the policies and the frameworks, including preceding versions of these frameworks.

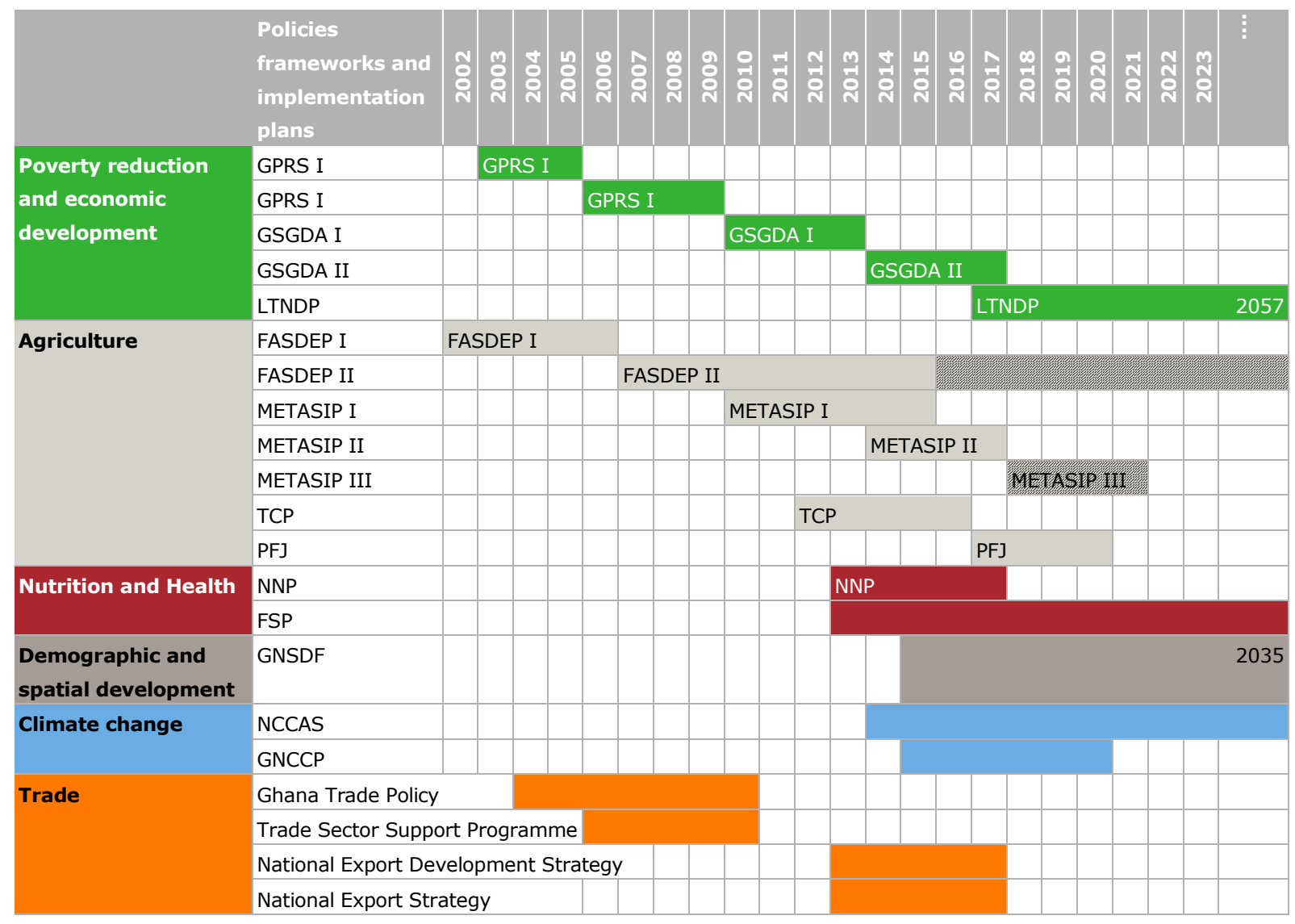

*Periods of the policies are indicated by the coloured bars. The first coloured block indicates the implementation year. Years in the final column show the end year when the policy extends beyond 2023. If no end year is shown but the bar does reach the final column, no clear end date of the policy exists.

Figure 4 Implementation years and running periods of policies

The policies with indirect links to (urban) food security will be briefly described in the next section as they will serve as additional context (which will be referred back to in the synthesis sections in the later chapters as well). This includes the Ghana Shared Growth and Development Agenda (GSGDA), the Long-term National Development Plan (LTNDP, see Section 2.2.3), international targets like the Sustainable Development Goals (SDGs) and export policy as the main trade policy (implications of import and general trade policies and their possible conflicts with the policies with direct links to UFS are discussed in the sections of those other policies).

The policies with direct links to (urban) food security are, after also having been described from Section 2.3 onwards, more extensively reviewed (in Chapters 3-5). Besides the direct-link criterion, and for reasons of practicality we also applied the following criteria for inclusion in this extensive review:

- Policies were forward-looking and non-reactive measures.

- Policies and plans were the domain of specific sectors or ministries. Thus, general policy frameworks or networks that did not provide information on implementation were excluded, such as the general development strategy and ECOWAS.

- Only the most recent policies were considered. Exceptions were made when policies were officially expired but not replaced yet; we included the most recent policies (e.g. METASIP III). 
- When available, (i.e. when documents were sufficiently similar) we used the implementation plans rather than the general policy statement/frameworks. The Food and Agriculture Sector Development Plan (FASDEP) and Medium-term Agricultural Sector Investment Plan (METASIP) are an exception here because there were some significant differences found between these documents which are especially relevant. See Section 5.2.1 for an example.

Based on these criteria, we selected four policies with seven policy documents in total for our review:

1. Agricultural Policy: FASDEP II, METASIP II, and Planting for Food and Jobs (PFJ);

2. Nutrition policy: National Nutrition Policy (NNP);

3. Spatial development policy: Ghana National Spatial Development Framework (GNSDF) and Climate policy, National Climate Change Adaptation Strategy (NCCAS) and Ghana National Climate Change Policy (GNCCP).

Before we present the selected policies in more detail, we first explain some contextual aspects of policy in Ghana which might interact with UFS, such as international collaboration (Section 2.2.1), the membership of customary unions and trade (Section 2.2.2), and the implementation of the Long-term National Development Plan (LTNDP) (see Section 2.2.3).

\subsection{Context of policy on UFS in Ghana}

\subsubsection{International collaboration}

The economic policy of Ghana is affected by its membership of several international organisations such as the World Trade Organization (WTO), and the UN and its organisations such as the Food and Agriculture Organization (FAO) and the United Nations Framework Convention on Climate Change (UNFCCC, which will be discussed in Section 2.3.6).

As a member state of the UN, Ghana is also influenced by the SDG agenda and especially the second SDG goal of ending hunger: 'Achieving food security and improved nutrition and promoting sustainable agriculture by 2030' (UN 2018). In 2018, the World Food Programme (WFP) commissioned the John Kufuor Foundation (World Food Programme and John Kufuor Foundation 2018), a civil society organisation chaired by the former Ghanaian President Kufuor to begin reviewing Ghanaian policy with respect to its progress towards achieving the second SDG. The organisation's board consists of a representative of the (current) president's office, the Ministry of Food \& Agriculture, the Ministry of Health among others, the UN and the National Development Planning Commission (NDPC) (Glopan 2016). The Zero Hunger Strategic Review (ZHSR) for Ghana is the main outcome of the combined efforts of these organisations. The report was received by the President of Ghana in 2018. During the reception conference, he linked the ZHSR to the PFJ programme and specific other programmes like the 'One district, one factory' policies by emphasising the need to boost agricultural productivity and self-reliance of Ghana with respect to food production (Republic of Ghana 2018b). Since the Zero Hunger Strategic Review is an assessment rather than a policy, it is not further discussed in detail in our review. However, it can help us by indicating to what extent policy in Ghana has been focused on food security so far.

On the level of West Africa, Ghana is part of the Economic Community of West African States (ECOWAS) and the Comprehensive Africa Agriculture Development Programme (CAADP). Next, Ghana is also a member of less institutionalised initiatives, such as the Scaling Up Nutrition (SUN) network and the African Growth and Opportunity Act (AGOA). These initiatives are described in more detail later as they provide the broader context.

\section{ECOWAS}

ECOWAS consists of Ghana and many other West African countries: Benin, Burkina Faso, Cabo Verde, Côte d'Ivoire, the Gambia, Guinea, Guinea Bissau, Liberia, Mali, Niger, Nigeria, Senegal, Sierra Leone and Togo. Currently, ECOWAS is moving towards a Common External Tariff (CET) for, among other things, agricultural products ranging from cotton to food crops such as rice. This means that from now to especially 2019, Ghana's import tariffs on agricultural products will increasingly be determined by 
ECOWAS. In practice, there could for instance be a significant effect on the import of rice. Ghana's tariffs for this crop are relatively high at $20 \%$ (of the ECOWAS member states, only Nigeria levies more at 50\%); as part of the CET they will have to be lowered in the next couple of years to $10 \%$, meaning that rice imports will become cheaper and will likely increase (De Roquefeuil et al. 2014). Many products such as cassava and tomatoes have higher rates, generally around $20 \%$ which is higher than the average rate that Ghana applied in 2018 which means that imports might decrease. However, it is expected that after the negotiations have been completed (which also have to take the WTO rules into account) regional trade within ECOWAS will increase while overall the rate of protection is expected to remain unchanged (De Roquefeuil et al. 2014).

At the same time, ECOWAS is negotiating with the EU for an Economic Partnership Agreement, which should make exporting to the EU easier - although concerns exist that, due to the relatively high rate of European protectionism for the agricultural sector, this will mainly mean that ECOWAS and Ghana will be importing more, rather than exporting more easily. What sort of impact this opening up of Ghanaian trade will have, both in the West African region as well as more general trade liberalisation that ECOWAS is thus trying to achieve, is unclear. But two issues stand out in the literature. The first issue considered is the 'sign' of the effect on food prices themselves, so whether prices decline or increase, and secondly, the variability of food prices. As noted in Section 1.1, an increase in food prices can be beneficial for those who are involved in agricultural activities, which is still a large share of the population, but it is likely to have a negative effect on affordability of food for those not involved in agricultural activities, which are often the population in urban areas. In the case of Ghana, the result can be especially ambiguous as farmers not only make up a large share of the population, but the surplus produce they sell can also make up a large share of their total income. Indeed, in some cases farmers sell their surplus shortly after harvest, only to buy most of their food later in the year (de Jager et al. 2018). In the case of decreasing prices, this is the other way around. So, the variability of food prices through trade can have either positive or negative influences on food security through production, distribution, exchange and affordability. The exact impact depends on different factors such as type of crops grown or the region considered.

Whether there is any impact of liberalisation on food security through changes in price variability at all, first depends on the kind of products that are grown. The FAO has for instance shown that farmers producing export crops such as those in the forest zone of Ghana, will generally benefit from measures that opened up the Ghanaian market in the 1980s and 1990s (FAO 2006) even in the face of possible price fluctuations; but the same is not necessarily true for those farmers producing food crops. In the cases where there is an impact of reduced price variability, such as during the acute food price crisis in 2008, the impact is usually felt most by the poor (Cudjoe et al. 2010), who in the case of Ghana are mainly located in the rural areas but in some regions such as the northern region, also in urban areas (FAO 2006). Second, the impact of liberalisation on food security through price variability can be negligible when controlling for exchange rates, GDP per capita and yields (Adom 2014). So, liberalisation on its own does not cause the impact as it is the combined effects with the other independent variables that give liberalisation its explanatory value (FAO 2006)). To summarise, the effect of liberalisation of trade usually runs through decreased variability of prices, and through changes in the price levels. The effects of these changes on the population and its food security are inconclusive as the effects can vary with population segments, or even within population segments throughout a year (de Jager et al. 2018).

\section{CAADP}

CAADP is a framework aimed at agricultural transformation and wealth creation for the entire African continent, which began with the Maputo declaration on Agriculture and Food Security in the capital of Mozambique in 2003 , declaring a goal of $6 \%$ annual growth in agriculture by investing at least $10 \%$ of total government spending each year (NEPAD 2003). This target has only been reached by very few member countries (Kreuger 2015), with Ghana achieving only about 3\% in agricultural spending relative to total government spending, and reaching less than $5 \%$ growth in most agricultural subsectors (a strong contraction could even be observed for the forestry sector) from 2008 to 2011 (Ministry of Food and Agriculture 2013). Some recovery in growth rates followed, for instance for rice between 2011 and 2013, but it fell again in 2014. Overall, productivity growth has been limited (Mohan and Matsuda 2013; Ministry of Food and Agriculture 2016b). 


\section{SUN and bilateral relations}

Ghana is also a member of several other, less institutionalised initiatives such as the Scaling Up Nutrition (SUN) network of developing nations which includes many African countries and ECOWAS members, but also non-African countries such as Afghanistan and Indonesia. SUN is implemented through the National Nutrition Policy (NNP) and consists of general ethical principles such as 'do no harm' when performing tasks related to food production for example, meaning that quality standards are increased which could open up foreign markets that demand higher standards and thus make it easier for Ghana to export.

Bilaterally, strong economic ties exist between Ghana and several European countries (Switzerland, Belgium, United Kingdom and the Netherlands), the USA and China (OEC 2018). As a result, the USAmade laws that specifically deal with American imports of agricultural commodities from African countries such as the African Growth and Opportunity Act (AGOA) are quite important for food and agricultural trade and trade of Ghana in general (Ministry of Trade and Industry n.d.). Indeed, Ghana's strategy to use AGOA is not limited to agricultural products as the strategy focuses on so-called priority products, which are selected based on their ability to contribute to revenue targets, and their spillover effects to the entire economy. Besides agricultural products such as yams, cassava, pineapple, tomato and cocoa, the list also includes gold, clothing and products made of these crops as the strategy also tries to promote the processing of these basic goods.

\subsubsection{Export and the food system}

Although exports do not necessarily have a direct impact on food security, they might have an indirect impact as revenue from imports or tariffs could be used to buy, for example, rice from countries such as Vietnam or Thailand that is preferred in Ghana (OEC 2016) or create jobs in sectors that export food crops or products derived from those. In the period from 2004 to 2010 Ghana already showed its ambition to create (1) an export-led strategy and (2) a domestic market-led industrialisation strategy based on import competition as expressed in the Ghana Trade Policy (GTP) which was supplemented by the Trade Sector Support Programme (TSSP) implementation document (Ministry of Trade and Industry n.d.).

In 2011, Ghana presented its National Export Strategy (NES). The goals of this export strategy were as follows:

- To transform the export sector by moving from traditional exports (gold, cacoa) to non-traditional exports (see list of priority products in Appendix C) so that the export sector could spearhead economic growth, opportunities and 'decent, formal jobs' (Ministry of Trade and Industry 2013, p.5);

- To strengthen trade and export institutions, and business development providers;

- To imbide the export culture nationwide, so that each district is able to have one commercially viable agro-based export product.

The NES was implemented from 2013 to 2017 through the National Export Develoment Programme (NEDP). In the NEDP the government worked out 23 programmes, which related to land access, water and market access among other things (Ministry of Trade and Industry 2013b) and which were implemented over the period 2013-2017. With respect to market access, the government of the Republic of Ghana encouraged the utilisation of preferential trade regimes such as AGOA (USAID 2016) and the economic partnership with the European Union, as discussed earlier (Ministry of Trade and Industry 2013a).

Both the NEDS and the NES were embedded within GSGDA II as indicated by the trade-specific policy objectives of GSGDA II: i) to improve trade competetiveness, ii) to diversify and increase exports, and iii) to accelerate economic integration (such as with ECOWAS).

Elements of food security like food safety are mentioned in NES and NEDP, but only with respect to safety standards for exports of food. Issues like availability and the possible competition between foreign and domestic demand are not considered in these trade policies. In fact, export interests might conflict with food security in the case of particular crops such as cereals, vegetables and fruit for instance. NES an NEDP also do not pay specific attention to UFS. 


\subsubsection{Long-term development policy}

The acceleration of economic growth and the increase of food and nutrition security of Ghana's poorest have been the main subject of policy of the economic growth and poverty reductions for a long time. This began with the 'Vision of 2020: First Step' plan and is currently laid out in the GSGDA II, with the following steps in between:

- The Vision of 2020: First Step (1996-2000);

- Ghana Poverty Reduction Strategy I (GPRS I) (2003-2005);

- Growth \& Poverty Reduction Strategy II GPRS II) (2006-2009);

- Ghana Shared Growth Development Agenda I (GSGDA I) (2010-2013);

- Ghana Shared Growth Development Agenda II (GSGDA II) (2014-2017).

The GSGDA aims to continue the growth of the economy and raise the living standards of the Ghana population. To this end, it provides a set of policy objectives, builds upon the previous medium-term plan GSGDA I, and tries to maintain consistency with the Millennium Development Goals (MDGs), CAADP and ECOWAS. The main part of the policy that dealt with food focused on agriculture rather than food security (which is stated as a goal in the main text of the GSGDA):

- Ensuring and sustaining macroeconomic stability;

- Enhancing competitiveness in Ghana's private sector;

- Accelerated agriculture modernisation and sustainable natural resource management;

- Oil and gas development;

- Infrastructure and human settlements development;

- Human Development, Productivity and Employment;

- Transparent, Responsive and Accountable Governance (Republic of Ghana 2014).

Through this focus on agriculture, it can be linked to most of the policies we will review as Table 4 below shows. With respect to the third point for example, the following elements are part of FASDEP and METASIP: 'reduce the risks and bottlenecks associated with agriculture; promote the development of irrigation; improve agriculture financing; ensure sustainable environment, land and water management; support selected crop development; promote the development of agriculture estates; promote livestock and poultry development; promote fisheries and aquaculture development; improve institutional coordination.'

Table 4 Agricultural objectives of the GSGDA and the link to other policies

\begin{tabular}{ll} 
GSCDA III objectives & Policies/sections related to objective \\
Improve the productivity of agricultural production & METASIP, FASDEP \\
\hline Exploit opportunities in the sector for accelerated jobs creation & PFJ \\
\hline Enhance the competitiveness of the agricultural sector & METASIP, FASDEP, NES \\
\hline Ensure integration into domestic and international markets & NES, AGOA, ECOWAS \\
\hline Reduce the risks and bottlenecks associated with agriculture & FASDEP, METASIP
\end{tabular}

Source of the objectives: Republic of Ghana (2014)). Table based on own analysis.

As the GSGDA II includes different thematic areas, different ministries, agencies and sectors are involved. The overview of the GSGDA and its predecessors lies with the same high-level commission however: the NDPC. Specifically, this council is responsible for the preparation of national development plans, and monitoring, evaluating and coordinating these (Functions of the NDPC, 2011).

With the Long-term National Development Plan (LTNDP), which was expected to be launched officially in 2018, the government of the Republic of Ghana is moving towards more integrated, long-term planning of economic development. For instance, the LTNDP is not only focused on economic development, but also on other policy objectives such as the SDGs (Abubakari et al. 2018), as well as the national infrastructure plan and the spatial development framework. The time horizon of the LTNDP is 2057. 


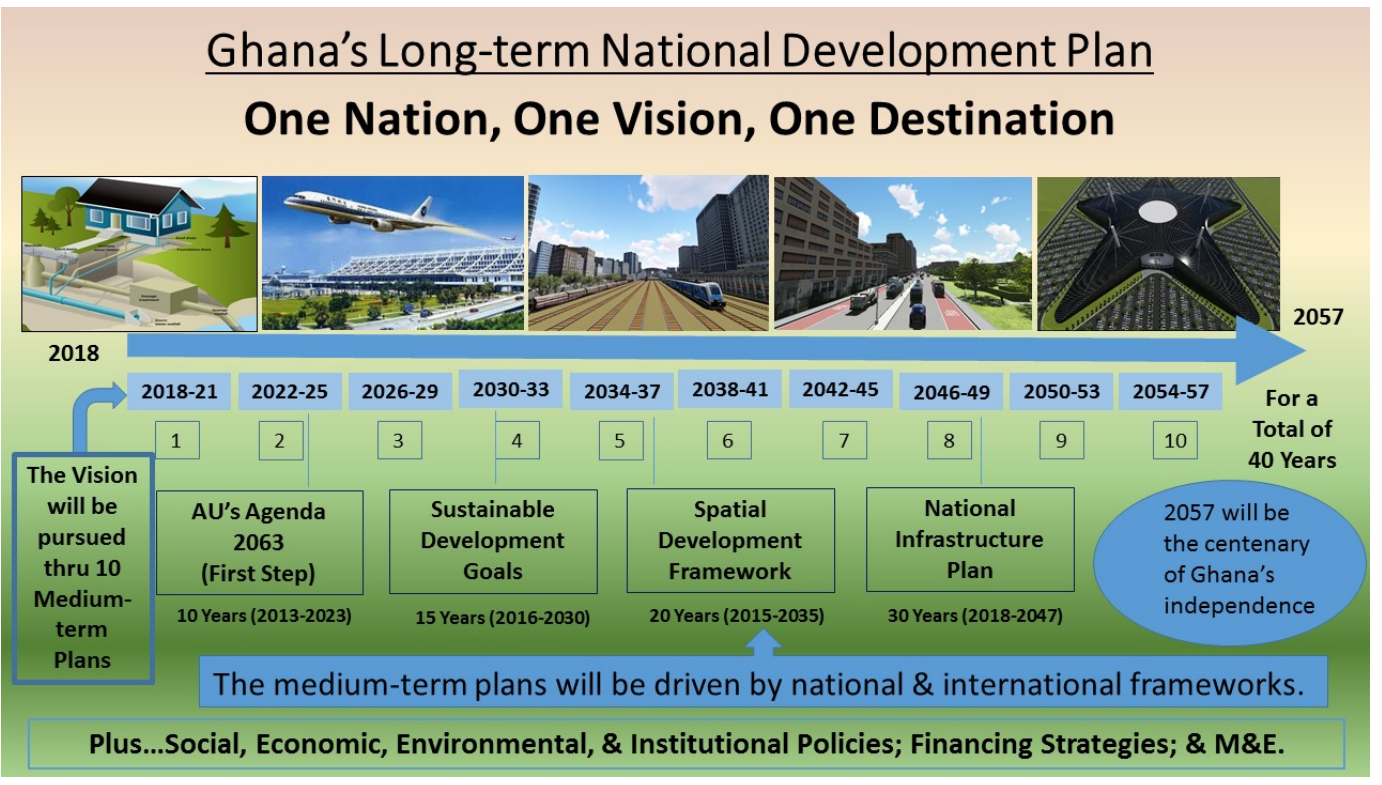

Figure 5 Schematic representation of the LTNDP

Source: NDPC (2018).

The overall vision of the plan is to achieve 'a just, free and prosperous society' in the 40 years that it will cover (see also Figure 5). The main characteristics of the LTNDP are:

- The government has revealed its commitment to contribute to global efforts towards sustainability through several development attempts;

- The NDPC was mandated to prepare a 40-year development plan to guide governmental efforts in a sustainable manner, for growth and development;

- LTNDP is expected to be issued in 2018 , although the start date is delayed because the sectors do not yet align with the proposed long-term plan;

- The LTNDP will embrace a broad participatory framework and ensure political legitimacy.

The LTNDP includes spatial planning, petroleum revenue, population growth of the country, monitoring and a national infrastructure plan. It will consist of four medium-term development plans (MTDPs) each with a time span of 10 years or so. The MTDPs will be the basis for annual plans which will be aligned with the annual national budget of Ghana. The plan is composed of medium-term plans (see Figure 5) to allow for effective evaluation of the entire plan. Decennial evaluations (10-year intervals) will be conducted during implementation periods (2027, 2047 and 2057) to report on the plan's progress in achieving its objectives (Abubakari, 2018).

From an international perspective, LTNDP includes compliance with the international objectives of the Africa Union's 50-Year Agenda 2063 and the 15-year SDGs of the United Nations.

Within Ghana, various concerned bodies declared their support for the LTNDP, and also called for support from all citizens for the LTNDP. Notable bodies are the Trades Union Congress, Ghana Employers Association, Private Enterprise Foundation, Federation of Association of Ghanaian Exporters, National Union of Ghana Students, religious organisations, National House of Chiefs, Ghana Culture Forum, Ghana Journalists' Association, Ghana Union of Traders' Association and the Council of Indigenous Business Associations.

\subsection{Agricultural policies}

The Ministry of Food and Agriculture (MoFA) is responsible for agricultural policy. The long-term agricultural sector-specific policy objectives and guiding strategies are included in Ghana's FASDEP. The main objective of FASDEP is to promote agricultural development and interventions for the modernisation of the agricultural sector (Baah 2017; Ministry of Food and Agriculture 2007). There are 
two periods of FASDEP. FASDEP I ran from 2002 to 2006 and was replaced by FASDEP II in 2007. FASDEP II had the same main objective as FASDEP I, but it adopted a value-chain approach to agricultural development. FASDEP II aligned its specific objectives with GPRS I, GPRS II, ECOWAS, CAADP and the MDGs (see also Figure 3).

FASDEP II is solely carried out by MoFA and is implemented through METASIP, which include several strategies, activities and programmes for the promotion of agricultural development in Ghana. So far, two implementation plans have been published. METASIP I ran from 2011-2015 (Ministry of Food and Agriculture 2010) and was replaced by METASIP II (2014-2017) in 2014 (Ministry of Food and Agriculture 2015). As far as we know, a third implementation plan METASIP III that should run from 2018 until 2021 is currently under review (AGRA 2017; Ministry of Food and Agriculture 2010, 2015, 2017).

\subsubsection{FASDEP II}

The second FASDEP II was officially launched in 2007. Its objectives have been the structural transformation of the agricultural sector through measures such as increased incomes of farmers, sustainable land management and developing key staple crops. Although these key staple crops were not specifically defined in FASDEP, the PFJ policy document mentions major crops such as maize and rice (see Section 2.3.3). The structural transformation of agriculture component of the policy aligned with the GPRS II (2006-2009), with agriculture being the main sector to lead the structural transformation and growth of the whole economy (Ministry of Food and Agriculture 2007).

While the phrase 'food security' is often mentioned in the FASDEP II document, the interpretation is that it mainly considers food security from the production side, which is a long-standing characteristic of Ghanaian food policy - a policy motivated by the existence of large yield gaps (Cudjoe et al. 2010) (see Table 3).

In FASDEP II, pressures such as urbanisation have been acknowledged and it is noted that urban agriculture can be 'a major livelihood strategy of the urban poor' (Ministry of Food and Agriculture 2007,11 ). The intention of FASDEP II has been to promote urban agriculture through the development of community land-use plans and increasing access to water and extension services for instance.

FASDEP II has been implemented through the second METASIP, METASIP II. Although METASPIP II has expired (see next section), there is no new METASIP installed yet.

In contrast to its implementation plan, FASDEP II has no official end date. As far as we know, there are no concrete plans to abolish or revise FASDEP. FASDEP II is still treated as main agricultural policy in Ghana.

\subsubsection{METASIP II}

As already mentioned and shown in Figure 3, the agricultural policy has been implemented through the second METASIP. The investment plan in METASIP II was developed following the guidelines of the ECOWAS agricultural policy and CAADP - i.e. spending at least $10 \%$ of the annual national budget on agriculture and achieving a $6 \%$ growth in agriculture - and is in accordance with the aim to respond to the agricultural transformation and sustainable management of natural resources of the GSGDA I (Ministry of Food and Agriculture 2015).

METASIP officially ran from 2014 to 2017, and there has not been a successor plan yet even though there appears to have been the intention to develop a METASIP III policy (AGRA 2017).

For FASDEP II and METASIP II, the emphasis of these policies is on farmers and their agricultural practices, i.e. food availability pillar in the FAO definition of food security. METASIP II aims for enhancing food security and emergency preparedness by transforming the country's agricultural sector. METASIP II considers the whole value chain in its objectives including the whole range of 
actors from smallholders to agribusinesses and post-production managing activities, such as packaging. In 2014, it was found that the programme had a positive impact on productivity improvement in access to fertiliser, seed quality and meeting market conditions. The impact of METASIP II on the production side is thus not a narrow one; METASIP's programme of action for instance consists of six programmes with multiple subprogrammes:

1. Management and administration, mainly about the implementation strategy itself (Ministry of Food and Agriculture 2015, 39);

2. Food and nutrition security and emergency preparedness, which concerns increasing irrigation, providing seeds and materials and developing livestock farming (Ministry of Food and Agriculture 2015, 40-44);

3. Increased incomes in agriculture through its subprogrammes of stimulating investments and financing (Ministry of Food and Agriculture 2015, 44-46);

4. Marketing of agricultural products, with the development of a domestic market, post-harvest management and export promotion as subprogrammes (Ministry of Food and Agriculture 2015, 47-49);

5. Land management (Ministry of Food and Agriculture 2015, 50-51);

6. Scientific research (Ministry of Food and Agriculture 2015, 51-53).

The subprogrammes within METASIP II that will be reviewed with respect to food security in more detail are the subprogrammes on food and nutrition security, increased income in agriculture, and marketing of agricultural products and their components, as well as the subprogramme dedicated to promoting the development of community land-use plans, particularly in urban and peri-urban agriculture under land management.

METASIP II does not explicitly consider the issue of UFS. It does mention that food safety in urban agriculture should be supported. The subprogramme on land-use plans can in theory also benefit urban agriculture and thus UFS.

\subsubsection{The Plan for Food and Jobs (PFJ) initiative}

In 2017, the Ministry of Food and Agriculture released the Plan for Food and Jobs (PFJ) initiative (Ministry of Food and Agriculture 2017a). PFJ has three objectives:

1. To ensure immediate and adequate availability of the selected crops (maize, rice, sorghum, soya bean, tomato, onion and chilli pepper) in Ghana through improved productivity and intensification of food crops, and extended support to private sector service providers;

2. To provide job opportunities for the many unemployed youth in the agriculture and allied sectors (for instance, packaging and branding companies); and

3. To create general awareness for all formal workers to either have farms and grow some cereals or vegetables, or establish backyard gardens when not enough land is available and accessible.

The PFJ programme is influenced by the SDG on Zero Hunger (SDG-2); the sustainable use of genetic resources, as the PFJ calls it, can be directly linked to maintaining seed varieties in the Zero Hunger goal of the SDG-2, for example. Moreover, by focusing on providing job opportunities, the government also hopes to incorporate other SDGs such as the promotion of sustained, inclusive and sustainable growth, full and productive employment and decent work for all (SDG-8).

Like FASDEP and METASIP, the PFJ programme emphasises food availability, as indicated by the first objective of the PFJ programme indicated above. The PFJ programme is based on five pillars: providing extension services, seeds, fertiliser, marketing and what is called 'e-agriculture' or a platform for strengthening the monitoring and evaluation of other activities. It mentions a selection of crops, and this selection was based on the following criteria:

1. Improve food security,

2. Increase smallholder farm profitability and incomes,

3. Supply raw material for the livestock and industrial sector,

4. Reduce the food import bill of crops in which Ghana enjoys comparative and competitive advantages,

5. Create jobs, and

6. Increase economic activity from various segments along the value chain. 
As further elaborated by the second goal, the PFJ programme takes a value chain approach. By trying to increase linkages between different companies active in the value chains of the selected crops, it tries just as much to improve job opportunities in agriculture and allied sectors.

In addition to the documents, policymakers of the government of the Republic of Ghana have indicated that they would like to make Ghana self-sufficient with respect to maize, rice, sorghum and soya. Moreover, the vice-president has recently mentioned a similar wish for the poultry sector (Bureau 2018). Messages surrounding this wish are ambivalent however, as although it is mentioned in a message on the website of the MoFA (Ministry of Food and Agriculture 2017b) this is not literally stated in the policy document itself. Beyond self-sufficiency, the general concern for economic viability of the crops may also be why there is an overlap between this policy's priority crops, and those of the export policies.

The PFJ programme is described as a so-called flagship programme, designed to resolve some major constraints for the agricultural sector that the Ministry of Food and Agriculture identified (such as limited availability of inputs like seeds or extension services). As such, it is well aligned with the FASDEP and METASIP documents, where noting of the perceived need to increase agricultural productivity is taken as the context in the PFJ document. Also in the document, it is stated that PFJ will be implemented under the not yet released METASIP III. Targeting of farmers with, for instance, improved inputs such as fertiliser, is done through farmer-based organisations and nucleus farmers (larger farmers who support smaller, subsistence farmers).

With respect to UFS, the PFJ states that urban and peri-urban growers of food crops are just as eligible for the programme's benefits as rural ones. The subsidised inputs that form four of the five pillars described are limited to a maximum of two hectares per farmer - which means that urban citizens of smaller plots should benefit relatively well.

\subsection{Nutrition policy}

Through the Ministry of Health $(\mathrm{MoH})$, Ghana has formulated different national nutrition policies. The first one, dating back to 2013, had five purposes (Ministry of Health 2013b):

1. To reposition nutrition as a cross-cutting issue;

2. To facilitate integration and mainstreaming of nutrition into all national development efforts;

3. To provide the framework for nutrition services and interventions in Ghana;

4. To guide the implementation of high-impact interventions;

5. To strengthen sectoral capacity for the effective delivery of these interventions .

The cross-cutting character of the nutrition policy was emphasised again in 2016. The Ministry of Health split the policy into three parts and according to two different branches, namely nutritionspecific and nutrition-sensitive policies.

The NNP formulated policy measures for each of the three objectives (Ministry of Health 2013b; Republic of Ghana 2016):

1. To increase coverage of high-impact, nutrition-specific interventions that ensure optimal nutrition of Ghanaians throughout their lifecycle, with special reference to maternal health and child survival;

2. To ensure high coverage of nutrition-sensitive interventions to address the underlying causes of malnutrition;

3. To reposition nutrition as a priority multisectoral development issue in Ghana.

Specific target groups mentioned in the 2016 policy include women and children, and the elderly. As can be seen especially from the nutrition-sensitive branch of the policy, it is related to the topics described in many other policies and their target groups. A policy explicitly mentioned in the 2016 version is the GSGDA; optimal health and the role of nutrition in it are seen as a prerequisite for socioeconomic development both at the individual and national level. 
Despite its broad and, in the thematic sense, cross-cutting approach, much of the NNP can be described as reactionary policy where very specific situations of food insecurity (or in terms of the policy: malnutrition) are addressed. This is also reflected in food policies in general; very few policies to specifically provide food with direct intervention into the accessibility of food for the food-insecure exist. Instead, most pro-poor policies, including those in the NNP cover a wide variety of benefits, such as healthcare insurance schemes.

One notable exception is the Ghana School Feeding Programme. This programme does specifically aim for provision of free meals for schoolchildren - but it covers only about $20 \%$ of pupils in Ashanti and around $10 \%$ or even less in most other regions (Republic of Ghana 2017). Other food security programmes in the GSGDA are again mainly focused on ensuring that poor people, whether urban or rural citizens, can plant their own food, for example through providing seeds and stimulating mechanisation, as specifically worked out in the PFJ programme mentioned earlier.

The government is thus limited in its direct involvement when it comes to food allocation to the needy and where such reactive programmes have that specific focus, they are aimed at very specific demographic (but not necessarily urban) groups that are still only served on a limited basis.

As we only looked at policies, the review of the NNP will be limited to:

- preventing and managing acute malnutrition (Republic of Ghana 2016,14)

- health, water, sanitation and hygiene services (Republic of Ghana 2016, 15)

- agriculture and food security (Republic of Ghana 2016, 15)

- social protection and safety nets (Republic of Ghana 2016,16)

- nutrition as a priority (Republic of Ghana 2016, 16)

Furthermore, in Chapter 5 we will review Ghana's Food Safety Policy. This policy deals specifically with food safety and falls under the health policy framework; this policy and most of the specific laws it tries to supplement and combine are (in some cases shared) the responsibility of the Ministry of Health. As such, it is not relevant for Chapters 3 and 4.

\subsection{Spatial development policy}

In 2013, the government of the Republic of Ghana launched the first comprehensive urban governance framework in the country's history, the National Urban Policy and Action Plan (GNUPAP). The GNUPAP aimed to address the challenges confronting urban development, being proposed as a comprehensive intervention in the urban sector to facilitate and promote a sustainable, spatially integrated and orderly development of urban settlements with adequate housing, infrastructure and services. It was developed by the Ministry for Local Government and Rural Development, with financial and technical support from the Support for Decentralisation Reforms Programme of the German Development Cooperation and the Ghana Urban Transport Project of the World Bank. The implementation of the policy is coordinated by the Urban Development Unit. The GNUPAP comprises the development of a vision, guiding principles and twelve main objectives and related action areas, particularly:

1. Balanced redistribution of the urban population

2. Spatially integrated hierarchy of urban centres

3. Urban economic development

4. Environmental quality of urban life

5. Planning and management of urban growth and sprawl

6. Urban infrastructure and services

7. Adequate and affordable housing

8. Urban safety and security

9. Urban governance

10. Climate change adaptation and mitigation mechanisms

11. Research in urban and regional development

12. Urban development finance 
These action areas are further refined in the action plan, which outlines detailed policy interventions, responsibilities and timelines. GNUPAP includes a few initiatives that address the pillars of food security. In particular, it aims to directly contribute to food availability by promoting food production, distribution and exchange through investments in agriculture and agro-based industries, creation of new market centres for agriculture products and improvement of the transportation networks. Furthermore, it addresses food utilisation, by attending to the hygiene and quality of food for the urban public. In addition, it may also indirectly contribute to access to food, by improving food affordability through the promotion of employment and income generation, and promotion of access to adequate and affordable low-income housing. The underlying rationale of this policy is to create and develop new growth points as countermagnets to fast-growing cities such as Accra and Kumasi. Hence, its related initiatives are mainly targeted at increasing the vitality and quality of life in small and medium-sized towns and their surrounding rural areas, including their food security. Our review is, however, focused on revising policies that address UFS in large metropolitan areas. Although GNUPAP might contribute to alleviate UFS in large metropolitan areas (e.g. by contributing to the redistribution of expected urban population growth from large cities to smaller settlements), its interventions related to food security do not explicitly target these regions. Therefore, GNUPAP will not be further reviewed in Chapters 3-5.

More recently, the government of the Republic of Ghana has published the Ghana National Spatial Development Framework (GNSDF) 2015-2035, a long-term 20-year strategy for the spatial development of Ghana. GNSDF was jointly developed by Ministry of Lands and Natural Resources (MLNR), the Ministry of Environment, Science, Technology and Innovation (MESTI), the Town and Country Planning Department and the NDPC. The development of the GNSDF was informed by (i) the Medium-Term National Development Policy Frameworks and GSGDAs I and II; (ii) the sectoral plans and policies in areas such as economy, transport, education, health, environment, energy, climate change and land use; and (iii) the views of several government agencies at the national, regional and district levels. The framework is expected to contribute to the National Long-term Development Strategy, as well as guiding local authorities in preparing regional, subregional and district level spatial development frameworks and lower-level plans. The GNSDF is composed of three volumes, namely i) the conditions and the main issues, ii) overall strategy, and iii) implementation of the framework. GNSDF has five main objectives:

1. Emphasise balanced polycentric development;

2. Improve regional, national and international connectivity;

3. Strengthen the metropolitan city regions of Accra and Kumasi;

4. Promote development in networks and secondary cities;

5. Ensure sustainable development and protect ecological assets.

GNSDF sets out a place-based framework that includes i) an urban settlement hierarchy; ii) a megaregion amalgamating several large urban centres in the ECOWAS region; iii) a linear, two-city-region that have taken on a larger scale than individual large cities - Accra and Kumasi; and iv) eight urban networks. In contrast to GNUPAP, GNSDF thus explicitly targets the large metropolitan areas of Ghana, promoting not only their further consolidation as poles of economic activity and growth but also their greater integration into the global and West African economies. It recommends an overall policy of concentrated development, which includes the following key strategies to be implemented:

- Promote the Accra Capital region;

- Promote existing urban settlements and discourage new ones;

- Promote larger/discourage smaller settlements;

- Promote urban settlements along major transport corridors;

- Plan for integration of rural settlements into expanding urban areas;

- Protect agricultural land and forests from settlement development;

- Maintain and improve the efficiency of the main expressway network.

Ten national policy initiatives are planned for the period 2015-2035:

1. A national and international expressway system;

2. Upgraded and improved trunk roads;

3. A national and international rail network;

4. Two international airports; 
5. New airport city at centre of triangle;

6. Options for three new seaports;

7. Green infrastructure network;

8. Agricultural growth corridor;

9. Proposed urban food sheds;

10. Alternative energy projects.

\subsection{Climate change policy}

Ghana became a party to the UNFCCC in 1995 . Upon ratification, Ghana committed to pursue coordinated actions to reduce greenhouse gas emissions and climate change impacts on the most vulnerable, while continuing to advance national economic development. Since then, Ghana also ratified the Kyoto Protocol in 2003 and the Paris Agreement in 2016. The Ministry of Environment, Science, Technology and Innovation and its technical implementing agency, the Environmental Protection Agency (EPA), are the key institutions that coordinate the implementation of policies and programmes on climate change including national, regional and international UNFCCC conventions and initiatives. The National Climate Change Committee (NCCC) is an administrative mechanism hosted by the Ministry of Environment, Science, Technology and Innovation, which is responsible for leading the interministerial process of developing Ghana's climate change policy, and facilitate intersectoral coordination. In addition, the Ghana Environmental Conventions Coordinating Authority has been established to coordinate the Rio Conventions (desertification, climate change, and biological diversity) and to ensure synergy with the 35 international environmental conventions to which Ghana is a signatory.

In 2012, EPA published the National Climate Change Adaptation Strategy (NCCAS). The NCCAS was developed in a joint partnership between the United Nations Environmental Programme (UNEP) and the United Nations Development Programme (UNDP), through the Climate Change and Development Adapting by Reducing Vulnerability (CC-DARE) programme, with funding support from the Danish Ministry of Foreign Affairs. The NCCAS is jointly managed at the central level by the Ministry of Environment, Science, Technology and Innovation and the NCCC in regards to policy, planning, monitoring and evaluation of development programmes and projects, with the latter being responsible for operationalising the strategy at the national level. The District Assemblies assume local-level responsibility in the selection and development of programmes, with assistance from decentralised agencies.

The NCCAS policy document describes the expected impacts and vulnerabilities resulting from climate change in Ghana, and outlines the main goals towards the development of an adaptation strategy:

- Improve societal awareness and preparedness for future climate change;

- Enhance the mainstreaming of climate change into national development to reduce climate change risks;

- Increase the robustness of infrastructure development and long-term investments;

- Enhance the adaptability of vulnerable ecological and social systems by increasing the flexibility and resilience of these systems;

- Foster competitiveness and promote technological innovation.

It also establishes a multisector (livelihoods, energy, agriculture, health, early warning, fisheries management, land use and water) adaptation strategy, which are divided across ten principal working programmes:

1. Increasing resilience to climate change impacts: identifying and enhancing early warning systems;

2. Alternative livelihoods: minimising impacts of climate change for the poor and vulnerable;

3. Enhancing national capacity to adapt to climate change through improved land use management;

4. Adapting to climate change through enhanced research and awareness creation;

5. Developing and implementing environmental sanitation strategies to adapt to climate change;

6. Managing water resources as climate change adaptation to enhance productivity and livelihoods;

7. Minimising climate change impacts on socio-economic development through agricultural diversification;

8. Minimising climate change impacts human health through improved access to healthcare; 
9. Taking demand- and supply-side measures for adapting the national energy system to impacts of climate change;

10. Adaptation to climate change: sustaining livelihoods through enhanced fisheries resource management.

In 2013, the government approved GNCCP, which was officially launched by the president in 2014. The GNCCP was developed under the guidance of the NCCC, with technical leadership from the Ministry of Environment, Science, Technology and Innovation, and the EPA. The first phase's final document was preceded by the NCCPF: the Ghana Goes for Green Growth (G4) discussion document, prepared with support from the Climate and Development Knowledge Network (CDKN). The GNCCP also aimed at complementing and enhancing the overall strategic objectives of national development strategies outlined in GSGDA I 2011-2013. The Ministry of Environment, Science, Technology and Innovation is responsible for monitoring the implementation of the NCCP and the associated programmes and plans, with the National Environmental and Natural Resources Council (NENRC) also playing an supervisory role in this regard.

The GNCCP provides strategic direction and coordinates issues of climate change in Ghana, being composed of three phases:

- Phase one presents the policy, analyses the current situation, and describes the broad policy vision and objectives;

- Phase two presents in greater detail the initiatives and programmes identified in phase one, in the form of an action programme for implementation;

- Phase three details how climate change programmes and actions identified in phase two can be mainstreamed and embedded in a time-bound and budgeted manner, into annual work plans of implementing units.

Phase one corresponded to the publication of the main GNCCP policy document (Ministry of Environment, Science, Technology and Innovation 2013), which outlines the main objectives of the policy: 1) effective adaptation, 2) social development, and 3) mitigation, in regard to five priority policy areas:

- Agriculture and food security

- Disaster preparedness and response

- Natural resource management

- Equitable social development

- Energy, industrial and infrastructural development.

These policy areas are then subdivided into a total of ten programme areas:

1. Develop climate-resilient agriculture and food security systems;

2. Build climate-resilient infrastructure;

3. Increase the resilience of vulnerable communities to climate-related risks;

4. Increase carbon sinks;

5. Improve management and resilience of terrestrial, aquatic and marine ecosystems;

6. Address impacts of climate change on human health;

7. Minimise impacts of climate change on access to water and sanitation;

8. Address gender issues in climate change;

9. Address climate change and migration;

10. Minimise greenhouse gas emissions.

This document was then followed by the publication of the Ghana National Climate Change Master Plan Action Programmes for Implementation: 2015-2020, which corresponds to phase two of the GNCCP. This document gives details of the ten GNCCP strategic programme areas, including tasks, budgets and timelines. This strategy is now the key government climate change agenda in the country and will inform nationwide climate change programme and development activities, including sector plans and budgets. At the time of this review, phase three has not been implemented.

Lastly, Ghana appears to be working on the creation of a National Climate-Smart Agriculture and Food Security Action Plan. In this document, the Ministry of Food and Agriculture explains how it will fill in 
each of the eight programmes identified in the NCCP with respect to agriculture and food security. The document is a working document however, and the policy appears to be in development; no official publication on websites of the government or the Ministry of Food and Agriculture was found at the time of writing this review (Essegbey et al. 2015). With the Climate Change Agriculture Food Security (CCAFS) programme, Ghana receives support to start a national science-policy dialogue platform for the exchange of knowledge on climate change adaptation. CCAFS is hosted by the CGIAR, the Consultative Group for International Agricultural Research (CGIAR 2019). In METASIP, its aims were formulated as follows:

i. Develop climate-resilient agriculture and food systems for all agro-ecological zones;

ii. Develop human resource capacity for climate-resilient agriculture;

iii. Elaborate on the implementation framework and the specific activities to be carried out at the respective levels of governance.

Since this action plan is thus not released yet, agricultural policy will be limited to FASDEP, METASIP and PFJ while we will look at the GNCCP and NCCAS for climate change policy (after discussing the NNP and GNSDF for their themes). 


\section{$3 \quad$ Availability}

\subsection{Link to the food system}

In this chapter we describe, given high rates of urbanisations and climate change, how policies in Ghana address the first pillar of food security: the availability of food. According to Ingram (2011) it includes production, distribution and exchange (see Figure 6). So, in economic terms, food availability is not only about supply and relative supply according to different spatial and temporal dimensions, but also about demand and the interaction between supply and demand.

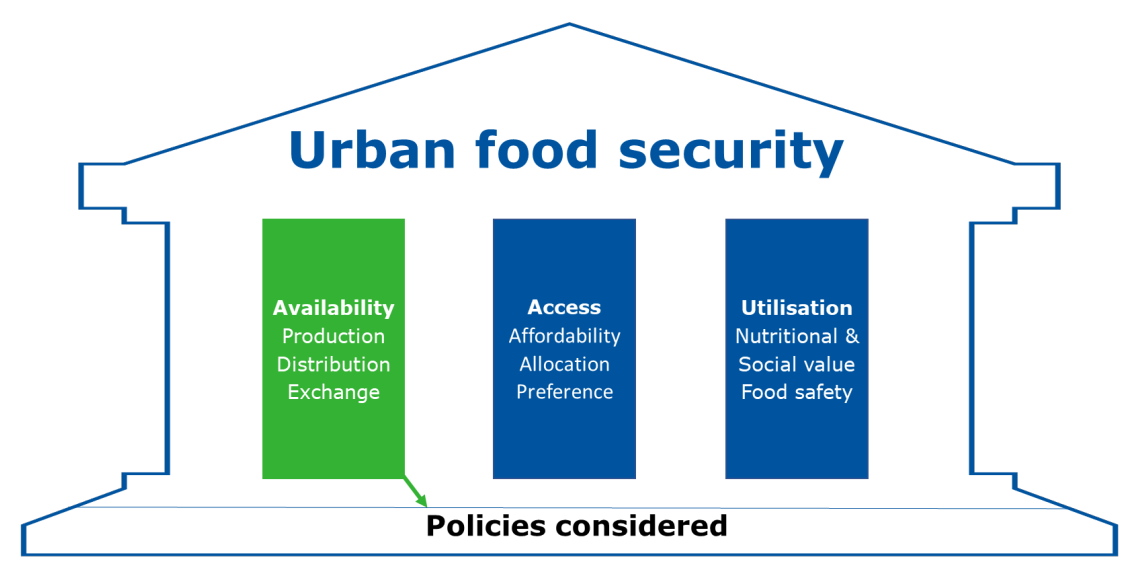

Figure 6 Food system elements of food availability

Production of food deals with more than just the bio-physical process of growing crops or managing livestock. It also considers inputs, access to land, and laws and conventions governing such aspects as access, property rights and everything else that might influence production as well as producers.

Distribution in terms of the food system is about the actual practice of distributing food from the primary producers to the consumers, and the channels along which the distribution takes place. In rural areas, the distribution channels are usually local or regional, but since we are focusing on UFS, it also includes long-distance networks of food distribution. Moreover, distribution would also include all factors and conditions such distribution and the ability of people to reach allocated produce. However, because affordability and allocation belong to the pillar of access, the element 'distribution' is considered here in a narrower sense.

Exchange of food is about more than just the trade interactions in economic terms. Following the food security-food system framework, exchange of food is defined in a broad sense so that it includes policymaking regarding marketplaces, retail outlets and the like as physical components, but conventions, social norms and other institutions that govern such exchanges are also important elements of exchange-governing mechanisms.

While reviewing the situation in Ghana with respect to food insecurity, the ZHSR took the availability of food into account. As a word of advice, it called for empowerment by insisting that people should own the food policies, from making to implementation and monitoring. In this sense, it claimed that not just food itself, but also the policy and decision-making power therein should be distributed to the people. 
More practically speaking in terms of production, the ZHSR had argued for the inclusion of the agricultural cluster approach where different - private, as it is emphasised - actors around specific farmers who together form the value chain, cooperate. The approach it advertised appeared to be space-based, and is somewhat reminiscent of the nucleus farmer-outgrower model of the PFJ, with the main difference being (in terms of value chains) that the agricultural cluster approach focuses more on vertical cooperation, rather than horizontal cooperation between only farmers (World Food Programme and John Kufuor Foundation 2018).

The ZHSR noted that the growth of the service sector (including banking and financial services) had made it easier to market imported products and it caused the detriment of domestic agricultural and industrial products. The authors of the ZHSR considered this a bad development, because producers in Ghana found it more difficult to compete while dumping practices were going on. Thus, the authors of the Strategic Review apparently supported the drive towards self-sufficiency and the associated domestic sourcing of products that was also mentioned in other policies, such as the PFJ that promotes vegetable gardens.

With respect to the exchange of food, the ZHSR emphasised the need to develop markets, noting that, according to consulted stakeholders, it is limited market access rather than limited production inputs that is the main culprit for agriculture. Besides mentioning the importance of standards of weights on markets, few specific actions were suggested though. Indeed, the ZHSR also suggests that farmer practices of smallholders, as long as they are sustainable and scaled up (Sustainable Agricultural Intensification), can be the core of a 'food-based' approach. So, the focus seems to be on production and agriculture, even though the importance of market access is acknowledged. This focus on production and agriculture is already an important aspect of food policy in Ghana, as we will see below.

The ZHSR is not specifically focused on urban food availability or any of its components; it only notes that food security can (and indeed does) differ per region, for different demographic groups and that different kinds of insecurity (micronutrient deficiency) can be experienced by these different groups and in these different areas. As the ZHSR thus shows, food security and policies designed to address it deserve to be disaggregated with specific attention for rural, but also urban areas. We will therefore look for such specific attention towards UFS in the policy documents.

\subsection{Review of the policies}

Table 5 presents the review of the selection of policies with respect to food availability aspects and UFS. First, FASDEP and METASIP are considered. To provide an overview, the policies and how they consider the elements of availability are summarised in Table 5. 
Table $5 \quad$ Availability of food in the main policy documents, sorted by element

\begin{tabular}{|c|c|c|c|}
\hline & \multicolumn{3}{|l|}{ Element of food availability } \\
\hline & Production & Distribution & Exchange \\
\hline FASDEP \& METASIP & $\begin{array}{l}\text { Long-standing tradition of } \\
\text { focusing on agricultural } \\
\text { production. Access to food } \\
\text { considered in terms of } \\
\text { productivity, market access (for } \\
\text { producers) and sustainable } \\
\text { production. }\end{array}$ & $\begin{array}{l}\text { FASDEP emphasises } \\
\text { infrastructure, but from the } \\
\text { production side and marketing } \\
\text { agricultural produce. }\end{array}$ & $\begin{array}{l}\text { No specific policy measures, } \\
\text { although diversified diets and } \\
\text { some cultural challenges are } \\
\text { identified in especially the } \\
\text { ZHSR. } \\
\text { Some attention for clear } \\
\text { market price signalling in } \\
\text { METASIP. }\end{array}$ \\
\hline PFJ & $\begin{array}{l}\text { Increasing access to } \\
\text { agricultural inputs to increase } \\
\text { productivity. Also moving up } \\
\text { the value chain of a selection of } \\
\text { crops. Encouraging all citizens } \\
\text { to plant something. }\end{array}$ & $\begin{array}{l}\text { Much focus on national self- } \\
\text { sufficiency. Everyone } \\
\text { encouraged to be a producer } \\
\text { of food. Roads and } \\
\text { infrastructure considered, but } \\
\text { from the production side. }\end{array}$ & No specific policy measures. \\
\hline NNP & Little attention for production. & $\begin{array}{l}\text { Distribution is described in } \\
\text { terms of targeting specific } \\
\text { demographic groups such as } \\
\text { women and schoolchildren, } \\
\text { also through the utilisation of } \\
\text { existing care facilities. } \\
\text { High coverage of both } \\
\text { nutrition-specific and } \\
\text { nutrition-sensitive policies is } \\
\text { ensured, for instance through } \\
\text { promoting nutrition } \\
\text { interventions within existing } \\
\text { facilities. }\end{array}$ & $\begin{array}{l}\text { Limited attention, although the } \\
\text { extension of social security } \\
\text { nets is encouraged which } \\
\text { could influence how and when } \\
\text { people buy food. }\end{array}$ \\
\hline GNSDF & $\begin{array}{l}\text { Increasing food production in } \\
\text { regions with unrealised } \\
\text { agricultural production. }\end{array}$ & $\begin{array}{l}\text { Improving food distribution } \\
\text { through the targeted provision } \\
\text { of strategic infrastructure. } \\
\text { Deploying processing facilities } \\
\text { and distribution networks } \\
\text { within short distances of cities } \\
\text { in order to sustain the } \\
\text { availability of fresh food to } \\
\text { nearby populations. }\end{array}$ & $\begin{array}{l}\text { Linking markets and } \\
\text { promoting exchange between } \\
\text { urban cores and their service } \\
\text { areas or hinterlands. }\end{array}$ \\
\hline NCCAS & $\begin{array}{l}\text { Increasing agricultural } \\
\text { productivity and awareness of } \\
\text { climate issues. Promoting new } \\
\text { farming technologies in order } \\
\text { to enhance their support for } \\
\text { farmers, including crops and } \\
\text { livestock adapted to harsh } \\
\text { climatic conditions. }\end{array}$ & $\begin{array}{l}\text { Promoting post-harvest } \\
\text { technologies to minimise } \\
\text { losses of farm produce. }\end{array}$ & No specific policy measures. \\
\hline GNCCP & $\begin{array}{l}\text { Supporting climate change } \\
\text { adaptation in cropping, } \\
\text { livestock, fisheries and } \\
\text { aquaculture systems. }\end{array}$ & $\begin{array}{l}\text { Improving post-harvest } \\
\text { management and marketing } \\
\text { systems. }\end{array}$ & No specific policy measures. \\
\hline
\end{tabular}

\subsubsection{Agricultural policy}

With regard to the 'availability' pillar of food security, FASDEP and METASIP mainly focus on production. For instance, METASIP was mainly concerned about food and nutrition security, and emergency preparedness deals which are related to agricultural production. This includes seed and planting material development, machinery availability, irrigation networks, development of selected crops and livestock development (Ministry of Food and Agriculture 2015, 40-43). A direct impact on 
food production is to promote the development of a wide variety of plantation types such as cotton, dawadawa trees and rubber, which would thus allocate land to the production of non-food crops in the case of cotton and rubber, and non-staple crops in the case of dawadawa (Ministry of Food and Agriculture 2015,46 ). The expected negative impact of food availability is reduced as much as possible, as the Tree Crops Policy also promotes the potential of intercropping with food crops for instance. Moreover, the increase in tree crops production should not compete with food crops production while trying to increase employment, diversify production, induce economic growth, increase foreign exchange earnings and contribute to poverty alleviation.

An indirect concern with production was through increased incomes for those working in agriculture, which had to be achieved by stimulating investments and financing. Also linked to production concerns were post-harvest production practices, specifically ways to limit post-harvest losses by promoting processing and storage capacity. On the other end of the production process, METASIP devoted attention to land availability.

For the distribution of food, there were programmes aiming at improved rural infrastructure and the development of an effective domestic market. Measures included in table format in METASIP range from promoting local(ly processed) products by focusing on quality and good packaging to improving market infrastructure and sanitary conditions, and development of standards for quality in general. So, the reason for the focus of METASIP on infrastructure is essentially the improvement in transport for agricultural produce from towns to cities, and the reduction of post-harvest losses, which were expected to have a significant adverse impact on availability of food in the Ghanaian urban environment.

With respect to the exchange of food, METASIP was limited to the market development issue already described.

\section{PFJ}

Interestingly, the PFJ programme has already incorporated the food system perspective, because it regards citizens as both consumers and producers of food. Every citizen - regardless where they live, either in rural or urban areas - is encouraged to plant something, as well as linking farmers who have proved to be commercially successful, to other agents in the value chains. In addition, citizens producing food or working in food value chains increase food availability and might even provide jobs. Another aim of PFJ programme was to decrease the reliance on food imports and reduce the import bill. Further, it aimed to support private actors active in the food value chain of the selected food crops (see Section 2.3.3). For example, it aimed to set up a certification system for providers of nursery stock. Also, PFJ facilitated the provision of fertiliser and improved inputs such as drought-stress or disease-resilient seeds. In short, through both long-term and large-scale economic transformation on the one hand, and stimulating home-grown production on the other hand, PFJ tries to increase the availability of food while at the same time aiming for raised incomes in order to increase access to food (more on that in Chapter 4).

The PFJ programme mainly considered the production of food including the distribution and exchange of inputs for production. For instance, the programme delineates how seeds and other agricultural inputs should be distributed. Exchange is only considered in relation to the provision of inputs; the document clearly outlines the procedures and organisations involved in distributing seed packages, weights of the packages, quality control and inspection, and subsidies in the form of vouchers.

Distribution and exchange of food were hardly mentioned in the PFJ programme. It stated that information on the preferences of consumers should be obtained.

One important element of food security is diet diversity (which will be discussed in more detail in Chapter 5). When it comes to production and distribution, very little attention is actually devoted to stimulating diversity; most policies, including those that relate to the PFJ programme, are moving in the opposite direction (Donkor 2018) by promoting the production of very specific staples such as maize and rice, and aiming for district-level specialisation in the production of these crops. 
PFJ did not pay much specific attention to urban food availability. Instead, it distinguished targets of both rural-based and urban-based farmers. In many cases the rural and urban areas were even mentioned closely after each other, such as when discussing forward and backward linkages to the agricultural sector. As the programmes tried to prevent elite capture, inputs were available to owners of, at most, two hectares of land. This means that the programme was well suited for support to urban farmers as well.

\subsubsection{Nutrition policy}

The NNP paid some attention to the general process of producing food. For instance, it promoted the uptake of modern agricultural technologies in order to increase production (Republic of Ghana 2016, 15). Most of its attention for food production related to the promotion of locally grown and indigenous nutritious foods. It further called for promotion of scaling up of local production, processing and preservation systems (Republic of Ghana 2016, 16).

With respect to distribution, the NNP argued for increasing the capacity to manage moderate and severe malnutrition in all facilities (Republic of Ghana 2016,14). No attention was paid to exchange.

\subsubsection{Spatial development policy}

GNSDF included several policy initiatives that aim to contribute to the availability of food in large metropolitan areas. The Agricultural Growth Corridor (AGC) initiative, in particular, aimed at increasing food production in regions with unrealised agricultural production by facilitating commercial agricultural development. In addition, it pursued improvement of food distribution through the targeted provision of strategic infrastructure such as storage and processing facilities, roads and railways connecting high production areas to ports, international borders and major urban centres. Two options were being appraised for the establishment of such corridors, both located in the vicinity of the national-level trunk road from Accra to Bolgatanga. The AGC initiative was also linked to activities from other GNSDF policy initiatives related to the deployment of transport infrastructure, particularly the initiatives for the national and international expressway system, and the upgraded and improved trunk roads. In fact, the development of the Kumasi-Paga expressway, improving connectivity around and across Lake Volta, and the improvement of the connectivity in the western region had the objective of improving access to agricultural areas in order to unleash agricultural potential and expedite transport of agricultural produce to the major markets (Republic of Ghana 2015).

Furthermore, the proposed urban food sheds initiative intended to deploy processing facilities and distribution networks within short distances of cities in order to sustain the availability of fresh food to nearby populations. NSDF identified the cities where food shed planning is a priority, in particular Accra and Kumasi, which were estimated to have 15 and 13 people per hectare of cropland respectively within a radius of $50 \mathrm{~km}$. For comparison, Cape Coast and Tamale had only two and one person per hectare respectively.

\subsubsection{Climate change policy}

NCCAS supported food availability by addressing issues related to food production in general. It aimed at minimising climate change impacts (UNEP 2012, 21) through agricultural diversification, and had a number of initiatives targeting food production:

- Build and strengthen the capacity of local farmers to increase agricultural productivity and awareness of climate issues;

- Build and strengthen the capacity of extension workers in new farming technologies in order to enhance their support for farmers;

- Promote cultivation of crops and rearing of livestock adapted to harsh climatic conditions;

- Educate trainers to promote post-harvest technologies to minimise losses of farm produce.

It did not specifically target food availability in metropolitan areas. Similarly, GNCCP addressed general issues of food production and distribution with initiatives summarised under the objective 
'Develop climate-resilient agriculture and food security systems' (Ministry of Environment, Science, Technology and Innovation 2015, 6-11), such as:

- Development and promotion of climate-resilient cropping systems (Programme 1.2);

- Adaptation of livestock production systems (Programme 1.3);

- Support to climate change adaptation activities in fisheries and aquaculture (Programme 1.4);

- Support to water conservation and irrigation systems (Programme 1.5);

- Improved post-harvest management (Programme 1.7);

- Improved marketing systems (Programme 1.8).

\subsection{Synthesis}

In this section, we will synthesise the main findings for the pillar of availability. The key issues found were

- producer-oriented policies

- consumers as producers

- high need for distribution due to a desired regional specialisation

- focus on existing urban cores

- some specific measures to increase availability, but limited in coverage

- conflicts between spatial development and availability

- conflicts between PFJ and export ambitions.

The policies considered deal with food (security) and specifically with food availability. This can be partly explained by long-standing wishes of the government of the Republic of Ghana to be selfsufficient in food production as well as structural adjustment programmes from international organisations (Republic of Ghana 2018a; Abdulai et al. 2018) (see Table 6).

Table 6 Consideration of food availability in the policies reviewed

\begin{tabular}{|c|c|c|c|}
\hline \multicolumn{4}{|l|}{ Agricultural policy } \\
\hline \multicolumn{4}{|l|}{ METASIP } \\
\hline PFJ & $* \#$ & & \\
\hline \multicolumn{4}{|l|}{ Health/nutrition } \\
\hline Spatial development & & *\# & \\
\hline
\end{tabular}

Green $=$ the policy considers the element extensively, using the specific term and directly describing it. Orange $=$ the element is mentioned but not taken into account, or the policy considers the element without using the term explicitly. Grey = the element is not taken into account and not mentioned either. '\#' denotes possible adverse impacts of the policy on food security; ' ${ }^{\prime}$ indicates that the policy is especially relevant for urban areas.

Table 6 shows that availability is dominated by production concerns, followed at a distance by distribution. Exchange was considered mostly in terms of linking producers to markets, and not so much the exchange of food in terms of bartering or buying at these markets. Production concerned most clearly dominate the agricultural policies, for instance through the provision of inputs into agriculture and ways of distributing such inputs.

When it comes to distribution and exchange specifically, the latest policies reviewed here mainly try to link food to the people by encouraging everyone to plant something. This was related to the goal of regional specialisation, the so-called one district, one warehouse programme (Donkor 2018) which was worked out under the PFJ programme as the two measures were, for instance, linked in the president's speech (Akufo-Addo 2018) and which was also evident from the Ghana National Spatial Development Framework (Republic of Ghana 2015). So, the distribution and exchange of food were 
hardly discussed in agricultural policies. Some explicit attention exists for distribution in the form of urban food sheds in spatial policy though.

With respect to UFS especially, some policies might have had a positive impact - even though none of the policies were explicitly concerned with UFS. Generally speaking, the PFJ programme had a lot of potential in terms of food security and availability, like the promotion of urban agriculture for instance which has long been seen by scholars has having significant potential (De Zeeuw et al. 2011; Mackay 2018). Still, cities like Accra need a more clearly defined policy, safety regulations and investments to meet such regulations for urban agriculture to fulfil such potential (Nchanji 2017).

Moreover, the lack of integration from a perspective of infrastructure and the huge sums needed for increasing the effectiveness and reliability of transport and energy on the one hand, and the consistent lagging of the northern regions on the other hand means that significant efforts are needed to increase availability of locally grown food crops for the poorer, northern (also less urbanised) regions. This situation of lag in the north came about through long periods of neglect, which Abdulai et al. argued to be a result of the colonial regime as it was mostly the south that was interesting for the extractive industries such as gold mining (Abdulai et al. 2018). The renewed interest in crop specialisation on both the national and the district level had disruptive impacts on the production and distribution of food and on economic development. North Ghana has suitable soil for specific cropgrowing such as maize, plantain and pineapples. The north did not have comparative advantages with respect to these crops when compared to the south (Ministry of Food and Agriculture 2016b, 91-92). Given the current policies, each region would have to choose at least one or two crops to specialise in; the northern region could nevertheless specialise in such crops.

For the urban areas, specialisation as desired by the government was also possible for the generally more urbanised southern part of the country (Ministry of Food and Agriculture 2016b; Abdulai et al. 2018).

\section{Food availability in its international context}

On the national level, policy with respect to distribution and relative availability of different foods was becoming less integrated due to regional specialisation. Crop specialisation was already present due to the differences in agro-climatic circumstances (Ministry of Food and Agriculture 2016b), but it was now further aimed for in newly announced plans as indicated previously (Republic of Ghana 2011; Donkor 2018; Akufo-Addo 2018) and as part of the National Export Strategy or NES (Ministry of Trade and Industry 2013a). This regional specialisation with export opportunities gave more rural parts the country the attention that the OECD argues is important in rural development, as opposed to the more classical approach of linking rural areas to urban ones (OECD, FAO and UNCDF 2016).

In terms of distribution, the effects of export policies were observed through the shift in availability of imported, processed and domestic food available in different parts of the country. Generally speaking, more imported and processed food was available in smaller cities compared to, for instance, Accra (Andam et al. 2017). Agricultural policy e.g. FASDEP and METASIP emphasised the improvement of the linkages between different markets and thereby the promotion of the exchange of food. In practice, this resulted in linking specific producers to their nearest market. It thus promoted the exchange of food between local producers and consumers rather than between local producers and spatially dispersed markets (i.e. different producers with different consumers from other regions). Spatial development policy was aimed at creating regional urban centres and linking their service areas with the urban core, which deviated from agricultural policy in which different regions were encouraged to specialise in an agricultural activity. Setting general economic development issues aside, this spatial development could be beneficial for urban areas with respect to food availability. Given that the large metropolitan areas (Kumasi, Accra) are placed at the top of the hierarchical approach, these metropolitan areas could benefit from the large urban cores in Ghana from a food security perspective.

On a national scale, the policy of Ghana focused on reducing the import bill (see PFJ in Section 3.2.3) by diversifying exports through moving up the value chain and exporting processed food. This shift also better fitted the AGOA conditions because processed foods were exempted from import tariffs in 
the US under this regime. Consequently, the availability of specific products such as tomatoes and sauces increased due to higher production (and productivity), but decreased due to higher exports. The balance of food availability might be positive or negative. Regardless of these contrary outcome possibilities, Ghana's efforts with respect to stimulating tomato production and export have largely failed; production is still lower than demand and thus import of tomatoes in large quantities remains necessary (Baba et al. 2013). The same development was observed for rice (Baba et al. 2013).

Furthermore, limitation of tariffs on food commodities (World Bank 2018) should in theory make trade of food more attractive and easier in the case of temporary shortages of food. From an international perspective, food markets would be more integrated, which improves food allocation stability and protects against price shocks. Consumers depending on imported food would benefit the most (Rapsomanikis and Sarris 2008; Cudjoe et al. 2010). Increased market integration is aimed for through the Economic Partnership Agreement and hence positive impacts on allocation and availability of food. It would open up the Ghanaian markets for food commodities to the European Union and vice versa (African Center for Economic Transformation 2015).

In terms of exchange and distribution though, the drive for self-sufficiency dominates the policies, such as PFJ, despite the potential increased availability of food that could come with increased trade. The international trade documents further reflected this in the competition element of the stated goals, although it should be noted that in general, the government aims for more integration in the international economy in its trade policy. In order to achieve such integration, the NES and NEDS have also laid out programmes and strategies for achieving integration and creating linkages on the national level, although the ultimate goal is for international integration and for increasing the export potential for the selected crops and products derived from those, not to increase food security and availability domestically (even though that will likely also be increased as a side effect). Even so, there is significant overlap between the crops targeted for export, and those in the PFJ (see Appendix C). Thus, there may be adverse impacts from the export policies on UFS, and from PFJ on UFS as increased domestic availability is not automatically destined for domestic consumption. The policies do not discuss these contrasts. 


\section{$4 \quad$ Access to food}

\subsection{Links to the food system}

In this chapter we describe, given urbanisation and climate change, how and whether access to food is incorporated in policy in Ghana. In terms of the food system, access to food deals with consumers' ability to obtain food (affordability or so-called economic access), the 'ability' of the food to reach the consumer (allocation or so-called physical access), and their ability to obtain the food they prefer (see Figure 7).

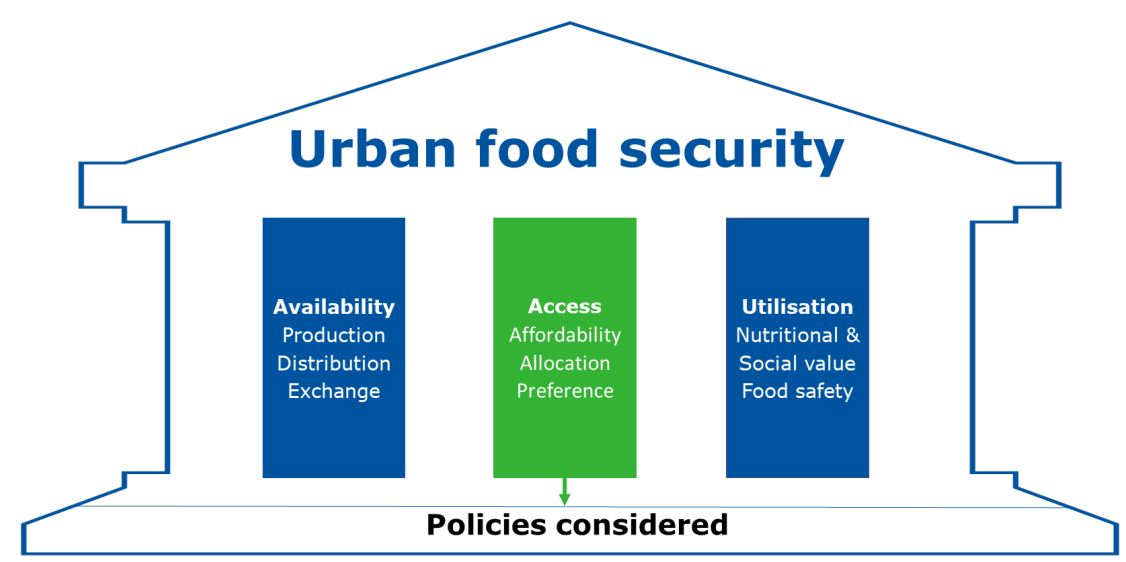

Figure 7 Food system elements of food accessibility

Affordability thus describes the linkage of consumer characteristics such as income to the availability and prices of food as determined by the rest of the food system. Allocation of food describes logistical matters as perceived from the consumer and their preferences dealing with individual, household and cultural wishes. Of course, these preferences at individual, household and cultural level overlap, such as in the case of food preferences of different households or household members, which is very likely jointly shaped by similar cultural aspects, disposable household income and food choices of the households.

As noted in the ZHSR, poverty rates significantly differ across different parts of Ghana (World Food Programme and John Kufuor Foundation 2018). Generally speaking, northern Ghana has lagged behind in poverty reduction trends compared to the rest of Ghana. For example, stunting rates among children in northern Ghana (33\%) are higher than in Greater Accra (10\%) (World Food Programme and John Kufuor Foundation 2018). In general, poverty rates in the rural areas in Ghana are higher than in the urban areas except for the Greater Accra region (Republic of Ghana 2012).

The ZHSR emphasised the importance of addressing the malnourishment and health gaps, and criticises the limited special attention for distinct demographic groups in food insecurity policies (World Food Programme and John Kufuor Foundation 2018). However, the ZHSR paid little attention to access to food in food security. The ZHSR presented analyses and trends of affordability of food which is the situation analysis. The recommendations of the ZHSR addressed equity, inclusiveness issues, the trade-offs between different livelihoods, and the geographically targeting of interventions. Equity and inclusiveness relate to affordability of food for specific groups and their preferences, and allocation of food and geographic targeting of policies relate to allocation. 
In the next sections, the policies are therefore reviewed using the food system model and the elements of affordability, allocation and preference explicitly. Policies are reviewed in the same order as in Chapter 3.

\subsection{Review of the policies}

This section discusses policies linked to the food security pillar of access, following the same thematic approach as the previous chapter and while analysing mostly the same documents and policies plus some others. First, FASDEP, METASIP and the PFJ will be analysed with respect to access to food. Then, the NNP, GNSDF, NCCAS and GNCCP are reviewed. Table 7 provides an overview of key elements of food accessibility incorporated in the policies considered.

Table 7 Accessibility of food in the main policy documents

\begin{tabular}{|c|c|c|c|}
\hline & \multicolumn{3}{|l|}{ Element of food access } \\
\hline & Affordability & Allocation & Preference \\
\hline FASDEP \& METASIP & $\begin{array}{l}\text { Limited attention; FASDEP } \\
\text { mentions urban agriculture as a } \\
\text { livelihood strategy. }\end{array}$ & $\begin{array}{l}\text { METASIP showed some } \\
\text { attention to the allocation of } \\
\text { agricultural land. }\end{array}$ & $\begin{array}{l}\text { No specific policy, although } \\
\text { diversified diets and some } \\
\text { cultural challenges were } \\
\text { identified in various policies } \\
\text { and the ZHSR. }\end{array}$ \\
\hline PFJ & $\begin{array}{l}\text { Increasing access to } \\
\text { agricultural inputs. } \\
\text { Affordability of food limitedly } \\
\text { considered. Main idea is to } \\
\text { influence the price level } \\
\text { through increasing supply, and } \\
\text { to some extent fluctuation, by } \\
\text { increasing stocks. }\end{array}$ & $\begin{array}{l}\text { Much focus on self-sufficiency } \\
\text { of food in Ghana to reduce } \\
\text { import bills. } \\
\text { Regional specialisation } \\
\text { programmes, specialisation on } \\
\text { the district level. } \\
\text { Making citizens also producers } \\
\text { of food means allocation by } \\
\text { bringing producers and } \\
\text { consumers together to some } \\
\text { extent. }\end{array}$ & $\begin{array}{l}\text { No attention given to } \\
\text { preference; priority crops are } \\
\text { selected based on economic } \\
\text { contributions (jobs, value } \\
\text { chain additions). }\end{array}$ \\
\hline NNP & $\begin{array}{l}\text { Mainly stimulating poor } \\
\text { citizens' potential to } \\
\text { substistence production, } \\
\text { although some attention for } \\
\text { extending social security nets. }\end{array}$ & $\begin{array}{l}\text { Targeting specific } \\
\text { demographic groups such as } \\
\text { women and schoolchildren. } \\
\text { Attention for locally grown } \\
\text { foods. }\end{array}$ & $\begin{array}{l}\text { Attention given to indigenous } \\
\text { foods. }\end{array}$ \\
\hline GNCCP & $\begin{array}{l}\text { Improving marketing and } \\
\text { establishing cooperatives to } \\
\text { reduce price fluctuations. Also } \\
\text { social support systems to } \\
\text { support capacity-building and } \\
\text { skills development for the } \\
\text { poorest and most vulnerable } \\
\text { communities. }\end{array}$ & No specific attention. & No specific attention. \\
\hline
\end{tabular}




\subsubsection{Agricultural policy}

Although FASDEP and METASIP were mainly focused on the food availability aspect of food security, there are elements related to access to food such as in the METASIP II programmes area Food and Nutrition Security and Emergency Preparedness (Programme 2), Increased Growth in Incomes (Programme 3), and Marketing of Agricultural Products (Programme 4).

In Food and Nutrition Security and Emergency Preparedness (Programme 2) improved productivity is advocated, which will have an influence on access to food as well. For instance, when the subsistent smallholders increased output due to increased availability of inputs, improved storage capacities and irrigation, access to food for these farmers increased as well (Ministry of Food and Agriculture 2007). In addition, FASDEP acknowledged that urban farming can indeed be an important livelihood strategy. In general, METASIP does not directly address access to food for urban citizens. The same holds for Increased Growth in Incomes (programme 3), when subsistent farmers can switch to cash crops and improve income. As for Marketing of Agricultural Products (programme 4), which is not directly concerned with the affordability of food, improvements in post-production management such as handling and storage of food would reduce seasonal variations in supply, and thereby reduce price fluctuations.

For allocation, the relevant subprogrammes tried to stimulate the use of an e-agriculture platform (similar to the PFJ, see Section 2.3.3) with standard enforcement, promoting awareness of and enforcing compliance with rules aimed at ensuring quality and safety of agricultural produce as well as in markets by sensitising phytosanitary inspectors for instance (Ministry of Food and Agriculture 2015, 45). Market information dissemmination also played a role (Ministry of Food and Agriculture 2015, 49). So, these subprogrammes all managed information streams which determine what kind of food is available and at what prices. This was further influenced by the subprogrammes that deal with the physical variant of infrastructure in the form of rural roads (Ministry of Food and Agriculture 2015, 45) and supply chain management in general, as well as packaging of locally produced products and their storage and marketing (Ministry of Food and Agriculture 2015, 47). General market development, access to markets and conditions at those markets all influenced the allocation of food while the operationalisation of the Ghana Commodities Exchange did the same thing in a more specific setting (Ministry of Food and Agriculture 2015, 48).

With respect to preference, the METASIP document did not outline specific policy measures. The same held for urban policy in general; METASIP's programmes often did not distinguish between urban and rural areas, and when they did, they usually did so in favour of rural ones such as when it comes to road building (Ministry of Food and Agriculture 2015, 19). Cities and markets found in cities were mainly considered as places that rural areas should be linked to, to get agricultural produce there quickly. In this sense, METASIP was concerned with UFS, but it considered the issue of allocation from the perspective of rural areas and their 'poor infrastructure'.

\section{PFJ}

As the prominence of marketing (one of the five pillars of the policy) already suggests, the goal of the PFJ is to stimulate overall production and promote the commercialisation of agricultural production by marketing this produce rather than stimulate subsistence farming. The PFJ aimed at linking access and availability to food through their respective elements of affordability and the production-distribution linkage. In particular, PFJ promoted the linkages between producers and consumers of food through involving everyone in this production and the marketing of home-grown food crops, An example of this was the distribution of seeds. With this distribution of production inputs, the government hoped to increase food availability and to lower the base price of the selected food crops by increasing supply (Ministry of Food and Agriculture 2017b, 29).

As an implementation of the PFJ programme, with respect to allocation specifically, the government focused on a regional specialisation programme (the so-called one sector, one factory). This programme was already in its implementation phase, with the first factory already built for a fruit and juice company (Republic of Ghana 2018b). Other measures within this programme included spending on feeder roads and building new warehouses to increase storage capacity outlined in the one district, 
one warehouse programme (Donkor 2018). Together with the factory element it formed the Infrastructure for Poverty Eradication Programme. While it is emphasised that all districts should be included, it was not entirely clear whether these programmes were aimed at improving allocation towards urban areas. Based on a statement from the President of Ghana, it seemed that the beneficiaries would be mainly located in rural areas: 'We must banish the spectre of young and ablebodied men and women who leave our rural areas for urban areas in search of non-existent jobs. Every district in our country abounds in raw materials, and it is the vision of government to create economic growth poles out of them.' (Republic of Ghana 2018b).

More specifically with respect to affordability and allocation, the PFJ dedicated a section to the marketing of produce, where issues such as warehouses for storage and price volatility are considered. The Ministry of Food and Agriculture assumed that the base prices for the selected crops will change due to increased output, and price volatility will remain as existing market forces remain dominant. The Ministry did not plan to interfere in the market under normal circumstances, but it did identfy the role for the National Food Buffer Stock Companies (NFBSC) to stabilise supply by building up strategic reserves.

The government expected the numbers of jobs to increase and the linkages to other sectors through benefits from agricultural growth to be the main mechanism that will increase urban food affordabillity. This convinction is based on the fact that such linkages were also beneficial during the Green Revolution in Africa (Ministry of Food and Agriculture 2017b, 6). So, the main way the government considered issues related to access to food for citizens, either from urban or rural areas, was through limited availability of inputs to smallholders and associated production restrictions (either for subsistence consumption or marketing of the produce). No specific attention was devoted to the element of preference or even to different kinds of consumers (urban, rural, demographic groups) in general.

\subsubsection{Nutrition policy}

The NNP (Ministry of Health 2013b) considered the nutritional value of food and its importance in ensuring optimal health in an integrated manner. In terms of access to food and allocation, attention was paid to education (which can influence people's wishes and help them obtain affordable and healthy food), social protection and safety nets, water and sanitation services under the heading of ensuring high coverage of food-sensitive policy interventions. As part of nutrition-specific policies, emphasis was placed on children and breastfeeding mothers at critical moments: below 6 months and an hour after birth (Republic of Ghana 2016). More generally speaking, the NNP mentioned the importance of enabling a working, social and family environment that was conducive to caregivers' optimal feeding practices.

The NNP tried to promote the facilitation of food access. One way it advocated for such increased access was by arguing for the need to extend social protection measures, including conditional cash transfers to vulnerable groups. Extending social protection benefits could directly impact food affordability by increasing poor people's income (see Section 3 of NNP (Ministry of Health 2013b)).

With respect to allocation, increasing nutrition service availability at all health centres could increase access when looking at it from the perspective of the food consumer. Such increased access through the promotion of food preservation, processing and storage was also considered in the policy.

The NNP considered preference by focusing on the importance of acceptability of malnutrition interventions and the importance of stakeholder participation in general, in such interventions. In particular, the involvement of those targeted by the interventions could also be seen in the emphasis on locally grown and indigenous food. This could mean that the programme tried to stimulate urban agriculture as well in the case of large urban areas, even though such urban agriculture was not explicitly considered in the policy. 


\subsubsection{Spatial development policy}

The GNSDF did not include any programme initiative directly targeting inhabitants of large metropolitan areas for improved access to food. The proposed urban food sheds, however, showed an option to indirectly contribute to UFS by decreasing the transport costs of supplying food to the cities, and thus improving food affordability for urban populations. By creating distribution networks aiming at sustaining the flow of fresh food to cities, this initiative can contribute to the direct allocation of food to the cities. However, it did not specifically address issues related to the heterogeneous allocation of food across different types of households in large metropolitan areas, in particular to the most vulnerable low-income communities.

\subsubsection{Climate change policy}

The programme initiatives of NCCAS related to food security were mostly focused on addressing production issues due to climate change impacts in agricultural systems and food availability. Therefore, NCCAS did not include initiatives directly aiming at improving access to food.

Climate change is expected to have an impact on food affordability due to food price fluctuations resulting from increased variability in the availability of food. Therefore, the NCCAS programme is aimed at improving the marketing strategies of farmers in order to improve the handling of perishable crops and avoid large fluctuations of prices between periods of harvest and periods of limited availability (Ministry of Environment, Science, Technology and Innovation 2015, 11). In particular, it included specific actions on developing and implementing pricing mechanisms and facilitating the development of marketing cooperatives in order to reduce seasonal price fluctuations. While this initiative did not specifically address access to food in urban areas, it might contribute to food affordability in the cities by addressing food price volatility in general.

In addition, GNCCP's social support systems included an action to create and support livelihood empowerment programmes in rural and urban areas to improve the productivity and income of vulnerable communities (Ministry of Environment, Science, Technology and Innovation 2015, 75). In particular, it envisaged supporting capacity-building and skills development interventions to equip the marginalised urban poor to become more productive and more resilient to climate change disasters (Ministry of Environment, Science, Technology and Innovation 2015,91). This initiative could indirectly contribute to increased food affordability of low-income communities in large metropolitan areas. Likewise, the Policy Focus Area on climate change and migration included 'alternative livelihoods' (Ministry of Environment, Science, Technology and Innovation 2015, 235) that aimed at facilitating the adoption of alternative sources and diversification of livelihoods of vulnerable migrants, particularly those moving from rural areas affected by climatic changes, to cities.

\subsection{Synthesis}

Key issues:

- Strong emphasis on boosting affordability through promoting citizens as producers of food, particularly in the PFJ programme

- Focus on increasing productivity at the national level, in order to maintain the sector's contribution to jobs and contribute to structural economic transformation

- Access constrained by wishes to limit imports and boost exports, moving up the value chain

- Urban policy mainly restricted to issues of planning, but some attention for service areas

- Urbanisation seen as an opportunity when it comes to food servicing, but solutions not used

- Conflicts between PFJ and urban food access

- Conflicts between spatial development and food access

Access to food was very much dependent on the distribution of food, or the flows and stocks of food in the food system but then perceived from the perspective of the consumer. Two levels of governance were relevant here: the international level related to import and export of food, and the national level 
of trade across districts and migration of people. So far, the focus has been on national policies in this chapter has focused on national policies as summarised in Table 8.

Table 8 Consideration of food access in the policies reviewed

\begin{tabular}{|c|c|c|c|}
\hline Policy & \multicolumn{3}{|c|}{ Element of Access } \\
\hline \multicolumn{4}{|l|}{ Agricultural policy } \\
\hline PFJ & $*$ & $\#$ & $\#$ \\
\hline \multicolumn{4}{|l|}{ Health/Nutrition } \\
\hline Spatial Development & * & $*$ & \\
\hline
\end{tabular}

Green $=$ the policy extensively considers the element, using the specific term and directly describing it. Orange $=$ the element is mentioned but not taken into account, or the policy considers the element without explicitly using the term. Grey = the element is not taken into account and not mentioned either. '\#' denotes possible adverse impacts of the policy on food security. '*' indicates that the policy is especially relevant for urban areas.

With respect to access to food, the elements of affordability and allocation were the two most emphasised elements on the national level, with policies being targeted to citizens as producers. There was no specific attention to food security of urban citizens. Note however that urban citizens were also not ruled out in the policies considered as in the case of PFJ for instance. The concern with affordability and allocation was driven by general economic concerns: the aim was to provide jobs in agriculture and to realise structural changes of the economy through linkages within the agricultural value chains for the selected products. International issues were influencing the allocation of food: from the second SDG goal to its implementation, to the wish to increase food independence. The reduction of the import bill was emphasised and the wish to increase both the volumes and values of exports. In particular, food export concerns had higher priority than food preferences of the population.

Accessibility was thus considered as a supply-side issue as it was largely influenced by the distribution element of the food availability pillar of food security. Within the access to food pillar, affordability dominated over distribution and preferences. There was hardly any attention for preference.

Indeed, the ZHSR seemed to confirm these findings. It mentioned the very specific Ghana School Feeding Programme (GSFP) which provided meals free of charge to schoolchildren. It also mentioned cultural norms and social attitudes: some foods, like fruits, that could alleviate micronutrient shortages were seen as 'food for the sick' (World Food Programme and John Kufuor Foundation 2018). Based on the GSFP, more attention on healthy diets was considered in policies. The inclusion of food preferences (healthy diets) has serious implications for policies according to scientific research. For instance, given diverse food preferences, the creation of linkages with selected value chains (such as in PFJ), in order to create a Green Revolution using Asia as a template, may not be realistic. A greater diversity of value chains would be needed to satisfy domestic demand and maintain dietary diversity as long as no active policy regarding food preferences exists (Mellor 2014).

\section{Urbanisation}

Moreover, while the increasing pressure from urbanisation was acknowledged, little attention was paid to it in the agricultural policy documents that were analysed. Also, in urbanisation policy, little attention was paid to food security or agriculture. Indeed, urbanisation was stimulated, following the principles of hierarchical polycentric urban centres, where cities were categorised according to their service area, which was determined by the maximum distance citizens would be prepared to travel to utilise the services of that urban centre. While the policy tried to reduce overlap between the service areas of the different cores in this hierarchy to maximise efficiency, it did so (among other ways such as enhancing linkages between urban areas and their hinterlands or creating so-called urban food sheds) by stimulating the growth of existing urban centres, integration of smaller centres into larger ones and discouraging the migration towards these smaller centres. In the agglomerated urban 
centres, implementation of the policy means there would be some limited attention for open areas, green belts and other spaces that could counter urban sprawl (Republic of Ghana 2012) - places that could, in theory, be used for urban agriculture as well (Mackay 2018) and would fit well with the government's wish to better link urban areas and the regions that produce their food, to reduce inequality (poverty and malnutrition are, as noted, generally higher in rural areas) and to create increased growth (Republic of Ghana 2015).

The use of such areas for urban agriculture, however, is questionable. The first reason is that the potential for urban agriculture was hardly used and there was little official policy to guide it (Cofie et al. 2005; Nchanji 2017). Moreover, there was opposition towards the urban agriculture practices in Africa in general (De Zeeuw et al. 2011). In Ghana, there was a perception that urban agriculture could have negative health consequences (Amoah et al. 2007) such as pesticide build-up in the direct urban environment and increases in mosquitoes (Obosu-Mensah 2002).

In this sense, Ghana's urbanisation and agricultural policy seemed to be further driven by a certain element of incoherence. Moreover, while the aim of increasing productivity and closing the yield gaps was clearly quantified and supported by both research and international organisations such as the World Bank (World Bank 2017), programmes and the second SDG that focused on smallholders or tried to encourage the general population to participate in agriculture, were less substantiated. The main justification for such a focus seemed to be that almost half the population of Ghana depends on employment in the (subsistence) agricultural sector. Moreover, the agricltural sector has generated a significant share of GDP of Ghana. From spatial development and the disproportional growth of urban population there is a need or wish to increase population densitiy in (peri-)urban areas to establish clear core-periphery relations around cities and reduce fragmentation in the peri-urban areas. This is an example of the 'one district, one warehouse' element of the Infrastructure for Poverty Eradiction Programme, which contradicts the concerns of inhabitants in peri-urban areas involved in agriculture. Higher population densities in peri-urban areas (less land fragmentation) inevitably means that smallholders in the peri-urban areas have to leave to go to more rural areas. There is another contraction between elements of the food system in the policies considered. On the one hand, one of targets of PFJ advocated mass mobilisation of food production with the aim of establishing industrial agriculture in less fragmented rural areas and processing industries in the urban ones. It increases income from agriculture so it improves affordability. On the other hand, mass mobilisation of food production with the aim to export the agricultural output might leave consumers in Ghana will lower levels of food available because it is all exported.

Moreover, urban agriculture was already a livelihood strategy of the (urban) poor (Armar-Klemesu and Maxwell 2000; Knudsen and Fold 2011; Nchanji 2017). The livelihood strategies have the benefits of a space-based approach towards food security, economic development and poverty alleviation (OECD, FAO, and UNCDF 2016). Food security, economic development and poverty alleviation, so the OECD argues, are intertwined as the occurrence of urban agriculture as a livelihood strategy and the fact that the more rural areas are generally poorer, both indicate this. A space-based approach would go beyond linking markets through feeder-road construction, and would instead also focus on building the right institutions and addressing related challenges such as the currently lacking clear land ownership rights and the associated clientelism (Knudsen and Fold 2011; OECD et al. 2016; Nchanji 2017). It would, in other words, build the institutions that the rural and urban areas need, encouraging their specific development without necessarily equating rural development with, in this case, smallholder agriculture, but instead ensuring that opportunities outside that specific sector can be taken. While the government did try to incorporate these different elements, its overal strategy was mainly tailored towards increases in production, and less to issues of land access, regulation of alternative livelihood strategies such as urban agriculture - or even promoting alternative livelihoods that were not dependent on agriculture at all.

\section{Food accessibility in its international context}

Combined with the goal of reducing the import bill and the promotion of export under the NES and NEDP, the allocation of domestically consumed food will face challenges; for instance, Ghana would have to more than double or even triple its domestic production of rice (Oxford Business Group 2013). This implies i) an increase in rice productivity, ii) the need to cultivate more land for rice production, 
or iii) both. For crops such as rice, productivity could be increased. However, as the yield gaps (share of gap between actual and potential production over potential production) were less than $50 \%$, cultivation of more land would most likely be required for agricultural production, along with new allocation issues.

A final element of the food system that is largely absent from the policies considered with respect to (physical) allocation, is policy dealing with retail outlets. Up until 2016, the number of supermarkets in Ghana was limited, but in cities where they did exist, they were important outlets for access to processed and imported foods (Andam et al. 2017). Of course, the absence of policy on the retail sector might reflect the idea that it should be left to the market, as Ghanaian trade policy stated in multiple sections (Ministry of Trade and Industry n.d.). 


\section{$5 \quad$ Utilisation}

\subsection{Link to the food system}

Within the concept of food security, the utilisation pillar includes the elements of nutritional value, social value and food safety (Ingram 2011). So this pillar mainly addresses food security issues from the perspective of the consumer and society at large, as well as actors such as the government or dedicated organisations that regulate what can and cannot reach the consumer (see Figure 8).

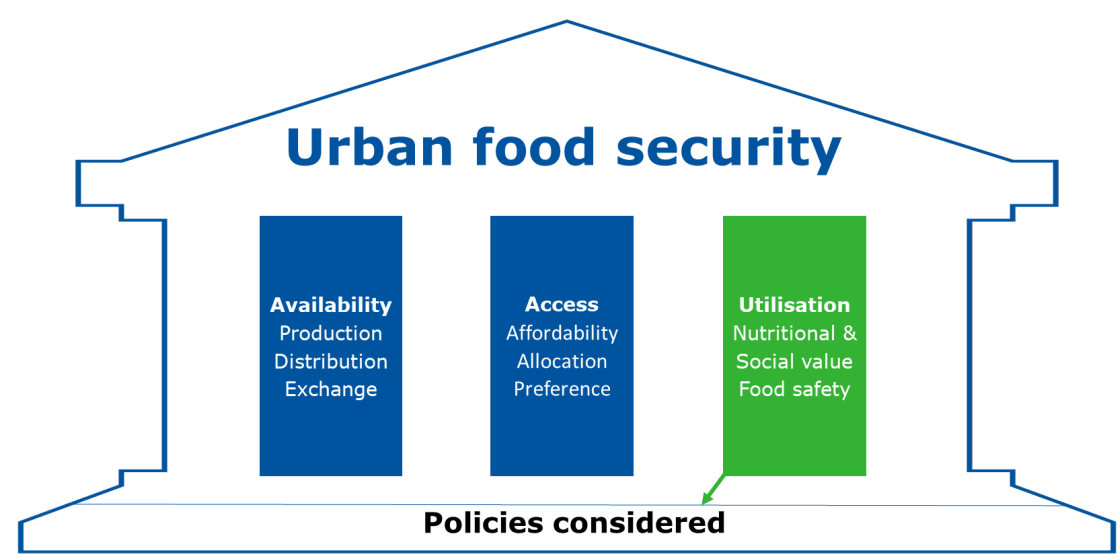

Figure 8 Food system elements of food utilisation

Concerns on food utilisation and food quality in terms of food safety and nutritional value were already considered and integrated in the main policy of the Ministry of Health. The existence of the NNP showed that food security and nutritional value have priority for the government of the Republic of Ghana. Despite this, the Zero Hunger Strategic Review noted that limited attention has been paid to the needs of different demographic groups that were more likely to be vulnerable to food insecurity, such as women, the elderly and youth. For instance, ZHSR mentioned the need to take into account the nutritional needs of pregnant women; it framed its solutions in more production-related terms from a food system perspective, namely improving the underappreciated role of women as farmers and the unattractiveness of agriculture to youth. With these solutions, ZHSR pointed on the one hand to the utilisation aspect of food security for the vulnerable groups and on the other hand at production-related solutions such as the promotion of production by these vulnerable groups, which was part of the availability aspect. So, the link between urgency (nutritional value) and solution (improving productivity) was rather indirect and effectiveness might be uncertain.

A similar aspect can be observed from the Zero Hunger SDG goal (SDG-2). Out of the five objectives of SDG-2, the first target stated access to food, but mainly stimulated it through production-improving solutions, such as the promotion of agricultural production by women and indigenous people, the doubling of the production of smallholders, the improvement of the sustainability and resilience of production systems, and the promotion of the urgency of maintaining seed varieties (Battersby 2017). There was only one target of SDG-2 that explicitly mentioned the ending of malnutrition. So, even for the SDG-2 as well as the ZHSR for Ghana, we observed a strong emphasis on the availability aspect of food security rather than the utilisation of food security including nutrition security.

The ZHSR balanced agricultural production and nutritional concerns though, and so has Ghanaian policy to some extent. Besides the triple burden of malnutrition (caloric shortage, micronutrient shortage and obesity), the ZHSR emphasised the importance of having wholesome foods, i.e. foods without non-nutritious additives such as added sugar or salt. Since 1992, it had been mandatory for 
Ghanaian food producers and importers to fortify wheat flour and vegetable oils with nutrients such as iodised salt. Further, adding sweeteners to food and beverages intended for consumption by children is prohibited. At the same time, consumption of unhealthy foods such as fast food is on the rise in Ghana (Omari and Frempong 2016; Searcey and Richtel 2017). Indeed, research on the food preferences and habits of the Ghanaian population showed an increase in consumption of fats, sugar and salts and limited consumption of fresh fruit. This development contributed to serious health issues, which indicates the need to change these habits (Ogum Alangea et al. 2018).

Other policies and reviews did mention the potential benefits of food fortification (Republic of Ghana 2016) in the case of specific nutrients, such as adding vitamin A or iron to combat anaemia (Republic of Ghana 2019) or providing products such as super cereal to people living with HIV (World Food Programme 2018). Also, Ghana has had restrictive import policies for fatty meats for almost 20 years (Annan et al. 2018). In April 2015, the food safety regime was amended with the Food Safety Policy (World Health Organization Africa 2018). Its principles ranged from raising public awareness and education, to food-borne disease surveillance and consumer protection. It also urged new laws (Ministry of Health 2013a). However, such laws however were not yet implemented at the end of 2018.

This chapter has the same structure as Chapter 3 on food availability and Chapter 4 on access to food; first, agricultural policy is discussed, through the lens of the governance of food utilisation. Then, nutrition policies are discussed, including the FSP. After that, spatial development policy is discussed and finally, climate change policy is discussed, followed by the synthesis section.

\subsection{Review of the policies}

This section discusses policies linked to the food security pillar of utilisation, analysing mostly the same documents and policies plus the dedicated Food Safety Policy. First, FASDEP, METASIP and the PFJ were analysed with respect to utilisation of food. Then, the NNP including the FSP, GNSDF, NCCAS and GNCCP were reviewed. For the national level, the main policies and some key elements with respect to the elements of utilisation can be found in the table below. 


\begin{tabular}{|c|c|c|c|}
\hline & \multicolumn{3}{|l|}{ Element of food utilisation } \\
\hline & Nutritional value & Social value & Food safety \\
\hline FASDEP \& METASIP & $\begin{array}{l}\text { Very limited attention in } \\
\text { FASDEP, importance of dietary } \\
\text { diversity acknowledged. } \\
\text { Some attention for 'nutrition- } \\
\text { sensitive agriculture' in } \\
\text { METASIP. } \\
\text { Calls for research on bio- } \\
\text { fortified, high nutrition foods } \\
\text { and general promotion of } \\
\text { micronutrient-rich foods. }\end{array}$ & $\begin{array}{l}\text { Not taken into account. } \\
\text { But there is some mention of } \\
\text { good agricultural practices. }\end{array}$ & $\begin{array}{l}\text { Surveillance and control of } \\
\text { diseases. Improving market } \\
\text { sanitary conditions. Creating } \\
\text { awareness of safety } \\
\text { regulations. }\end{array}$ \\
\hline NNP & $\begin{array}{l}\text { Much attention given: emphasis } \\
\text { placed on importance of } \\
\text { nutrient-rich foods, diversity } \\
\text { and adequacy. }\end{array}$ & $\begin{array}{l}\text { Policy calls for creating } \\
\text { awareness through education. } \\
\text { Also attention given to } \\
\text { indigenous foods. }\end{array}$ & $\begin{array}{l}\text { Dedicated food safety policy, } \\
\text { which calls for cooperation } \\
\text { across sectors and value } \\
\text { chains to increase food safety, } \\
\text { from farm to fork. }\end{array}$ \\
\hline GNSDF & $\begin{array}{l}\text { Urban food sheds: Reducing } \\
\text { potential losses in their } \\
\text { nutritional value by decreasing } \\
\text { the time of distribution } \\
\text { between harvest and supply to } \\
\text { consumers. }\end{array}$ & Not mentioned. & Not mentioned. \\
\hline GNCCP & $\begin{array}{l}\text { Strengthening platforms for } \\
\text { intersectoral collaboration and } \\
\text { policy. Dialogue with relevant } \\
\text { ministries and institutions } \\
\text { working on the availability of } \\
\text { food and the management of } \\
\text { water and sanitation to address } \\
\text { malnutrition. }\end{array}$ & No specific attention. & $\begin{array}{l}\text { Public health measures aimed } \\
\text { at improving sanitation and } \\
\text { hygiene services in vulnerable } \\
\text { communities. Developing and } \\
\text { strengthening platforms for } \\
\text { intersectoral collaboration and } \\
\text { policy dialogue with relevant } \\
\text { ministries and institutions to } \\
\text { increase food safety: } \\
\text { specifically the availability of } \\
\text { food and the management of } \\
\text { water and sanitation. }\end{array}$ \\
\hline
\end{tabular}

\subsubsection{Agricultural policy}

Utilisation as a pillar of food security was discussed although in a limited way, in the two main documents originating from within the Ministry of Food and Agriculture.

In FASDEP II, policy measures promoting improved nutrition were only vaguely mentioned. Some attention was paid to the importance of dietary diversity and the potential for this (given Ghana's different agro-ecological zones) was appreciated. It was, however, not the main concern of agricultural policy. 
In METASIP, there is a section on 'nutrition-sensitive agriculture' (subsection of Subprogramme 2.6). METASIP emphasised the importance of nutrition education and various measures (Ministry of Food and Agriculture 2015,56). Most of these elements were production related (and part of the availability aspect) such as the provision of research into seed development of high-nutrient crops. So, the Ministry of Food and Agriculture hardly took food utilisation into account except for some market and producer-specific measures. For example: producers could be awarded the Green Label allowing for a premium price in the sale of products when good agricultural practices are followed (Ministry of Food and Agriculture 2016a). Other labels such as UTZ certification existed already for the cocoa industry (Waarts et al. 2015). However, actual policy on this seemed limited, as although its importance was mentioned in FASDEP, in the later METASIP and PFJ documents little attention was paid to it.

Still, METASIP did mention the different elements of utilisation in the subprogrammes that we analysed. With respect to nutritional value (subprogramme 2.6) it heavily emphasised nutritional issues and measures that should be taken. The measures ranged from promoting research on 'biofortified high-nutrient crops' to promotion of micronutrient-rich foods especially by rural women and children, to education campaigns on nutrition and stimulating school and kitchen gardens. Linking METASIP to the NNP, it argued for the positioning of nutrition as a cross-cutting issue that should be integrated in all national policy frameworks (see subprogramme 2.6.4 of METASIP II).

Social value and cultural or religious functions of food were not taken into account in METASIP.

Food safety was considered from different angles in METASIP. First, it called for the promotion of disease- and pest-resistant varieties for production (Ministry of Food and Agriculture 2015, 40), public awareness of food safety issues and for increased control and surveillance of food-related diseases (Ministry of Food and Agriculture 2015,43) in general and in relation to cash crops specifically (p. 46). Further concerns for food safety related to promotion of awareness of related rules and regulations (Ministry of Food and Agriculture 2015, 45). Finally, market sanitary practices were promoted for markets in general and for international trade, specifically meeting import requirements of other countries (Ministry of Food and Agriculture 2015, 48-49).

\section{PFJ}

Similarly to FASDEP and METASIP, PFJ did not directly address food utilisation or nutritional value. Indeed, as dietary diversity was an important indicator reflecting nutritional value and food security, PFJ focused on promoting only a few specific crops (Nykänen et al. 2018; Masters et al. 2018).

Moreover, PFJ did not consider the social value of food in its selection of crops related to its value chains. While it did mention that food security was considered, there were no indications in the PFJ document showing that social value was taken into account.

We could argue that economic value is related to social value as food crops would most likely not have any economic value if there was no demand for them. Nevertheless, the element of social value, as formulated in Ingram (2011), was never explicitly mentioned or considered in PFJ.

Food safety was considered in PFJ, but only indirectly. The programme was mainly concerned with input facilitation: safety of seeds as an input was considered in terms of their ability to withstand biotic and abiotic stresses. The PFJ further incorporated early warning systems and dissemination of good agricultural practices within its 'e-agriculture' pillar. Such early warning systems were related to pest and disease control, while 'good agricultural practices' had been mentioned in the agricultural sector progress report of MoFA (Ministry of Food and Agriculture 2016a) in relation to the Ghana Green Label. The Green Label defined good agricultural practices as practices that especially took food safety into account, including the limitation of 'chemical plant protection products' (Ghanagreenlabel.org 2018). 


\subsubsection{Nutrition policy}

\section{NNP}

Some policies and policy reviews (World Food Programme and John Kufuor Foundation 2018) and also research (Battersby 2017) mentioned the importance of challenging the triple burden and that simply increasing food production (availability) and food access was not sufficient. Utilisation of food was covered in the nutrition and health policy only. As shown before, the policies of the Ministry of Health distinguished between nutrition-sensitive and nutrition-specific policies. Nutrition-sensitive policies dealt with a wide variety of specific groups and their nutritional needs. Since health was basically the nutrition-sensitive domain of policy, the fact that nutrition-specific policies were also included led us to conclude that the Ministry of Health and associated agencies and policies were most important actor for the food utilisation part of food security. The nutrition-specific policies dealt with obesity and chronic illness prevention.

With regard to nutritional value, most of NNP's subprogrammes were relevant in that they addressed this element of food utilisation. This started with the general notion that acute malnutrition should be prevented and managed. The integration of nutrition and management of infectious diseases was also mentioned. Further, NNP argued in favour of the need to have what ZHSR called 'wholesome foods': nutrient-rich foods that were also diverse and which form adequate diets and nutrition enhancement along the value chain. Moreover, nutrition was established as a priority for policy in terms of political leadership, policy plans at different levels within the health service and ensuring that all MDAs had budgets for nutrition.

Social value was addressed through some education- and awareness-focused subprogrammes, for example by including educational activities in social protection interventions to increase household awareness of health and nutrition in care giving and health-seeking behaviours.

As indicated above, food safety in the NNP was linked to nutrition in terms of preventing infectious diseases. Likewise, safe food was placed next to diversity and adequacy, while the importance of food safety along the value chain was also explicitly emphasised. In addition to the NNP, there was also the national Food Safety Policy (FSP), which was part of the framework of the National Health Policy (Ministry of Health 2013a).

\section{Food Safety Policy (FSP)}

The FSP was implemented in 2013, because significant gaps in food safety were identified. At the same time, the Ministry of Health recognised that there was an overlapping of responsibilities across agencies in executing certain laws of food safety. For example, in the case of the Plants and Fertilizer Act an agency from the Ministry of Food and Agriculture and the EPA of the Ministry of Science, Technology and Innovation shared responsibilities with respect to regulation of pesticides.

The FSP stated that other policies such as FASDEP complemented the FSP. Indeed, FSP heavily emphasised the integration of policies. Its first guiding principle aimed for intersectoral coordination and collaboration, while the second guiding principle called for stakeholder participation - from all parts of the value chain - in ensuring food safety. Moreover, FSP was placed in the food production context, i.e. 'from fork to farm', import and export, management, public education on food safety, laboratories and surveillance, and biosafety issues.

The policy measures described in the FSP ranged from conducting research on food safety, to surveillance and inspection. Besides these measures related to the provision of knowledge, it further prescribed food safety training and education as measures that should be taken.

\subsubsection{Spatial development policy}

The GNSDF did not have any initiative particularly aimed at contributing to the utilisation pillar of UFS. However, the initiative 'Proposed urban food sheds' mentioned in its formulation that it was expected to (indirectly) contribute to the nutritional value of food available in the cities by providing greater 
access to fresh fruit, as well as reducing potential losses in their nutritional value by decreasing the time of distribution between harvest and supply to consumers.

\subsubsection{Climate change policy}

As previously mentioned, NCCAS dealt broadly with issues related to climate change adaptation in agricultural production issues, but not with other components of the food system. Therefore, it did not include any initiative dealing with food utilisation.

GNCCP recognised the risk of climate change increasing the incidence of food-borne diseases such as diarrhoeal diseases and nutrition-related illnesses. The programmes in the GNCCP potentially contributed indirectly to food safety by implementing public health measures aiming at improving sanitation and hygiene services, especially in vulnerable communities (Ministry of Environment, Science, Technology and Innovation 2015, 146). Another indirect contribution came from addressing malnutrition and food safety by developing and strengthening platforms for intersectoral collaboration and policy dialogue with relevant ministries and institutions working on the availability of food, and the management of water and sanitation (Ministry of Environment, Science, Technology and Innovation 2015, 147-48). However, none of these programmes specifically targeted food utilisation in large metropolitan areas.

\subsection{Synthesis}

Key issues:

- Little attention is paid to utilisation, the only exception was the NNP;

- The implementation of nutrition-specific policies goes beyond agricultural concerns

- Focus is mostly on the double burden, but there is limited attention to the third element of obesity and other chronic illnesses;

- Our approach shows limited attention to overnutrition, but so do Ghanaian policy and international framings of food security;

- Food safety is incorporated into export targets.

Nutritional value has received considerably more attention mainly thanks to the Ministry of Health and its NNP, as well as some international organisations such as the World Food Programme and some of its specific measures like food fortification. Indeed, other policies ignored the nutritional value of food, or the potential impact on it such as in the case of PFJ and its narrow selection of crops (see Table 10). Moreover, while food safety was supposed to become an integral part of agricultural policy (see the METASIP document), little of this initial intent was preserved in the latest agricultural policies such as PFJ. Indeed, most attention for food safety came from other ministries such as the Ministry of Health in the case of the dedicated FSP, which calls for the issue to be of cross-sectoral concern, the Ministry of Environment, Science, Technology and Innovation with the climate change policy and the Ministry of Trade and Industry with the National Trade Policy.

Table 10 Consideration of food utilisation in the policies reviewed

\begin{tabular}{|c|c|c|c|}
\hline Policy & \multicolumn{3}{|c|}{ Element of Utilisation } \\
\hline \multicolumn{4}{|l|}{ Agricultural policy } \\
\hline PFJ & \# & \# & \\
\hline \multicolumn{4}{|l|}{ Health/Nutrition } \\
\hline Spatial Development & & & \\
\hline
\end{tabular}

Green $=$ the policy considers the element extensively, using the specific term and describing it directly. Orange = the element is mentioned but not taken into account, or the policy considers the element without explicitly using the term. Grey = the element is not taken into account and not mentioned either. '\#' denotes potential adverse impacts of the policy on food security. 
However, even the NNP was mainly concerned with two of three elements of malnutrition, namely lack of food and lack of specific nutrients, while there was increasing evidence of obesity as a third foodrelated health problem (Ofori-Aseno et al. 2016; Searcey and Richtel 2017; Battersby 2017). The lack of inclusion of obesity could be explained from the way food security has been framed by both international research (Ingram, 2011) and in international targets such as the Zero Hunger SDG.

As explained before in Chapter 4, spatial development policy in Ghana was mainly concerned with linking urban areas to their peripheral regions and with service areas. The lack of urban agricultural or food policy and the characterisation of the political arena as one of multilevel and pluriform governance (which can well be used as an euphemism for government absence) for instance, had adverse effects on food safety and health (with a cholera outbreak attributed to food being grown with untreated wastewater and the produce being eaten raw), as case studies in Tamale showed (Nchanji 2017).

\section{Food utilisation in its international context}

In summary, there seemed to be a lack of integration of nutrition policy as it is mainly considered at the Ministry of Health and its NNP, while other important aspects of food utilisation such as food safety, particularly in urban settings, were neglected in the other policies (Cofie et al. 2005). The NNP called for a cross-agency prioritisation, which has not been taken up.

The National Trade Policy (NTP) did concern itself with food safety in terms of consumer protection, as well as exports. This appeared to be a major concern, for example, in Ghana's AGOA strategy (USAID 2016). Another angle from which food safety was taken into account within trade policy was the pledge to limit the usage of non-tariff barriers; 'health' was considered as one of the legitimate criteria that the government wanted to use transparently in possible import limitations (Ministry of Trade and Industry 2005). Moreover, in the NTP, food safety was described in terms of its economic importance. This implied that there are some clear linkages between the NTP which considered food safety as a matter of economic importance (through aspects as diverse as health, consumer rights and export potential) and the FSP which considered food safety in general, placing heavy emphasis on production methods and inspection as well as on general information acquiring and consumer protection.

In general, utilisation was considered in a departmentally discrete manner; while the Ministry of Health called for food safety to be considered in each policy and each department, making it a crosscutting issue, other ministries such as that of Trade and Industry only considered the issue as a means to further goals such as exporting.

With respect to UFS specifically, if the spatial development policy of Ghana retained its focus on the non-competitiveness of service areas of urban cores and the NNP ensures that all facilities could provide nutrition interventions, then these two policies combined could have a positive impact on UFS - no explicit concern regarding urban food nutrition was expressed, however.

Given these results and those of the previous chapters, we now turn to the overall discussion of the results, looking at the overall situation of Ghanaian UFS policy while using the different elements and comparing the pillars. 


\section{Discussion}

In the previous chapters, we have extensively reviewed the national policy of Ghana with respect to UFS, using three food security pillars and their food system components as the framework. Although several issues were observed throughout the review, there are still some aspects which were not taken into account, such as the following.

- The stability aspect of food security, i.e. consistency of the food security over time: are the policies stable, did the policies draw attention to food security over time?

- Integration: 1) Internal - are there significant gaps, or is there overlap between policies?

2) External: is the policy complete, are all aspects of the food system covered?

- Consistency between policies: do policies have conflicting objectives?

- Theoretical foundation: how realistic are goals set by the government, based on the scientific literature?

Stability was not explicitly taken into account. Nevertheless, the policies reviewed did consider food security policies over time. For instance, Ghana's wish for self-sufficiency has long been a central theme. This self-sufficiency wish for food production dates back to the military regime and its promotion of community farms, which are nowadays partly revitalised as the nucleus farmeroutgrower model (World Bank 2017), and other measures such as provision of small inputs such as hoes and machetes and the National Redemption Council's policy called Operation Feed Yourself in the early 1970s. This shows that the 'bias' towards agriculture in Ghanaian policy is not new (Republic of Ghana 2018a).

Another main source of stability came from the government's focus on agriculture in general. Agricultural policies like the PFJ and METASIP heavily emphasised the fact that many people still rely on agricultural activities, despite the economic development in the last couple of decades. Therefore, the agriculture sector is still used as the basis for structural reform of the economy. The Zero Hunger Strategic Review for instance did not argue for a more food security persepective in policies in Ghana. The Strategic Review supported the perspective of the agricultural sector as they stated that the decline of the contribution of the agricultural sector to national GDP was 'worrying'. Moreover, it argued that Ghana did not have a well-developed industrial sector and the service sector was mainly helping foreign companies to market their products. At the same time however, policies like the PFJ that emphasise the importance of the agricultural sector, also devoted attention to market development and value chain development for job creation. So Ghana has remained focused on the agricultural sector as the leading sector for economic transformation.

In a recent study however, OECD, FAO and UNCDF argued that there are insufficient approaches towards solving food insecurity in low-income countries (OECD, FAO, and UNCDF 2016). One of the strategies identified by the OECD, FAO and UNCDF study was that there is more focus on urban areas with benefits for rural areas as well through spillover effects. To some extent Ghana followed this strategy, as it aimed for the creation of linkages between medium-sized urban cores and metropolitan areas and their hinterlands. In this sense, our results regarding the temporal stability of Ghanaian policy support the OECD's notion that such a focus on agriculture and smallholders is an established one, while the results from the OECD suggest that the Ghanaian case is not unique.

When FASDEP was published in 2007, there was some attention for urban agriculture for example. Eight years later in the METASIP implementation document, it was hardly mentioned. Other policies did mention that both rural and urban farmers were eligible for their benefits (PFJ), and that all facilities should have the ability to carry out nutrition interventions in the latter case (NNP) - but with no specific attention for urban areas, urban citizens or urban agriculture. This is partly due to the fact that it is the northern (less urbanised) part of Ghana that is lagging behind in terms of food security as well as poverty (World Food Programme and John Kufuor Foundation 2018) (see Table 11). 
Table 11 Comparing the pillars of food security

\begin{tabular}{|c|c|c|c|c|c|c|c|}
\hline \multirow{2}{*}{$\begin{array}{l}\text { Food security } \\
\text { pillar }\end{array}$} & \multirow{2}{*}{ Food system elements } & \multicolumn{6}{|c|}{ Policies } \\
\hline & & Overall & METASIP & PFJ & $\begin{array}{l}\text { Health/ } \\
\text { nutrition }\end{array}$ & $\begin{array}{l}\text { Climate } \\
\text { change }\end{array}$ & $\begin{array}{c}\text { Spatial } \\
\text { develop- } \\
\text { ment }\end{array}$ \\
\hline \multirow[t]{2}{*}{ Availability } & Production & & & $* A$ & & & \\
\hline & Distribution & & & & & & $*_{A} A$ \\
\hline \multirow[t]{3}{*}{ Access } & Affordability & & & $*$ & & & \\
\hline & Allocation & & & A & & & \\
\hline & Preference & & & A & & & \\
\hline Utilisation & Nutritional value & & & A & & & \\
\hline
\end{tabular}

Green $=$ the policy considers the element extensively, using the specific term and describing it directly. Orange = the element is mentioned but not taken into account, or the policy considers the element without explicitly using the term. Grey = the element is not taken into account and not mentioned either. ' $A$ ' denotes adverse impacts of the policy on food security. Asterisks indicate that the policy is especially relevant for urban areas.

\section{Integration}

The summary of all food security and food system elements showed that there was a clear separation in attention for the different pillars across policies (see Table 10 for an illustration).

As policies such as the PFJ and NNP were the responsibility of different ministries, there was a limited degree of internal integration at the level of the national government. Policies that are present and parts of the food system that are covered are clearly divided, meaning there was little overlap or a lack of clarity of responsibilities with respect to the different pillars of food security and the inputs and outcomes (Ingram 2011). For instance, productivity and input provision mainly fell under the responsibility of the MoFA and its programmes, while outcomes such as health and food safety were part of the MoH's tasks. For food safety policy, a dedicated policy was formulated to reduce the overlap that the $\mathrm{MoH}$ had observed prior to this policy's formulation.

In Ghana, food security was also linked to what Ingram has called environmental feedbacks. Ghana's climate change policy was linked to concerns and objectives similar to those outlined in METASIP regarding food security and emergency preparedness, for instance.

External integration or the scope of Ghanaian policy with respect to food security was limited however; although most elements such as production, distribution and food safety were (intensively) covered, there was very limited attention for the elements of exchange, preference and social value. In most policies such as the PFJ, these elements were completely absent or the policies went against such issues, but the ZHSR devoted some attention to social values. The consequences of neglecting such elements of the food system/food security framework vary, but some examples included the following.

- Health could be impacted adversely as Ghanaian citizens might be induced by the economic considerations of processing foods to consume more 'westernised' diets consisting of processed foods that contain more sugars and fats (Ogum Alangea et al. 2018). This was also likely as the Ghanaian diet was already energy dense rather than nutrient dense (Nykänen et al. 2018).

- Especially in Accra, such processed foods were more universal (Andam et al. 2017). The differing availability of such foods and food affordability could also lead to (internal) migration and urbanisation (Ackah and Medvedev 2012) - but such affordability of specific foods only became relevant when the food was actually demanded after basic needs were met. This was not the main restriction in the case of urban Ghana but it could be a reason to migrate away from rural areas (see Nykänen et al. (2018)).

- There are some obscure ideas about preferences - foods like poultry, cereals and grains were sometimes considered more 'prestigious', in that they were usually relatively expensive. Lower levels of their availability might be rationalised due to lower demand, although preferences for these food items did exist (Ogum Alangea et al. 2018). 
- The role of foods in diets could be neglected. Tomatoes (which are targeted under PFJ) for example were an important part of the Ghanaian diet - but as ingredients in dishes such as soup. The importance of soup itself also showed the importance of diversity of foods (FAO 2016; Ogum Alangea et al. 2018).

- Although cassava could be grown anywhere, because people want to consume it as fresh as possible, it is still not feasible to actually grow it at great distances from the urban centres (own communication, 29 November). Although policies such as METASIP acknowledge the need to improve storage facilities, it is unclear whether this is out of concern for such preferences.

- Maize was considered more important than rice for instance. PFJ focused on rice (besides maize) as one of the main staples and the government's focus on reducing the import bill especially with respect to this staple was therefore surprising.

From a level perspective, Ghanaian policy was well integrated as it is informed by many international agreements and conditioned by internationally set targets. In some cases, however, integration sometimes caused Ghanaian policy to establish its bias towards food production as a main solution to the food security problem. For example, the targets of the Maputo declaration, which called for more investments in agriculture, were very general and although they promoted investment, the agricultural growth component of the declaration combined with a seemingly arbitrary amount of investment meant that such targets do little beyond financing the sector. Another was the second SDG. Four of its five action points of SDG2 related to agricultural inputs, only one explicitly mentioned ending malnutrition.

Finally, Ghanaian policy showed little attention for the other elements of malnutrition, especially the increasingly important element of chronic diseases and obesity (Dake et al. 2016).

\section{Coherency}

We also evaluated the policies considered on how coherent they were when comparing them.

The overarching goals of the government were clear; to reach middle-income status, and to continue up the path towards high-income status, to end malnutrition, to increase productivity, and to become more self-reliant with respect to food supplies, and to increase exports. Such policies could in principle be well aligned. In practice, however, some policies showed contradictions. An important example was the limited calibration between the PFJ on the one hand, and Ghana's export policies and METASIP on the other. The PFJ's priority list consisted of major staples such as rice and maize, and products such as tomatoes. When the NES and NEDP were formulated, the government tried to promote the export of one or two crops per district; the list again included maize, rice, root crops such as sorghum, tomatoes and many other agricultural products. Moreover, METASIP, which originated from within the same ministry just two years before the release of PFJ's strategy, argued for the development of plantations of cotton and rubber for example.

In theory, promoting the production of certain crops for both export and domestic consumption was not considered to be problematic. In theory, both objectives were well aligned (Cudjoe et al. 2010). Given the high diversity of diets in Ghana and the regional specialisation of crop production, domestic supply and demand did not necessarily match. Moreover, there is little attention for food preferences or access to food in general. Total land use was likely to remain high either way, as a result of the combined effect of agricultural land being increasingly replaced by urban areas and more agricultural production being needed to supply expected increases in food consumption, both processes being essentially driven by population growth (Dijkshoorn-Dekker et al. 2019).

These food production and availability-related issues were also relevant when considering the access pillar. The access to crops not produced in the region will be limited due to high prices at local markets. Moreover, the promotion of export might lead to further concentration of trade in larger metropolitan areas. Those areas already had the ability to import foods, as in the cases of Kumasi and Tamale in comparison to Accra (Andam et al. 2017). As indicated in the first chapter, the consequences of such exposure to and participation in international markets varied with the perspective of producers and consumers. In the end, access to food also depended on whether the 
government plans to integrate all regions of the country including the remote regions in northern Ghana (Abdulai et al. 2018) and the ZHSR (World Food Programme 2018).

However, specialisation on the district level conflicted with Ghana's spatial policy. The main features of the government's spatial policy were a focus on polycentric urban cores and the service areas of distinctive cities and so-called urban food sheds. The policy aiming for district-level specialisation in one or two crops was likely to be difficult to align with the provision of dedicated urban food sheds if access to a large range of food had to be maintained and food security had to be increased. As also noted in Section 3.3, the northern part had been neglected for a long time. Investments in the area lagged behind those in industries in the southern part of Ghana. The renewed spatial specialisation might help the north achieve more food security by investing in production capacity; if establishing regional urban cores was the aim and further growth of Kumasi and Accra would not be stimulated, then such increased production would likely not only serve to supply the more urbanised southern part of the country. However, in reality that was not the case, since the GNSDF explicitly promoted the development and the provision of food in Accra Capital Region and Kumasi, and the further concentration of population in larger settlements as key strategies for spatial development. Hence, in practice, stopping urban sprawl and limited attention for urban agriculture combined with the focus on existing urban cores meant that such specialisation might prolong the position of the north as a remote region.

When further looking at the specialisation in specific crops at the district level while taking the urgencies described in Chapter 1 into account, climate change might make Ghana more vulnerable as elements such as stability, production or nutritional value might suffer from extreme weather events such as floods or droughts, or from increased temperature alone (Lobell, Schlenker, and CostaRoberts 2011; Zhao et al. 2017). While Ghanaian climate change policy was relatively well linked to agriculture through the Climate-Smart Agriculture Action Plan, the overall emphasis on agriculture rather than a full embracing of food security implied that the link was rather limited in practice, covering mainly climate change and agriculture and not (urban) food security as a whole. Of course, like in many countries, Ghanaian climate change policy was fairly recently formulated. The fact that the climate change policies existed and was already linked to agriculture proved the importance of the role of agriculture.

Overall, the consistency of policies was thus limited. Where policy goals were coherent (such as food security, resilience, increased growth or economic development), the policies often emphasised potentially conflicting elements such as regional specialisation, specialisation in crops and exporting. Furthermore, elements like preference, and clear separation between for example nutritional concerns and production were not mentioned in the policies despite calls from ministries for integrating elements like nutrition in all policies. 


\section{Conclusion}

Ghana's policy has for a large part been formed by a concern for improvement of agricultural production and setting productivity targets. Some of those concerns were influenced by international agreements such as the Maputo declaration of 2003 (NEPAD 2003) and the SDGs. The focus on the agricultural sector was part of a broad mix of international agreements and a national policy framework of structural economic transformation, including a broad array of topics ranging from a growing population and demographics, to poverty alleviation and job provision, to macroeconomic concerns like the balance of payments.

As a result, many of the policies reviewed dealt with food security or some components of it as identified by Ingram (2011). The agricultural policies were the responsibility of MoFA. Other policies were from the MoH (NNP), and the MESTI (spatial development and climate change policy). Such policies did not always directly consider food security however; indeed, the main reason why they were reviewed at all, was that the food security model took into account elements such as allocation, safety and distribution, and social pressures and feedbacks. By using the food system model, we could also systematically look at policies within the themes that also influence food security, such as trade, health, climate change and urbanisation.

The analysis of these policies revealed that those from the MoFA, which mainly focused on production, considered food security in a very narrow manner. Other policies such as the NNP and the FSP did consider other elements of food security (nutritional value and food safety, respectively). This means that almost all elements of food security are mentioned but the frequency and intensity differs across policies. However, the elements of preferences and social value were not taken into account in these policies. Moreover, as the different elements of food security (e.g. production, distribution, exchange, affordability, allocation, and food safety) were spread out over different ministries, there seemed to be limited interaction and collaboration to overcome the gaps related to the urgencies of urbanisation and climate change with UFS. Besides these gaps, malnutrition and specifically the elements of chronic diseases related to overconsumption of food were also not considered in the policies that were analysed.

In the cases where food security was explicitly considered, the focus on agriculture was part of rural and agricultural development, as well as through urban agriculture once in FASDEP. Urban areas were usually not excluded such as in the PFJ programme - but their food security issues did not receive attention in terms of elements such as allocation or distribution. In spatial policy, food security was addressed by initiatives promoting improved distribution networks and the deployment of urban food sheds so food was made available to cities from surrounding rural areas. However, no considerations were made at all regarding the allocation of food within the city across communities with different income levels.

Ghana's spatial policy was also exemplary in another issue we encountered, namely that urbanisation was considered more as an opportunity than a challenge. The focus on promoting existing urban centres and to form a hierarchy of polycentric cores was mentioned without considering the challenges this might pose to guaranteeing food supply in such urban cores. Similarly, the PFJ programme encouraged specialisation in specific crops, with the list including the same crops as those selected for district-level specialisation under the export policies. Such specialisation already put pressure on diet diversity. Although it would not necessarily reduce diet diversity and food security as different crops could be imported or production sufficiently increased, in practice the government also aimed for decreasing the food import bill. Yield gaps were sufficiently large so that production could be significantly increased, but for some food crops like rice the gaps were not sufficiently large and more land would have to be brought into cultivation. 
Through space and time, Ghana's food policy retained a relatively high degree of coherency. Its policies were well aligned with and informed by international targets, and organisations and platforms the country participates in. From the Maputo declaration to the SDG goals, Ghanaian food policy focused on increasing productivity historically, and by embedding its policies into a supranational context. Policies such as the Tree Crops Policy which recognised potential benefits of share cropping, as well as Climate-Smart Agriculture clearly showed that the government in Ghana did in some cases consider trade-offs between policies that tried to stimulate for instance the production of non-food crops intended for export such as cocoa. Intercropping, which was a solution to conflicts between for instance, export policies and domestic consumption, was not explicitly considered in the documents (PFJ, METASIP) that deal with increasing agricultural production.

Based on the indicators of integration and cross-policy consistency therefore and considering the gaps identified, we concluded that Ghanaian policy is only considering food security in a coherent, integrated and holistic manner in a limited way. The prospects for Ghanaian UFS are not necessarily very good, given that policy is addressing climate change but only partially incorporating the urgency of urbanisation. Moreover, food security was only addressed in a generic way; differences across regions were not addressed. 


\section{References and websites}

Abdulai, A.-G., J. Nyigmah Bawole, and E. Kojo Sakyi. 2018. 'Rethinking Persistent Poverty in Northern Ghana: The Primacy of Policy and Politics over Geography: RETHINKING PERSISTENT POVERTY'. Politics \& Policy 46 (2): 233-62. https://doi.org/10.1111/polp.12250.

Abubakari, M., P. Kitson Baffour Asamoah, and F. Okoh Agyemang. 2018. 'Ghana and Sustainable Development: The 40-Year National Development Plan in Retrospective'. Journal of Human Resource and Sustainability Studies 06 (01): 24-36. https://doi.org/10.4236/jhrss.2018.61024.

Ackah, C., and D. Medvedev. 2012. 'Internal Migration in Ghana: Determinants and Welfare Impacts'. International Journal of Social Economics 39 (10): 764-84.

https://doi.org/10.1108/03068291211253386.

Adom, P. 2014. 'Determinants of Food Availability and Access in Ghana: What Can We Learn beyond the Regression Results?' Studies in Agricultural Economics 116 (3): 153-64. https://doi.org/10.7896/j.1423.

African Center for Economic Transformation. 2015. 'Export Promotion in Ghana'. http://includeplatform. net/wp-content/uploads/2015/03/GTF-Export-Promotion-in-Ghana-SRformatted.compressed.pdf.

AGRA. 2017. 'AGRA Ghana Operational Plan'. https://agra.org/wp-content/uploads/2017/12/agraghana-final.pdf.

Akufo-Addo, N. 2018. Message on the State of the Nation Delivered by the President of the Republic. https://s3-us-west-2.amazonaws.com/new-ndpcstatic1/CACHES/PUBLICATIONS/2018/02/10/Speech+2018+State+of+the+Nation+Address.pdf.

Amoah, P., P. Drechsel, M. Henseler, and R. C. Abaidoo. 2007. 'Irrigated Urban Vegetable Production in Ghana: Microbiological Contamination in Farms and Markets and Associated Consumer Risk Groups'. Journal of Water and Health 5 (3): 455-66. https://doi.org/10.2166/wh.2007.041.

Andam, K.S., D. Tschirley, S.B. Asante, R. Al-Hassan, and X. Diao. 2017. 'Observing Ghana's Food System Transformation through an Assessment of Processed Food Retail in Four Major Cities', 20.

Annan, R.A., C. Apprey, N. Kwasi Oppong, V. Petty-Agamatey, L. Mensah, and A.M Thow. 2018. 'Public Awareness and Perception of Ghana's Restrictive Policy on Fatty Meat, as Well as Preference and Consumption of Meat Products among Ghanaian Adults Living in the Kumasi Metropolis'. BMC Nutrition 4 (1). https://doi.org/10.1186/s40795-018-0209-z.

Arene, C.J., and R.C. Anyaeji. 2010. 'Determinants of Food Security among Households in Nsukka Metropolis of Enugu State, Nigeria'. Pakistan Journal of Social Sciences 30 (1).

Armah, F.A., J.O. Odoi, G.T. Yengoh, S. Obiri, D.O. Yawson, and E.K.A. Afrifa. 2011. 'Food Security and Climate Change in Drought-Sensitive Savanna Zones of Ghana'. Mitigation and Adaptation Strategies for Global Change 16 (3): 291-306. https://doi.org/10.1007/s11027-010-9263-9.

Armar-Klemesu, M., M., and D. Maxwell. 2000. 'Accra: Urban Agriculture as an Asset Strategy, Supplementing Income and Diets'. In Growing Cities, Growing Food: Urban Agriculture on the Policy Agenda. A Reader on Urban Agriculture. Feldafing: Deutsche Stiftung fur Internationale Entwicklung (DSE), Zentralstelle fur Ernahrung und Landwirtschaft. https://www.cabdirect.org/cabdirect/abstract/20003032313.

Atkinson, S.J. 1995. 'Approaches and Actors in Urban Food Security in Developing Countries'. Habitat International 19 (2): 151-63. https://doi.org/10.1016/0197-3975(94)00063-8.

Baah, A. K. E. 2017. 'Subsistence Farmers' Perceptions of Pluralistic Agriculture Extension in Northern Ghana.'

https://scholarworks. waldenu.edu/cgi/viewcontent. cgi?article=4438\&context=dissertations.

Baba, I.Y., J. Yirzagla, and M. Mawunya. 2013. 'The Tomato Industry in Ghana - Fundamental Challenges, Surmounting Strategies and Perspectives. - a Review'. International Journal of Current Research. https://www.journalcra.com/article/tomato-industry-ghana-\%E2\%80\%93-fundamentalchallenges-surmounting-strategies-and-perspectives-revie.

Barthel, S., and C. Isendahl. 2013. 'Urban Gardens, Agriculture, and Water Management: Sources of Resilience for Long-Term Food Security in Cities'. Ecological Economics 86 (February): 224-34. https://doi.org/10.1016/j.ecolecon.2012.06.018. 
Battersby, J. 2011. 'Urban Food Insecurity in Cape Town, South Africa: An Alternative Approach to Food Access'. Development Southern Africa 28 (4): 545-61.

https://doi.org/10.1080/0376835X.2011.605572.

- - . 2017. 'MDGs to SDGs - New Goals, Same Gaps: The Continued Absence of Urban Food Security in the Post-2015 Global Development Agenda'. African Geographical Review 36 (1): 11529. https://doi.org/10.1080/19376812.2016.1208769.

Birhane, T., S. Shiferaw, S. Hagos, and K. Sarla Mohindra. 2014. 'Urban Food Insecurity in the Context of High Food Prices: A Community Based Cross Sectional Study in Addis Ababa, Ethiopia'. BMC Public Health 14 (1). https://doi.org/10.1186/1471-2458-14-680.

Bureau, Communications. 2018. 'Implement Policies To Make Ghana Self-Sufficient In Poultry - Dr Bawumia Charges Agric Ministry'. 2018. http://presidency.gov.gh/index.php/briefing-room/newsstyle-2/765-implement-policies-to-make-ghana-self-sufficient-in-poultry-dr-bawumia-chargesagric-ministry.

CGIAR. 2019. 'Climate Change Agriculture Food Security Policy Platform (CCAFS)'. Ghana. 2019. https://ccafs.cgiar.org/ghana-0.

Chen, J. 2007. 'Rapid Urbanization in China: A Real Challenge to Soil Protection and Food Security'. CATENA 69 (1): 1-15. https://doi.org/10.1016/j.catena.2006.04.019.

Codjoe, Samuel Nii Ardey, David Okutu, and Mumuni Abu. 2016. 'Urban Household Characteristics and Dietary Diversity: An Analysis of Food Security in Accra, Ghana'. Food and Nutrition Bulletin 37 (2): 202-18. https://doi.org/10.1177/0379572116631882.

Codjoe, S.N.A., and G. Owusu. 2011. 'Climate Change/Variability and Food Systems: Evidence from the Afram Plains, Ghana'. Regional Environmental Change 11 (4): 753-65. https://doi.org/10.1007/s10113-011-0211-3.

Cofie, O., T. Larbi, G. Danso, E. Abraham, S.K. Kufogbe, M. Henseler, T. Schuetz, and N. ObiriOpareh. 2005. 'A Policy Narrative on Urban Agriculture in Accra-Ghana'. https://www.ruaf.org/sites/default/files/A\%20policy\%20narrative\%20 on\%20urban\%20agriculture \%20in\%20Accra-Ghana.pdf.

Cordell, D., J.-O. Drangert, and Stuart White. 2009. 'The Story of Phosphorus: Global Food Security and Food for Thought'. Global Environmental Change 19 (2): 292-305.

https://doi.org/10.1016/j.gloenvcha.2008.10.009.

Crush, J., and B. Frayne. 2011. 'Supermarket Expansion and the Informal Food Economy in Southern African Cities: Implications for Urban Food Security'. Journal of Southern African Studies 37 (4): 781-807. https://doi.org/10.1080/03057070.2011.617532.

Crush, J., A. Hovorka, and D. Tevera. 2011. 'Food Security in Southern African Cities: The Place of Urban Agriculture'. Progress in Development Studies 11 (4): 285-305. https://doi.org/10.1177/146499341001100402.

Cudjoe, G., C. Breisinger, and X. Diao. 2010. 'Local Impacts of a Global Crisis: Food Price Transmission, Consumer Welfare and Poverty in Ghana'. Food Policy 35 (4): 294-302. https://doi.org/10.1016/j.foodpol.2010.01.004.

Dake, F.A.A., A.L. Thompson, S.W. Ng, Samuel Agyei-Mensah, and Samuel N. A. Codjoe. 2016. 'The Local Food Environment and Body Mass Index among the Urban Poor in Accra, Ghana'. Journal of Urban Health 93 (3): 438-55. https://doi.org/10.1007/s11524-016-0044-y.

De Roquefeuil, Q., D. Plunkett, and F. Ofei. 2014. 'The Impact of Closer Regional Economic Integration on Food Security in West Africa - Focus on the ECOWAS Common External Tariff'. www.ecdpm.org/dp154.

De Zeeuw, H., R. Van Veenhuizen, and M. Dubbeling. 2011. 'The Role of Urban Agriculture in Building Resilient Cities in Developing Countries'. The Journal of Agricultural Science 149 (S1): 153-63. https://doi.org/10.1017/S0021859610001279.

Dijkshoorn-Dekker, M., V. Linderhof, V. Diogo, W. Hennen, D. Oudendag, M. Kuiper, and L. Shutes. 2019. 'Urban Food Security in Ghana in the Future'. Report. The Hague, The Netherlands: Wageningen Economic Research.

Donkor, K.B. 2018. 'One-District, One-Warehouse Launched'. Graphic Online. 2018. https://www.graphic.com.gh/news/general-news/one-district-one-warehouse-launched.html.

Eigenbrod, C., and N. Gruda. 2015. 'Urban Vegetable for Food Security in Cities. A Review'. Agronomy for Sustainable Development 35 (2). https://link.springer.com/article/10.1007/s13593-014-0273-y.

Ericksen, P.J. 2008. 'Conceptualizing Food Systems for Global Environmental Change Research'. Global Environmental Change 18 (February): 234-45. https://doi.org/10.1016/j.gloenvcha.2007.09.002. 
Essegbey, G.O., D. Nutsukpo, N. Karbo, and R. Zourmoré. 2015. 'National Climate-Smart Agriculture and Food Security Action Plan of Ghana (2016-2020)'.

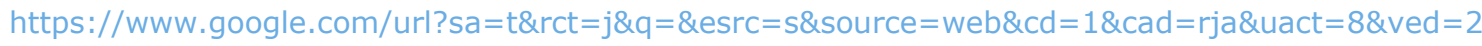
ahUKEwixpMi_go7eAhXIy6QKHX58A9UQFjAAegQICBAB\&url=https\%3A\%2F\%2Fccafs.cgiar.org\%2F publications\%2Fnational-climate-smart-agriculture-and-food-security-action-plan-ghana-20162020\&usg=AOvVaw3oGXTVEEYJXzs_Y9e1c3nC.

FAO. 1996. 'Rome Declaration and Plan of Action'. World Food Summit. http://www.fao.org/docrep/003/w3613e/w3613e00.HTM.

- - . 2006. 'Trade Reforms and Food Security - Country Case Studies and Synthesis'. http://www.fao.org/docrep/009/a0581e/a0581e00.htm.

- - . 2016. 'STREET FOOD IN URBAN GHANA A Desktop Review and Analysis of Findings and Recommendations from Existing Literature'. http://www.fao.org/3/a-i5804e.pdf.

Galbete, C., M. Nicolaou, K.A. Meeks, A. de-Graft Aikins, J. Addo, S.K. Amoah, L. Smeeth, et al. 2017. 'Food Consumption, Nutrient Intake, and Dietary Patterns in Ghanaian Migrants in Europe and Their Compatriots in Ghana'. Food \& Nutrition Research 61 (1): 1341809.

https://doi.org/10.1080/16546628.2017.1341809.

Garrett, J.L., and M.T. Ruel. 1999. 'Are Determinants of Rural and Urban Food Security and Nutritional Status Different? Some Insights from Mozambique'. World Development 27 (11): 1955-75. https://doi.org/10.1016/S0305-750X(99)00091-1.

Ghanagreenlabel.org. 2018. 'Green Label Factsheet'. http://www.ghanagreenlabel.org/wpcontent/uploads/2016/01/GREEN-LABEL-factsheet-final.pdf.

Glopan. 2016. 'Kufuor Foundation Launches Ghana Zero Hunger Strategic Review Project | Global Panel'. 2016. https://www.glopan.org/news/kufuor-foundation-launches-ghana-zero-hungerstrategic-review-project.

Gregory, P. J., J. S. I. Ingram, and M. Brklacich. 2005. 'Climate Change and Food Security'. Philosophical Transactions of the Royal Society B: Biological Sciences 360 (1463): 2139-48. https://doi.org/10.1098/rstb.2005.1745.

Headey, D.D., and W.J. Martin. 2016. 'The Impact of Food Prices on Poverty and Food Security'. Annual Review of Resource Economics 8 (1): 329-51. https://doi.org/10.1146/annurev-resource100815-095303.

Hertel, T.W. 2016. 'Food Security under Climate Change'. Nature Climate Change 6 (1): 10-13. https://doi.org/10.1038/nclimate2834.

Hollinger, F., and J.M. Staatz. 2015. Agricultural Growth in West Africa. Market and Policy Drivers. Rome. http://www.fao.org/3/a-i4337e.pdf.

Ingram, J. 2011. 'A Food Systems Approach to Researching Food Security and Its Interactions with Global Environmental Change'. Food Security 3 (4): 417-31. https://doi.org/10.1007/s12571011-0149-9.

IPCC. 2018. 'Impacts of $1.5^{\circ} \mathrm{C}$ of Global Warming on Natural and Human Systems'. https://www.ipcc.ch/site/assets/uploads/sites/2/2018/11/SR15_Chapter3_High_Res.pdf.

Jager, I. de, K.E. Giller, and I.D. Brouwer. 2018. 'Food and Nutrient Gaps in Rural Northern Ghana: Does Production of Smallholder Farming Households Support Adoption of Food-Based Dietary Guidelines?' Edited by Frank Wieringa. PLOS ONE 13 (9): e0204014. https://doi.org/10.1371/journal.pone.0204014.

Knudsen, M.H., and N. Fold. 2011. 'Land Distribution and Acquisition Practices in Ghana's Cocoa Frontier: The Impact of a State-Regulated Marketing System'. Land Use Policy 28 (2): 378-87. https://doi.org/10.1016/j.landusepol.2010.07.004.

Kreuger, L.J. 2015. 'Has the Maputo Declaration Made a Difference? Looking at the Past Ten Years of Sub-Saharan Agriculture within the CAADP'. http://lup.lub.lu.se/luur/download?func=downloadFile\&recordOId=8045580\&fileOId=8045604.

Kuiper, M., L. Shutes, and D. Oudendag. 2017. 'With Food and Nutrition Security Hinging on Inequality, Labour Allocation beyond Agriculture Proves a Neglected Key Driver in Long Term FNS Projections'.

Labadarios, D., Z. Mchiza, N.P. Steyn, G. Gericke, E. Maunder, Y. Davids, and W. Parker. 2011. 'Food Security in South Africa: A Review of National Surveys'. Bulletin of the World Health Organization 89 (12): 891-99. https://doi.org/10.2471/BLT.11.089243.

Lobell, D. B., W. Schlenker, and J. Costa-Roberts. 2011. 'Climate Trends and Global Crop Production Since 1980'. Science 333 (6042): 616-20. https://doi.org/10.1126/science.1204531. 
Mackay, H. 2018. 'Mapping and Characterising the Urban Agricultural Landscape of Two IntermediateSized Ghanaian Cities'. Land Use Policy 70 (January): 182-97.

https://doi.org/10.1016/j.landusepol.2017.10.031.

Masters, W.A, Y. Bai, A. Herforth, D.B Sarpong, F. Mishili, J. Kinabo, and J.C. Coates. 2018. 'Measuring the Affordability of Nutritious Diets in Africa: Price Indexes for Diet Diversity and the Cost of Nutrient Adequacy'. American Journal of Agricultural Economics, August. https://doi.org/10.1093/ajae/aay059.

Maxwell, D.G., ed. 2000. Urban Livelihoods and Food and Nutrition Security in Greater Accra, Ghana. Research Report 112. Washington, D.C: International Food Policy Research Institute.

Maxwell, S. 1996. 'Food Security: A Post-Modern Perspective'. Food Policy 21 (2): 155-70. https://doi.org/10.1016/0306-9192(95)00074-7.

Mellor, J.W. 2014. 'High Rural Population Density Africa - What Are the Growth Requirements and Who Participates?' Food Policy 48 (October): 66-75.

https://doi.org/10.1016/j.foodpol.2014.03.002.

Ministry of Environment, Science, Technology and Innovation. 2013. 'Ghana National Climate Change Policy'.

https: / www.google.com/url? sa $=$ t\&rct $=j \& q=\& e s r c=s \& s o u r c e=$ web\&cd $=1 \&$ cad $=r j a \& u a c t=8 \& v e d=2$ ahUKEwj-5pLasO_dAhUBK1AKHZS_C24QFjAAegQICBAC\&url=http\%3A\%2F\%2Fwww.unpage.org\%2Ffiles\%2Fpublic\%2Fghanaclimatechangepolicy.pdf\&usg=AOvVaw2cXj4uj7RLuFmABdDI FUTV.

-- . 2015. 'Ghana National Climate Change Master Plan Action Programmes for Implementation: 2015-2020'.

https://www.google.com/url?sa =t\&rct=j\&q=\&esrc=s\&source =web\&cd =1\&cad =rja\&uact =8\&ved =2 ahUKEwjF0Oa9su_dAhVJPFAKHS8sD0sQFjAAegQICRAC\&url=https\%3A\%2F\%2Fwww.weadapt.org \%2Fsites\%2Fweadapt.org\%2Ffiles\%2F2017\%2Fghana_national_climate_change_master_plan_20 15_2020.pdf\&usg=AOvVaw0kwOe4swveZI3jG4gI62eC.

Ministry of Food and Agriculture. 2007. 'Food and Agriculture Sector Development Policy (FASDEP II)'. http://mofa.gov.gh/site/?page_id=598.

-- . 2010. 'Medium Term Agriculture Sector Investment Plan (METASIP) 2011 - 2015'. Accra, Ghana. http://www.resakss.org/sites/default/files/pdfs/ghana-agriculture-sector-investment-plan45359.pdf.

-- . 2013. 'Basic Agricultural Public Eexpenditure Diagnostic Review'.

https://www. nepad.org/caadp/publication/ghana-basic-agricultural-public-expenditure-diagnosticreview.

---. 2015. 'Medium Term Agriculture Sector Investment Plan (METASIP) II, 2014- 2017'.

mofa.gov.gh/site/wp-content/uploads/2016/10/METASIP-II.pdf.

-- . 2016a. 'Agricultural Sector Progress Report 2016'. mofa.gov.gh/site/wp-

content/uploads/2016/09/Agric-Report_2016.pdf.

- - . 2016b. 'Agriculture in Ghana Facts and Figures (2015)'. http://www.e-

agriculture.gov.gh/index.php/2014-07-22-14-39-46/agric-facts-and-figures-2015.

- - . 2017a. 'Planting for Food and Jobs: Strategic Plan for Implementation (2017-2020)'. Accra, Ghana. http://mofa.gov.gh/site/wp-

content/uploads/2018/03/PFJ\%20document\%20New\%20New.pdf.

- - . 2017b. 'Planting for Food and Jobs (PFJ) FAQs'. Ministry of Food \& Agriculture (blog). 13

September 2017. http://mofa.gov.gh/site/?page_id=15114.

Ministry of Health. 2013a. 'National Food Safety Policy'.

http://www.acfs.go.th/FileSPS/Text\%20SPS\%20GHA\%201.pdf.

- - . 2013b. 'National Nutrition Policy for Ghana 2013 - 2017'.

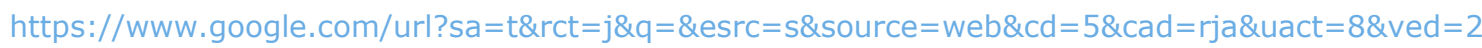
ahUKEwiKna3YiKHdAhVQQhoKHRImBZcQFjAEegQIAhAC\&url=https\%3A\%2F\%2Fextranet. who.int\% 2Fnutrition\%2Fgina\%2Fsites\%2Fdefault\%2Ffiles\%2FGHA\%25202013\%2520National\%2520Nutriti on\%2520Policy.pdf\&usg=AOvVaw1yh13sr2EYBrcOg7tnO6Lh.

Ministry of Trade and Industry. 2005. 'Ghana Trade Policy - Trade Sector Support Programme'.

https://www. google.com/url? sa =t\&rct=j\&q=\&esrc=s\&source=web\&cd=3\&ved=2ahUKEwjThM38kc zdAhUCyYUKHZYCCrAQFjACegQIBxAC\&url=http\%3A\%2F\%2Fwww.ghanachamber.org\%2Findex.p hp\%2Fdownloads\%2Fcategory\%2F4-national-policy-documents\%3Fdownload\%3D9\%3Atradepolicy-pdf\&usg=AOvVaw2l1uBpy42FkOHDzhwBTv2z. 
---. 2013a. 'Ghana National Export Strategy for the Non-Traditional Sector 2013-2017'.

http://ghanatrade.com.gh/images/products/laws/NATIONAL\%20EXPORT\%20STRATEGY.pdf.

---. 2013b. 'National Export Development Programme 2013-2017'.

http://ghanatrade.com.gh/images/products/laws/National\%20Export\%20\%20Development\%20Pr ogramme.pdf.

Mohan, G., and H. Matsuda. 2013. 'Regional Level Total Factor Productivity Growth in Ghana Agriculture'. Journal of Economics and Sustainable Development 4 (5).

https://www. iiste.org/Journals/index.php/JEDS/article/viewFile/5017/5116.

Nchanji, E. 2017. 'Sustainable Urban Agriculture in Ghana: What Governance System Works?' Sustainability 9 (11): 2090. https://doi.org/10.3390/su9112090.

NDPC. 2018. 'Home Page | National Development Planning Commission'. 2018. http://ndpccms. herokuapp.com/.

NEPAD. 2003. 'MAPUTO Declaration on Agriculture and Food Security'. http://www. nepad.org/resource/au-2003-maputo-declaration-agriculture-and-food-security.

Nykänen, E.-P., H. Dunning, R. Aryeetey, A. Robertson, and A. Parlesak. 2018. 'Nutritionally Optimized, Culturally Acceptable, Cost-Minimized Diets for Low Income Ghanaian Families Using Linear Programming'. Nutrients 10 (4): 461. https://doi.org/10.3390/nu10040461.

Obosu-Mensah, K. 2002. 'Changes in Official Attitudes Towards Urban Agriculture in Accra'. African Studies Quarterly 6 (3). http://asq.africa.ufl.edu/files/Mensah-Vol6-Issue3.pdf.

OEC. 2016. 'Import origins of Rijst to Ghana (2016)'. The Observatory of Economic Complexity. 2016. http://atlas.media.mit.edu/nl/visualize/tree_map/hs92/import/gha/show/1006/2016/?lang=nl.

-- . 2018. 'OEC - Ghana (GHA) Exports, Imports, and Trade Partners'. 11 September 2018. https://atlas. media.mit.edu/en/profile/country/gha/.

OECD, FAO, and UNCDF. 2016. 'Adopting a Territorial Approach to Food Security and Nutrition Policy'. OECD Publishing. https://doi.org/10.1787/9789264257108-en.

Ogum A., D., R.N. Aryeetey, H.L. Gray, A.K. Laar, and R.M.K. Adanu. 2018. 'Dietary Patterns and Associated Risk Factors among School Age Children in Urban Ghana'. BMC Nutrition 4 (1). https://doi.org/10.1186/s40795-018-0230-2.

Omari, R., and G. Frempong. 2016. 'Food Safety Concerns of Fast Food Consumers in Urban Ghana'. Appetite 98 (March): 49-54. https://doi.org/10.1016/j.appet.2015.12.007.

Oxford Business Group. 2013. 'Closing the Gap: The Rising Cost of Rice Imports Is Driving Change in Domestic Production'. Oxford Business Group. 1 October 2013.

https://oxfordbusinessgroup.com/analysis/closing-gap-rising-cost-rice-imports-driving-changedomestic-production.

Pingali, P. 2007. 'Westernization of Asian Diets and the Transformation of Food Systems: Implications for Research and Policy'. Food Policy 32 (3): 281-98.

https://doi.org/10.1016/j.foodpol.2006.08.001.

Rapsomanikis, G., and A. Sarris. 2008. 'Market Integration and Uncertainty: The Impact of Domestic and International Commodity Price Variability on Rural Household Income and Welfare in Ghana and Peru'. The Journal of Development Studies 44 (9): 1354-81.

https://doi.org/10.1080/00220380802265439.

Republic of Ghana. 1995. 'Ghana Vision 2020 (The First Step 1996-2000) Presidential Report on Coordinated Programme of Economic and Social Development Policies (Policies for the Preparation of 1996-2000 Development Plan)'. Accra, Ghana.

http://invenio.unidep.org/invenio//record/18439/files/vision_ghana2020.pdf.

--_. 2003. 'Ghana Poverty Reduction Strategy 2003-2005 an Agenda for Growth and Prosperity Volume I: Analysis and Policy Statement'. Accra, Ghana.

file:///C:/Users/Raaij019/Downloads/gprs_i___ghana_poverty_reduction_strategy_2003-2005.pdf.

- - . 2005a. 'Growth and Poverty Reduction Strategy (GPRS II) (2006 - 2009)'. Accra, Ghana.

http://siteresources.worldbank.org/INTPRS1/Resources/GhanaCostingofGPRS_2(Nov-2005).pdf.

- - . 2005b. 'Support to NEPAD-CAADP Implementation TCP/GHA/2908 (I) (NEPAD Ref. 05/41 E) Volume I of III National Medium Term Investment Programme (NMTIP)'. file:///C:/Users/Raaij019/Downloads/Enhancing\%20Stakeholder\%20Participation\%20in\%20the\%2 0Ghana\%20School\%20Feeding\%20Programme.pdf.

---. 2009. 'ECOWAS AGRICULTURAL POLICY (ECOWAP)/COMPREHENSIVE AFRICAN AGRICULTURE DEVELOPMENT PROGRAMME (CAADP) COMPACT TO SUPPORT THE SUCCESSFUL 
IMPLEMENTATION OF THE GHANA FOOD AND AGRICULTURE SECTOR DEVELOPMENT POLICY

(FASDEP II)'. Accra, Ghana.

---. 2010. 'Ghana Shared Growth and Development Agenda (GSGDA), 2010-2013. Volume I: Policy Framework Final Draft'. Accra, Ghana.

- - . 2011. 'National Export Development Programme 2011'.

http://www.ghanaiandiaspora.com/wp/wp-content/uploads/2014/08/National-Export-

Development-Strategy.pdf.

---. 2012. 'Ghana Poverty Reduction Strategy Paper'.

https://www.imf.org/external/pubs/ft/scr/2012/cr12203.pdf.

-- . 2014. 'Ghana Shared Growth and Development Agenda (GSGDA) II, 2014-2017.' Accra.

http://extwprlegs1.fao.org/docs/pdf/gha152510.pdf.

--_. 2015. 'Ghana National Spatial Development Framework (2015 - 2035) Volume II: Overall

Spatial Development Strategy'.

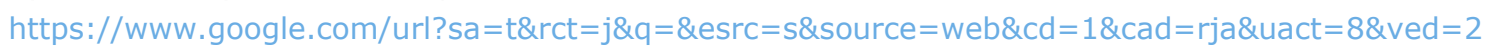
ahUKEwiZhuD39KPdAhUSJIAKHUuQD94QFjAAegQIAhAC\&url=https\%3A\%2F\%2Fwww.ghanalap.go V.gh\%2Ffiles\%2FNSDF-Final-Report-EXECSUM-Vol-III-Final-Edition-

TAC.pdf\&usg=AOvVaw0_iwadSoG8y0a6xVgKjpO1.

---. 2016. 'National Nutrition Policy for Ghana'. http://www.moh.gov.gh/launch-of-the-nationalnutrition-policy/.

- - . 2017. 'Implementation of the Ghana Shared Growth and Development Agenda (GSGDA) II 2014-2017'. https://s3-us-west-2.amazonaws.com/new-ndpcstatic1/CACHES/PUBLICATIONS/2018/04/18/2016+APR-Final+Version+(April+2018).pdf.

- - . 2018a. 'Ghana's Agric Policy since 1960...Planting for Food and Jobs the New Baby Government of Ghana'. 2018. http://www.ghana.gov.gh/index.php/media-center/features/3802ghana-s-agric-policy-since-1960-planting-for-food-and-jobs-the-new-baby.

-- . 2018b. 'One District, One Factory Officially Takes off - Government of Ghana'. 2018.

http://www.ghana.gov.gh/index.php/news/3939-one-district-one-factory-officially-takes-off.

- - . 2019. 'Ghana Review of Ongoing Agricultural Development Efforts'.

https://www.resakss.org/sites/default/files/pdfs//ghana-caadp-brochure-1-review-of-ongoingagricultu-42624.pdf.

Roudier, P., B. Sultan, P. Quirion, and A. Berg. 2011. 'The Impact of Future Climate Change on West African Crop Yields: What Does the Recent Literature Say?' Global Environmental Change 21 (3): 1073-83. https://doi.org/10.1016/j.gloenvcha.2011.04.007.

Searcey, D., and M. Richtel. 2017. 'Obesity Was Rising as Ghana Embraced Fast Food. Then Came KFC.' The New York Times, 2 October 2017, sec. Health. https://www.nytimes.com/2017/10/02/health/ghana-kfc-obesity.html.

Shutes, L., M. Verma, and M. Kuiper. 2015. 'Changing Diets in a Changing World: Assessing the Impact of Urbanisation on Agriculture'. The Hague, The Netherlands: Wageningen Economic Research.

Swinnen, J. 2010. 'The Right Price of Food: Reflections on the Political Economy of Policy Analysis and Communication'. LICOS Discussion Paper. LICOS - Centre for Institutions and Economic Performance, KU Leuven. http://econpapers.repec.org/paper/liclicosd/25910.htm.

Szabo, S. 2016. 'Urbanisation and Food Insecurity Risks: Assessing the Role of Human Development'. https://doi.org/10.1080/13600818.2015.1067292.

Tollefson, J. 2018. 'Can the World Kick Its Fossil-Fuel Addiction Fast Enough?' Nature 556 (7702): 422-25. https://doi.org/10.1038/d41586-018-04931-6.

UN. 2018. 'Sustainable Development Knowledge Platform'. Sustainable Development Knowledge Platform. 2018. https://sustainabledevelopment.un.org/sdg2.

UNDESA. 2015. 'World Urbanization Prospects: The 2014 Revision'. ST/ESA/SER.A/366. New York, USA:. United Nations, Department of Economic and Social Affairs, Population Division.

UNEP. 2012. 'National Climate Change Adaptation Strategy'. http://adaptationundp.org/sites/default/files/downloads/ghana_national_climate_change_adaptation_strategy_ncca S.pdf.

USAID. 2016. 'AGOA National Strategy The Republic of Ghana'. https://www.usaid.gov/documents/1860/agoa-east-africa.

Waarts, Y., V. Ingram, V. Linderhof, L. Puister-Jansen, F. van Rijn, and R. Aryeetey. 2015. 'Impact of UTZ Certification on Cocoa Producers in Ghana, 2011 to 2014'. http://edepot. wur. nl/366868. 
World Bank. 2017. 'Ghana Agriculture Sector Policy Note'.

http://documents. worldbank.org/curated/en/336541505459269020/pdf/119753-PN-P133833-

PUBLIC-Ghana-Policy-Note-Ag-Sector-Review.pdf.

- - . 2018. 'Trade Policies and Practices per Measure'.

https://www.wto.org/english/tratop_e/tpr_e/s194-03_e.doc.

World Food Programme. 2018. 'Ghana | WFP | United Nations World Food Programme - Fighting Hunger Worldwide'. 2018. https://www.wfp.org/node/3467/3707/644350.

World Food Programme, and John Kufuor Foundation. 2018. 'Ghana Zero Hunger Strategy Review'. https://www.wfp.org/content/2018-ghana-zero-hunger-strategic-review.

World Health Organisation Africa. 2018. 'Ghana Adopts Food Safety Policy'. WHO | Regional Office for Africa. 6 September 2018. https://www.afro.who.int/news/ghana-adopts-food-safety-policy.

Zezza, A., and L. Tasciotti. 2010. 'Urban Agriculture, Poverty, and Food Security: Empirical Evidence from a Sample of Developing Countries'. Food Policy 35 (4): 265-73.

https://doi.org/10.1016/j.foodpol.2010.04.007.

Zhao, C., B. Liu, S. Piao, X. Wang, D.B. Lobell, Y. Huang, M. Huang, et al. 2017. 'Temperature Increase Reduces Global Yields of Major Crops in Four Independent Estimates'. Proceedings of the National Academy of Sciences 114 (35): 9326-31. https://doi.org/10.1073/pnas.1701762114.

Zhu, C., K. Kobayashi, I. Loladze, J. Zhu, Q. Jiang, X. Xu, G. Liu, et al. 2018. 'Carbon Dioxide (CO 2) Levels This Century Will Alter the Protein, Micronutrients, and Vitamin Content of Rice Grains with Potential Health Consequences for the Poorest Rice-Dependent Countries'. Science Advances 4 (5): eaaq1012. https://doi.org/10.1126/sciadv.aaq1012. 


\section{Appendix 1}

Table 12 Selection of documents dealing with urban food security in the developing world

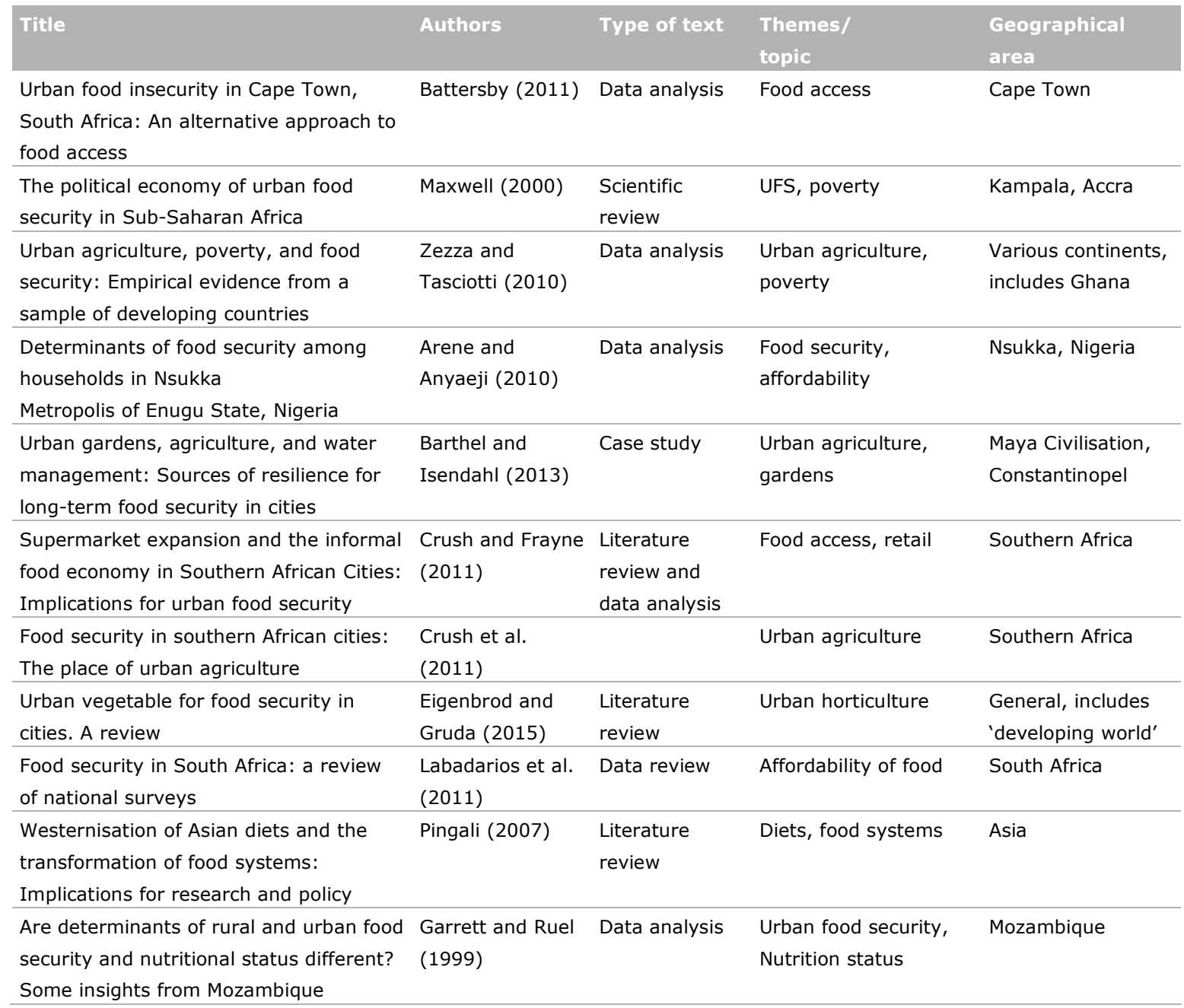




\section{Appendix 2}

Table 13 Overview of the different policies in Ghana, their period and publication date

\begin{tabular}{|c|c|c|c|c|}
\hline Policy & Period & Objective & Release date & Reference \\
\hline $\begin{array}{l}\text { The Vision of } \\
2020\end{array}$ & $1996-2020$ & $\begin{array}{l}\text { The long-term vision for Ghana is to become a } \\
\text { middle-income country by the year } 2020 \text {. }\end{array}$ & & \\
\hline $\begin{array}{l}\text { Ghana Vision } \\
\text { 2020: The First } \\
\text { Step (medium } \\
\text { development } \\
\text { plan) }\end{array}$ & $1996-2000$ & $\begin{array}{l}\text { Covered five thematic areas: economic growth, } \\
\text { human development, rural development, urban } \\
\text { development and the development of an } \\
\text { enabling environment. }\end{array}$ & January 1995 & $\begin{array}{l}\text { (Republic of Ghana } \\
\text { 1995) }\end{array}$ \\
\hline GPRS I & $2003-2005$ & $\begin{array}{l}\text { To create wealth by achieving sustainable } \\
\text { equitable growth, accelerated poverty reduction } \\
\text { and the protection of the vulnerable and } \\
\text { excluded within a decentralised democratic } \\
\text { environment. } \\
\text { / Focused on the macroeconomic stability, } \\
\text { production and gainful employment, human } \\
\text { resource development and provision of basic } \\
\text { services to the vulnerable and excluded, and } \\
\text { good governance. }\end{array}$ & $\begin{array}{l}\text { February } \\
2003\end{array}$ & $\begin{array}{l}\text { (Republic of Ghana } \\
\text { 2003) }\end{array}$ \\
\hline GPRS II & $2006-2009$ & $\begin{array}{l}\text { To accelerate the growth of the economy so } \\
\text { that Ghana can achieve middle-income status } \\
\text { within a measurable planning period } \\
\text { / Growth and poverty reduction: Continued } \\
\text { focus on macroeconomic stability, human } \\
\text { resource development, private sector } \\
\text { competitiveness, good governance, and civic } \\
\text { responsibility. }\end{array}$ & $\begin{array}{l}\text { November } \\
2005\end{array}$ & $\begin{array}{l}\text { (Republic of Ghana } \\
\text { 2005a) }\end{array}$ \\
\hline GSGDA I & $2010-2013$ & $\begin{array}{l}\text { To facilitate the acceleration of employment } \\
\text { and income generation for poverty reduction } \\
\text { and shared growth. To accelerate the growth of } \\
\text { the economy and raise the living standards of } \\
\text { Ghanaians. The GSGDA is anchored on seven } \\
\text { main themes: } \\
\text { Sustainable macroeconomic stability; enhanced } \\
\text { competitiveness of the private sector, } \\
\text { accelerated agricultural modernisation and } \\
\text { natural resource management; oil and gas } \\
\text { development; infrastructure; energy and } \\
\text { human settlements development; human } \\
\text { development; transparent and accountable } \\
\text { governance. }\end{array}$ & $\begin{array}{l}\text { September } \\
2010\end{array}$ & $\begin{array}{l}\text { (Republic of Ghana } \\
\text { 2010) }\end{array}$ \\
\hline GSGDA II & 2014-2017 & $\begin{array}{l}\text { Continued macroeconomic stability; private } \\
\text { sector competitiveness; human resource } \\
\text { development; good governance and civic } \\
\text { responsibility. }\end{array}$ & May 2015 & $\begin{array}{l}\text { (Republic of Ghana } \\
2014 \text { ) }\end{array}$ \\
\hline LTNDP & $2018-2057$ & & $\begin{array}{l}\text { No official } \\
\text { policy } \\
\text { document has } \\
\text { been found }\end{array}$ & (Abubakari et al. 2018) \\
\hline FASDEP I & $2002-2006$ & $\begin{array}{l}\text { Framework for the implementation of strategies } \\
\text { for modernisation of the agricultural sector. }\end{array}$ & 2002 & $\begin{array}{l}\text { (Baah 2017; Ministry of } \\
\text { Food and Agriculture } \\
\text { 2007) }\end{array}$ \\
\hline
\end{tabular}




\begin{tabular}{|c|c|c|c|c|}
\hline Policy & Period & Objective & Release date & Reference \\
\hline METASIP II & 2014-2017 & $\begin{array}{l}\text { Investment plan to implement, programmes of } \\
\text { the policy. }\end{array}$ & $\begin{array}{l}\text { December } \\
2015\end{array}$ & $\begin{array}{l}\text { (Ministry of Food and } \\
\text { Agriculture 2015) }\end{array}$ \\
\hline METASIP III & $2018-2021$ & & October 2017 & $\begin{array}{l}\text { (Ministry of Food and } \\
\text { Agriculture, 2017) } \\
\text { (AGRA 2017) }\end{array}$ \\
\hline TCP & 2012-? & $\begin{array}{l}\text { The policy is to provide a comprehensive and } \\
\text { holistic approach for the sustainable } \\
\text { development of the tree crops subsector and } \\
\text { for proper targeting of support to the TC value } \\
\text { chains. }\end{array}$ & & \\
\hline GCAP & 2012-2019 & $\begin{array}{l}\text { Aims towards improving the investment climate } \\
\text { for agribusiness and developing PPPs and } \\
\text { smallholder linkages intended to increase on- } \\
\text { farm productivity and value addition in selected } \\
\text { value chains. }\end{array}$ & & \\
\hline NNP & $2013-2017$ & $\begin{array}{l}\text { To ensure optimal nutrition and health of all } \\
\text { people living in Ghana, to enhance capacity for } \\
\text { sustainable economic growth and development. }\end{array}$ & March 2013 & $\begin{array}{l}\text { (Ministry of Health } \\
\text { 2013b) }\end{array}$ \\
\hline $\begin{array}{l}\text { African's Union } \\
\text { Agenda } 2063\end{array}$ & $2015-2063$ & & & \\
\hline CAADD & $2009-?$ & & October 2009 & $\begin{array}{l}\text { (Republic of Ghana } \\
\text { 2009) }\end{array}$ \\
\hline \multicolumn{5}{|l|}{ ECOWAS } \\
\hline \multicolumn{5}{|l|}{ MDG } \\
\hline
\end{tabular}


Wageningen Economic Research P.O. Box 29703

2502 LS The Hague

The Netherlands

$\mathrm{T}+31(0) 703358330$

E communications.ssg@wur.nl

www.wur.eu/economic-research

Wageningen Economic Research REPORT

2019-057b
The mission of Wageningen University \& Research is "To explore the potential of nature to improve the quality of life". Under the banner Wageningen University \& Research, Wageningen University and the specialised research institutes of the Wageningen Research Foundation have joined forces in contributing to finding solutions to important questions in the domain of healthy food and living environment. With its roughly 30 branches, 5,000 employees and 10,000 students, Wageningen University \& Research is one of the leading organisations in its domain. The unique Wageningen approach lies in its integrated approach to issues and the collaboration between different disciplines. 



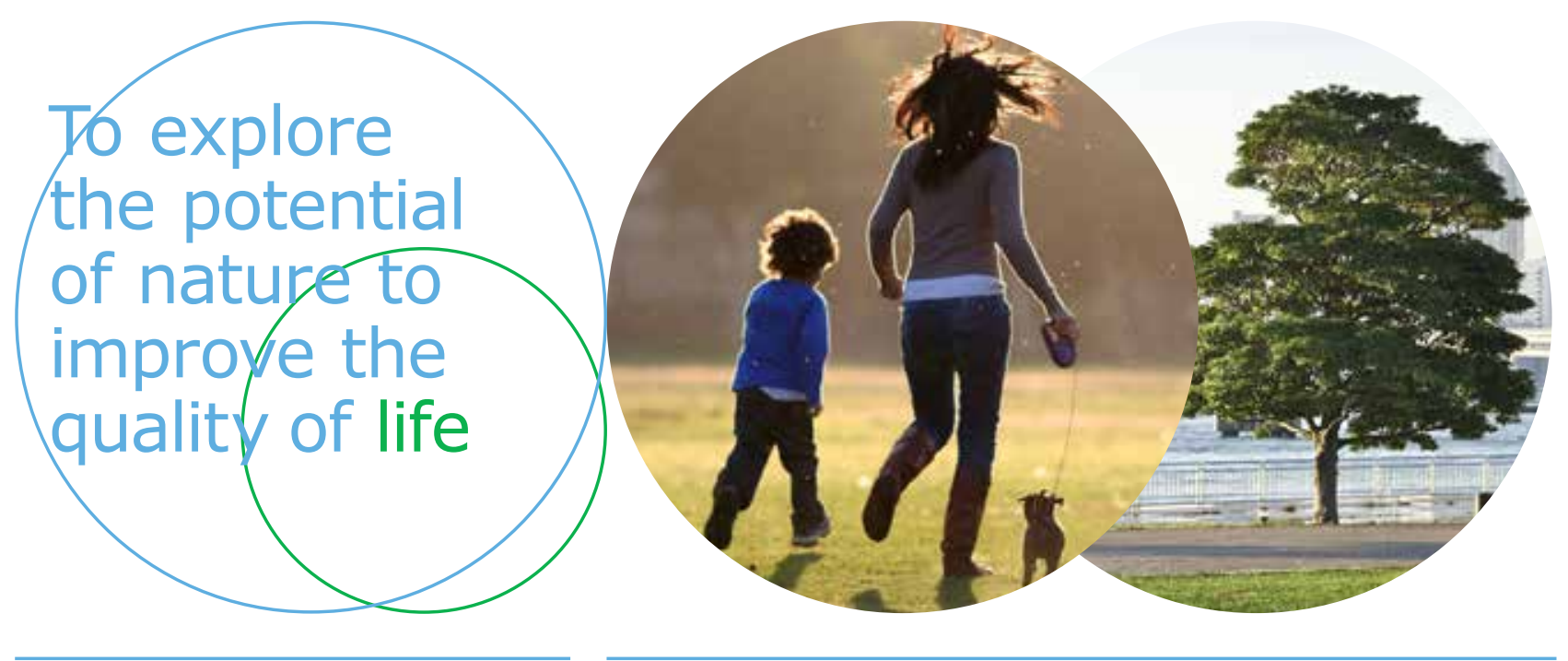

Wageningen Economic Research P.O. Box 29703

2502 LS Den Haag

The Netherlands

E communications.ssg@wur.nl

www.wur.eu/economic-research

Report 2019-057b

ISBN 978-94-6343-968-8
The mission of Wageningen University \& Research is "To explore the potential of nature to improve the quality of life". Under the banner Wageningen University \& Research, Wageningen University and the specialised research institutes of the Wageningen Research Foundation have joined forces in contributing to finding solutions to important questions in the domain of healthy food and living environment. With its roughly 30 branches, 5,000 employees and 10,000 students, Wageningen University \& Research is one of the leading organisations in its domain. The unique Wageningen approach lies in its integrated approach to issues and the collaboration between different disciplines. 